\section{Zwischen Stillstand}

und Aufschwung. Die

Prähistorische Kommission

der Österreichischen

Akademie der

Wissenschaften von 1918

bis 1938

\section{Brigitta Mader}

„Die Menschen sind Ameisen. Sie überwinden alle Störungen“

Moriz Hoernes ${ }^{1}$
Franz und Richard Pittioni vertretene Generation zählen, im Mittelpunkt, sondern es werden auch die der Kommissionstätigkeit zugrundeliegenden Fragen der Organisation, personellen Struktur und Finanzierung behandelt. Den Abschluss bildet die Ernennung Oswald Menghins zum Obmann der Kommission, die gleichzeitig einen Ausblick auf die vom Nationalsozialismus überschattete Zukunft der Prähistorischen Kommission eröffnet.

\section{Schlüsselbegriffe}

Prähistorische Kommission, Frühgeschichtsforschung, Siedlungsarchäologie, Montanarchäologie, Österreichische Akademie der Wissenschaften.

Abstract - Between Stagnation and Revival. The Prebistoric Commission of the Austrian Academy of Sciences from 1918 to 1938

This study presents the history and the activities of the Prehistoric Commission of the Austrian Academy of Sciences during the years 1918 to 1938 and therefore deals with a time period that was characterised by historical-political upheavals and economic hardships. During this time, the 'Commission for the promotion of prehistoric research and excavations on Austrian territory', installed in 1878 at the initiative of Ferdinand von Hochstetter, was confronted with completely changed circumstances. Through the dissolution of the Austrian-Hungarian Monarchy and the loss of the crown lands, the Prehistoric Commission was drastically reduced in its sphere of activities, which subsequently, paired with enormous financial difficulties, led to a considerable decline of research activities. While the Prehistoric Commission was able to finance about 110 excavations from own funds during the first four decades of its existence, only about one tenth of these were achieved in the inter-war period, and mostly only in combination with several subsidies and institutions.

1 Hoernes an Szombathy, Perchtoldsdorf 7.9.1914: Hoernes 1914. 
Even if this result seems meagre, the activities of the Prehistoric Commission nevertheless proved to be fruitful during these years. Following a short introductory review of the founding and the early years of the Prehistoric Commission, the development, characterised by new ways and sustainability, will be traced through so far unpublished archive material mainly from the inventories of the Austrian Academy of Sciences, but also from various museums, the archive of the University of Vienna and the Austrian State Archive. The main focus lies on the research activities of the Prehistoric Commission and its members, among which were not only renowned prehistorians such as Josef Szombathy or Walter Schmid, but also a new generation represented by Herbert Mitscha-Märheim, Leonhard Franz, and Richard Pittioni. In addition, the underlying questions of the organisation, personnel structure and financing of the commission's activities are dealt with. The study concludes with the nomination of Oswald Menghin as chairman of the Commission, which at the same time reveals an outlook on the future of the Prehistoric Commission that was overshadowed by National Socialism.

\section{Keywords}

Prehistoric Commission, research on early history, settlement archaeology, mining archaeology, Austrian Academy of Sciences.

\section{Präambel - Der Vertrag von Saint-Germain-en-Laye}

Am Vormittag des 21. August 1867 fanden sich die Teilnehmer des 2. Internationalen Kongresses für Anthropologie und Prähistorische Archäologie im Schloss von Saint-Germain-en-Laye ein. ${ }^{2}$ Am Tagungsprogramm stand die Besichtigung des Musée des antiquités nationales, das im ersten Stock des Schlosses untergebracht war. Alexandre Bertrand und Gabriel de Mortillet hatten die 1862 auf Betreiben von Kaiser Napoleon III. gegründete, ursprünglich als $\mathrm{Mu}-$ sée des antiquités celtiques et gallo-romaines konzipierte Schausammlung durch Einbeziehung des prähistorischen, insbesondere des für die Menschheitsgeschichte richtungsweisenden paläolithischen Fundmaterials Frankreichs, ${ }^{3}$ nicht nur zum archäologischen Nationalmuseum, sondern vor allem auch zum Referenzzentrum für die Urgeschichte des Menschen gemacht. ${ }^{4}$

Gerade an jenem Ort sollte ein halbes Jahrhundert später indirekt auch über das Schicksal der Prähistorischen Kommission der damals noch kaiserlichen Akademie der Wissenschaften ${ }^{5}$ entschieden werden. Am 10. September 1919 unterzeichnete nämlich Staatskanzler Karl Renner als Vertreter der am 12. November des Vorjahres verkündeten Republik Deutschösterreich im Schloss von Saint Germain den Staatsvertrag von Saint-Germain-en-Laye, mit

2 Congrès international d'anthropologie et d'archéologie préhistoriques, Paris 17.-30.8.1867.

3 Rhoné 1868.

4 Schnapp 2006, 289.

5 Die Umbenennung in „Akademie der Wissenschaften in Wien“ wurde erst am 14. Oktober 1921 per Bundesgesetz beschlossen: CZÁKY 1997, 24. dessen Inkrafttreten am 16. Juli 1920 nicht nur der Erste Weltkrieg formal beendet wurde, sondern auch die Österreichisch-Ungarische Monarchie völkerrechtlich als aufgelöst galt. Große Teile der österreichischen Reichshälfte (Cisleithanien) ${ }^{6}$ wurden den Nachfolgestaaten (Königreich der Serben, Kroaten und Slowenen, Tschechoslowakei), Italien, Polen und Rumänien zugesprochen ${ }^{7}$ und nach Festsetzung der neuen Grenzen bestand „'Autriche“ nur mehr aus dem, „ce qui reste“, wie es der französische Ministerpräsident Georges Clemenceau formulierte. ${ }^{8}$

Die völkerrechtlichen Konsequenzen des Friedensvertrages bedeuteten auch für die Prähistorische Kommission eine wesentliche Einbuße ihres Wirkungskreises. Forschungsgebiete waren mit einem Schlag abgeschnitten, Kontakte unterbrochen, das Ausland war in greifbare Nähe gerückt und damit auch die alt gewohnte Bewegungsfreiheit eingeschränkt. Eine zusätzliche Verschärfung der prekären Lage stellten die enormen finanziellen Belastungen dar, die Österreich als Rechtsnachfolger der Habsburgermonarchie durch die ebenfalls im Vertrag von Saint-Germain festgesetzte Verpflichtung zur Leistung von Reparationszahlungen zu tragen hatte.

Mit dem Zusammenbruch der Habsburgermonarchie ging für die Prähistorische Kommission eine vier Jahrzehnte dauernde glanzvolle Periode intensivster und aus heutigem Blickwinkel internationaler Tätigkeit zu Ende, deren wissenschaftliche Resultate nicht nur die Entwicklung der österreichischen Urgeschichtsforschung maßgeblich beeinflussten, sondern auch der nationalen prähistorischen Forschung der Nachfolgestaaten als Grundlage dienten.

6 Nach dem 1867 erfolgten österreichisch-ungarischen Ausgleich gehörten die Länder westlich der Leitha zur österreichischen Reichshälfte, dem sogenannten „Cisleithanien“, zu dem das Erzherzogtum Österreich unter der Enns (Niederösterreich), das Erzherzogtum Österreich ob der Enns (Oberösterreich), das Herzogtum Salzburg, die gefürstete Grafschaft Tirol mit Vorarlberg, das Herzogtum Steiermark, das Herzogtum Kärnten, das Herzogtum Krain, das Küstenland, das Königreich Dalmatien, das Königreich Böhmen, die Markgrafschaft Mähren, das Herzogtum Schlesien, das Königreich Galizien und Lodomerien sowie das Herzogtum Bukowina zählten. 7 An das Königreich der Serben, Kroaten und Slowenen kamen Teile der Untersteiermark und Kärntens, Krain und der Großteil Dalmatiens. Die Tschechoslowakei erhielt Böhmen, Mähren, das österreichische Schlesien und einige Gemeinden Niederösterreichs. Italien wurden Südtirol, das Kanaltal mit Tarvis, das ehemalige Küstenland sowie das dalmatinische Zara (Zadar) und einige Adriainseln zugesprochen. Polen bekam Galizien und Rumänien die Bukowina. 8 ZÖLlner 1990. - Vocelka 2000. - Suppan 2007. - MikoletZKY 2008. - Die gesamte Rechtsvorschrift für den Staatsvertrag von St. Germain kann auf der Seite des Bundeskanzleramtes heruntergeladen werden: http://www.ris.bka.gv.at (letzter Zugriff 29.10.2016). 


\section{Zur Entstehung und Geschichte der Prähistorischen Kom- mission 1878-1918}

1876 hatte der Geologe und Intendant des k.k. naturhistorischen Hofmuseums Ferdinand von Hochstetter (18291884) an seinem Haus als absolutes Novum eine anthropologisch-ethnographische Abteilung ins Leben gerufen, die dem historischen Verständnis der Anthropologie entsprechend über eine urgeschichtliche Sammlung verfügte, die das Fundmaterial aus allen Landesteilen der österreichischen Reichshälfte an zentraler Stelle vereinen und so einen Überblick über alle hier vertretenen Kulturerscheinungen geben sollte: ein angesichts der beträchtlichen Ausdehnungen Cisleithaniens höchst ambitiöses Unterfangen. Aber nicht nur das Museum, auch die damals noch junge Disziplin der prähistorischen Archäologie verlangten, wie Josef Szombathy (1853-1943) es ausdrückte, nach „reichlich zufliessender, womöglich abwechslungsvoller Nahrung". ${ }^{9}$ Was jedoch zu diesem Zeitpunkt fehlte, war eine ausschließlich auf prähistorische Forschung ausgerichtete, von Fachkräften getragene Institution, die aufgrund einer gesicherten Finanzierung in der Lage gewesen wäre, systematische und kontinuierliche Untersuchungen von „Fundstellen für die älteste Geschichte des Menschen, sowie für die Urbevölkerung Europa's“ vorzunehmen. ${ }^{10}$ Hochstetter erkannte klar die dringende Notwendigkeit einer derartigen Forschungseinrichtung, die auch dem zunehmenden Raubgräbertum und der professionellen Ausbeutung von Höhlen mit fossilen Ablagerungen Einhalt gebieten sollte, und ergriff im Frühjahr 1878 die Initiative zu deren Gründung. Als wirkliches Mitglied der kaiserlichen Akademie der Wissenschaften brachte er in der Sitzung der mathematisch-naturwissenschaftlichen Classe vom 14. März 1878 einen diesbezüglichen Antrag ein, worin er auf die "große wissenschaftliche Bedeutung“, die „die anthropologisch-prähistorischen Forschungen mehr und mehr gewinnen, sowie die Thatsache" verwies, „dass wichtige Forschungsgebiete und reiche Fundstätten in dieser Beziehung durch Sammler, welche keine wissenschaftlichen Zwecke verfolgen, ausgeraubt und verwüstet werden“, weshalb „es in hohem Grade wünschenswerth“ erschien, „dass derartige Forschungen und Nachgrabungen von den dazu berufenen Kreisen in die Hand genommen u. mehr gepflegt werden als bisher" ${ }^{11}$

Hochstetters Antrag fand Zustimmung, und bereits am 4. April 1878 wurde die neue Commission zur Förderung prähistorischer Forschungen und Ausgrabungen auf österreichischem Gebiete eingesetzt. ${ }^{12}$ Die „Prähistorische

9 Szombathy 1891.

10 STEFAN 1878, 160.

11 Hochstetter 1878.

12 Petitum 1878. - Sitzungsprotokoll 1878a.
Commission“, wie sie fortan genannt wurde, ${ }^{13}$ bestand neben Hochstetter, der in der ersten Sitzung (6. Juni) auch zum Obmann gewählt wurde, aus den Geologen Franz von Hauer (1822-1899) und Eduard Suess (1831-1914), dem Mediziner Carl Langer von Edenberg (1819-1887) sowie dem Zoologen Ludwig Karl Schmarda (1819-1908). ${ }^{14}$ Nach Hochstetters Tod im Juli 1884 übernahm Hauer die Obmannschaft, die nach dessen Ableben 1899 an den Zoologen und Intendanten des k.k. naturhistorischen Hofmuseums Franz Steindachner (1834-1919) überging.

Ursprünglich als Kommission der mathematisch-naturwissenschaftlichen Classe eingesetzt, wurde die Prähistorische Kommission acht Jahre nach ihrer Gründung unter Teilnahme der philosophisch-historischen Classe zur gemeinsamen Kommission beider Klassen erweitert. Die erste gemeinsame Sitzung fand am 31. März 1887 in Anwesenheit von Suess, Hauer und Steindachner sowie der beiden klassischen Archäologen Friedrich Kenner (1834-1922) und Otto Benndorf (1838-1907) und des Historikers Max Büdinger (1828-1902) von Seiten der philosophisch-historischen Klasse statt. Durch die Erweiterung zur Kommission beider Klassen verdoppelte sich nicht nur die Zahl ihrer Mitglieder, da nun jede Klasse drei Vertreter entsandte, auch deren Finanzierung sollte in Hinkunft von beiden Klassen zu gleichen Teilen getragen werden. Die Verbesserung der finanziellen Situation erlaubte schließlich auch die Herausgabe von einer eigenen Publikationsreihe, den „Mittheilungen der Prähistorischen Commission der kais. Akademie der Wissenschaften“, deren erster Band (Heft 1/1887) im Jahr 1888 erschien. ${ }^{15}$

Während der ersten vier Jahrzehnte ihrer Tätigkeit führte die Prähistorische Kommission an rund 110 Örtlichkeiten zum Teil über mehrere Jahre verfolgte Ausgrabungen durch, wobei die vom Paläolithikum bis zur späten Eisenzeit reichenden Forschungen vor allem Krain, die Südsteiermark, Böhmen und Mähren, das ehemalige Küstenland, aber auch die heutige Steiermark, Hallstatt, Niederösterreich und vereinzelt Oberösterreich, Salzburg, den damals zu Österreich gehörigen Teil Ungarns (heute Slowakei und Burgenland) und Süddalmatien betrafen (Abb. 1). ${ }^{16}$

13 Bereits in der ersten Kommissionssitzung vom 6. Juni 1878 wurde die Bezeichnung „Prähistorische Commission“ eingeführt: SітZUNGSPROTOKOLL $1878 \mathrm{~b}$.

14 Ohne Verfasser 1888, iii. - Mader 2018, Kap. 2.1.3.

15 Vor der Gründung der „Mittheilungen der Prähistorischen Commission" waren die wissenschaftlichen Berichte der Prähistorischen Kommission in den Denkschriften und Sitzungsberichten der kaiserlichen Akademie der Wissenschaften erschienen: OHNE Verfasser 1888 , iv.

$16 \mathrm{Zu}$ den Forschungen siehe MAder 2018. 


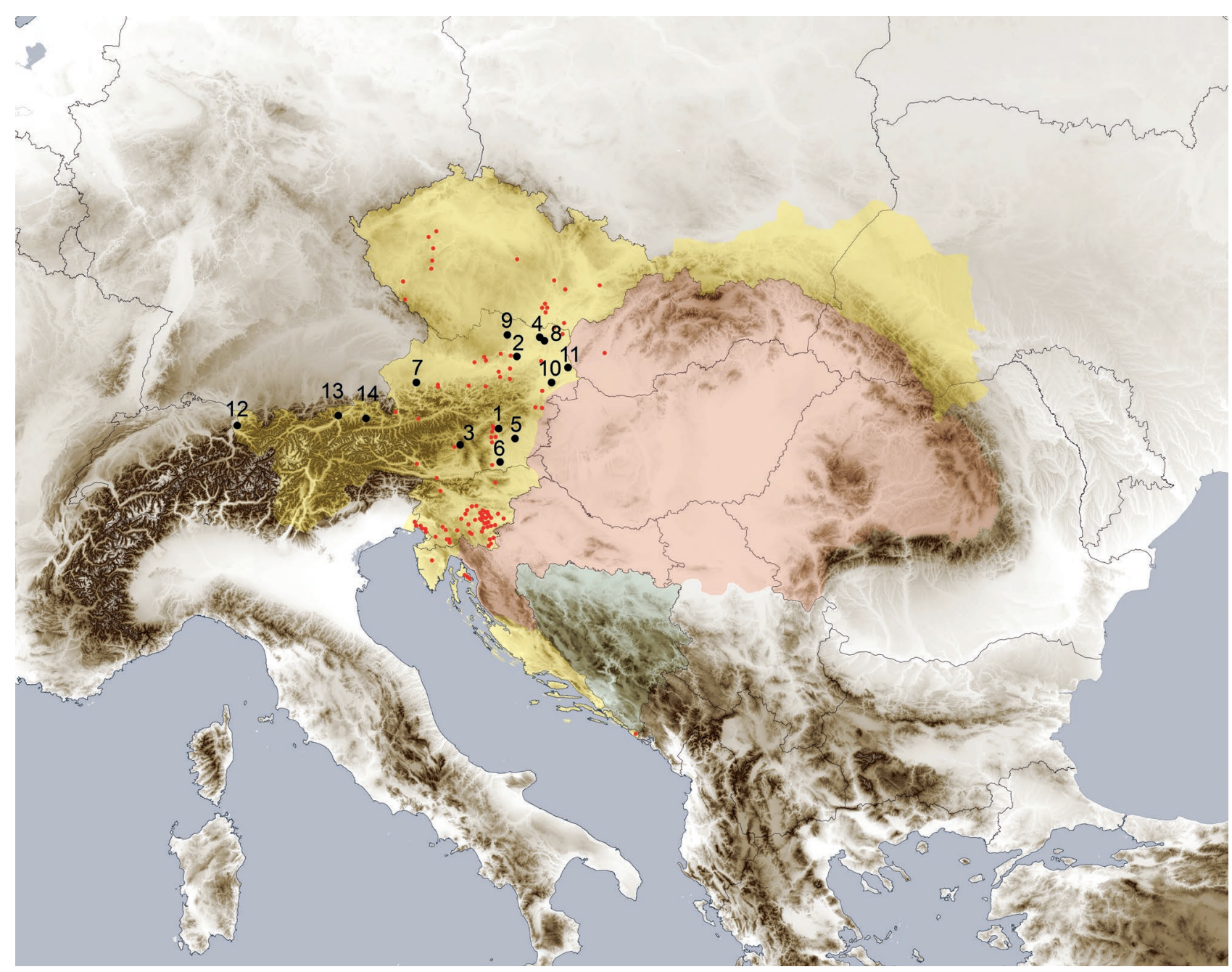

Abb. 1. Grafische Darstellung der Reduktion des Wirkungskreises der Prähistorischen Kommission nach dem Zerfall der Habsburgermonarchie. Politische Aufteilung 1914: Österreichisches Kaiserreich (Cisleithanien) = gelb, Königreich Ungarn = rot, Bosnien und Herzegowina = grün. Überblick der Ausgrabungsorte bis zum Ende des Ersten Weltkriegs (rote Punkte) und von 1918 bis 1938 im Bereich der Republik Österreich (nummerierte schwarze Punkte). - 1. Badlhöhle bei Peggau (W. Schmid, 1918). - 2. Gemeinlebarn (J. Szombathy, 1919-1921). 3. Noreia (St. Margarethen am Silberberg) (W. Schmid, 1921, 1929-1931). - 4. Oberleiserberg (H. Mitscha-Märheim und E. Nischer-Falkenau, 1925, 1926, 1929). - 5. Gleisdorf (W. Schmid, 1926). - 6. Burgstall Kleinklein (W. Schmid, 1927). - 7. Attersee (L. Franz, 1928,1929). - 8. Unterleis (E. Nischer-Falkenau, 1929). - 9. Altenburg am Kamp (A. Seracsin, 1929, 1931). - 10. Au am Leithagebirge (A. Seracsin, 1929, 1930-1931). -11. Braunsberg bei Hainburg (E. Nischer-Falkenau, 1931). - 12. Hochwindenkopf, Gemeinde Göfis (O. Menghin, 1937). - 13. Hochkapellenhügel bei Brixlegg (O. Menghin, 1937). - 14. Kelchalpe bei Kitzbühel (R. Pittioni, 1937). (Grafik: M. Negrete Martínez, OREA).

\section{Die prähistorische Kommission von 1918 bis 1938}

\section{1 „In alter Manier und Kontinuität“ 1918-1921}

1918 führte Walter Schmid (1875-1951), steirischer Landesarchäologe und seit 1911 Leiter des Münzen- und Antikenkabinetts am Grazer Joanneum, mit finanzieller Unterstützung der Prähistorischen Kommission Ausgrabungen in der Badlhöhle bei Peggau (Abb. 1) ${ }^{17}$ durch und

17 Höhlenkataster Nr. 2836/17, Tanneben, Gemeinde Peggau, Gerichtsbezirk Graz-Umgebung. schloss damit eine Reihe von Höhlenuntersuchungen im mittelsteirischen Karst ab, die er von 1915 bis 1917 neben der Durchforschung des Bacherngebietes in der Untersteiermark (Pohorje, Slowenien) ebenfalls mit Subvention der Prähistorische Kommission vorgenommen hatte. ${ }^{18}$

Durch den Ersten Weltkrieg war es zu keiner Unterbrechung der laufenden Projekte gekommen, vielmehr stand für die Prähistorische Kommission im März 1918 als

18 Mader 2018, Kap. 3.8.1 


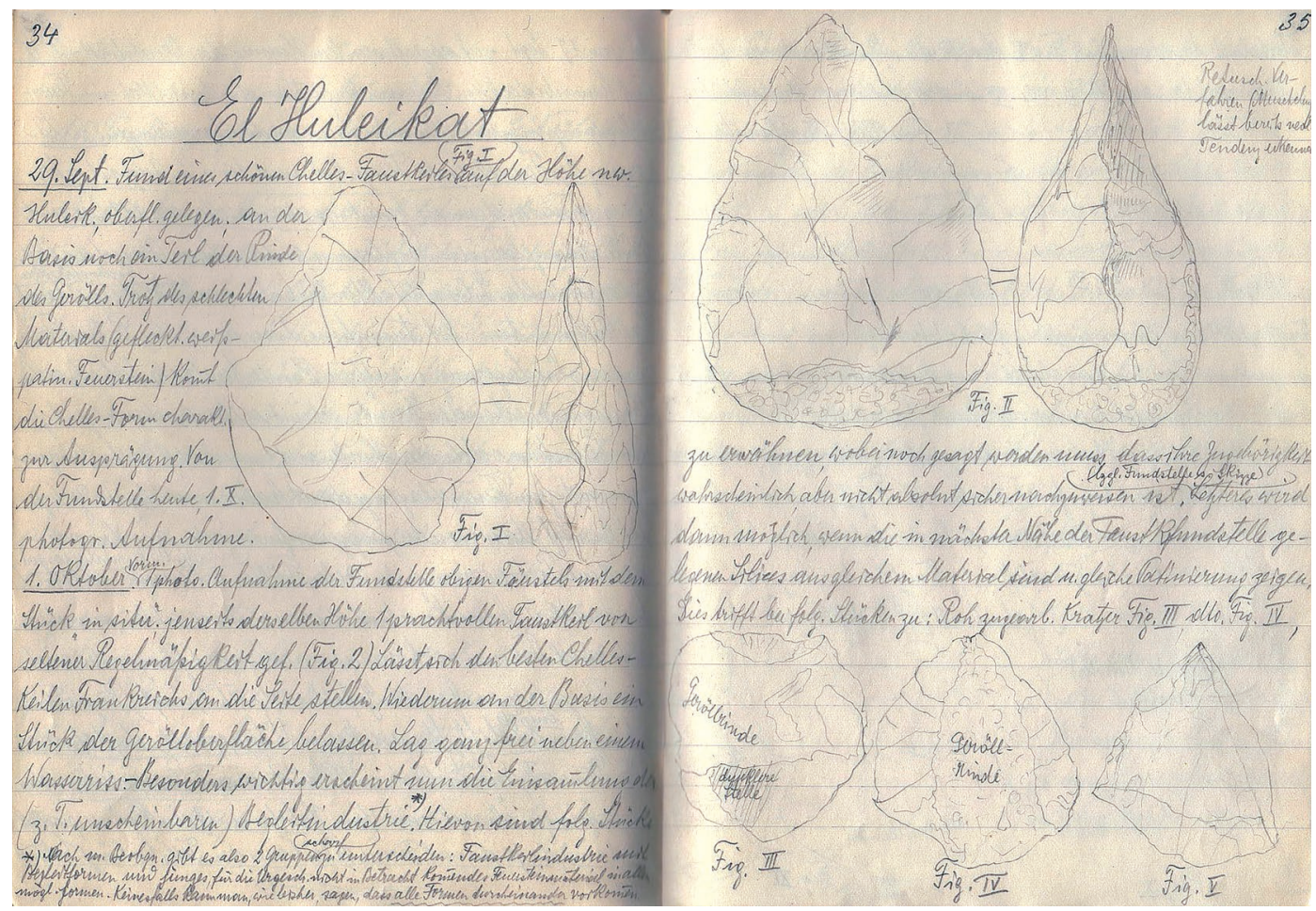

Abb. 2. Aufzeichnungen mit Fundskizzen aus dem Tagebuch von J. Bayer, El Huleikat 29.9.1917, S. 34 und 1.10.1917, S. 35 (Fundaktenarchiv, Prähistorische Abteilung, Naturhistorisches Museum Wien).

indirekte Folge der Ausweitung des Konfliktes auf den $\mathrm{Na}-$ hen Osten sogar die Realisierung eines zusätzlichen, ihren geografischen Wirkungskreis weit überschreitenden Vorhabens zur Diskussion.

Josef Bayer (1882-1931), Privatdozent ${ }^{19}$ und KustosAdjunkt an der Anthropologisch-prähistorischen Abteilung des k.k. naturhistorischen Hofmuseums, hatte nämlich, um durch den Krieg „nicht die ganze Zeit zu verlieren“, in der Absicht, „den milit. Dienst mit wissensch. Arbeit zu verbinden“, 20 im Februar 1917 um Versetzung von der Isonzofront zu einem am türkisch-russischen Kriegsschauplatz stehenden Militärkommando bzw. zu einem deutschen Kommando in Mesopotamien angesucht ${ }^{21}$ und in der Folge dank „Entgegenkommens des k. u. k. Hptm. i. Gstb. Friedrich Frh. Latscher von Lauendorf ${ }^{\alpha_{22}}$ während „seiner militärischen Dienstleistung an der Sinaifront vom Juli bis Dezember 1917 in Judäa, besonders in der Gegend von Gaza, praehistorische Forschungen betrieben, deren Ergebnisse er in einem Vortrag in der Wiener

19 Bayer hatte sich 1913 bei M. Hoernes in Wien für das Fach Urgeschichte des Menschen habilitiert.

20 Zitiert nach ANTL-WeISER 2007, 146.

21 ANTL-WeIser 2007, 146.

22 BAYer 1917, 32.
Anthropologischen Gesellschaft“ Anfang Februar 1918 während seines Fronturlaubes vorbrachte (Abb. 2). Dabei handelte es sich seiner Ansicht nach, „vor allem um die hochwichtige Frage des Zusammenhanges des Altpaläolithikums mit dem Neolithikum und um die Festlegung des Verhältnisses zwischen Aurignacien und Campignyien“. ${ }^{23}$ Um „diese und damit zusammenhängende Probleme der Lösung näher bringen zu können“, wandte sich Bayer, der sich schon länger mit chronologischen Fragen auseinandersetzte ${ }^{24}$ und seine Untersuchungen daher unbedingt fortsetzen wollte, Ende Februar 1918 mit dem Ansuchen „um Gewährung einer einmaligen Subvention in der Höhe von K. 6000 zur Bestreitung der Ausgrabungskosten" an die „hohe kaiserliche Akademie der Wissenschaften in Wien“. ${ }^{25}$

Bayers Ansuchen wurde von der mathematisch-naturwissenschaftlichen Klasse der Prähistorischen Kommission zugewiesen, die nun ihrerseits über das Vorhaben zu befinden hatte.

23 Bayer an die Akademie der Wissenschaften, 27.2.1918: BAYER 1918.

24 Bayer hatte bereits 1913 in den „Mitteilungen der Prähistorischen Kommission“ "sein quartärchronologisches System vorgestellt: BAYER 1913.

25 BAYER 1918. 
Sofort eingeholten „Erkundigungen im Kriegs Ministerium, Orient Abt.“ zufolge waren die „praehist. Forschungen des Oblt. Bayer [...] im Norden von Palaestina“ nicht nur „möglich“, man war sogar „der Ansicht, dass die Arbeiten jetzt leichter durchführbar seien als in Friedenszeiten“. Da dem Projekt somit von militärischer Seite nichts im Wege stand und das k.u.k. Reichskriegsministerium auch seine Unterstützung zugesagt hatte, beriet die Prähistorische Kommission über „die Eignung“ des „Gesuchstellers für diese Aufgabe“. Mit Ausnahme des Geologen und Paläontologen Carl Diener (1862-1928), der die „Motivierung des Gesuches“ bemängelte und Bayers ungenügende Literaturkenntnisse „des Gebietes“ befürchtete, waren sich die Kommissionsmitglieder über Bayers Befähigung zur „Durchführung der Arbeiten namentlich als Sammler“ einig. ${ }^{26}$

Schwieriger hingegen gestaltete sich die Lösung der „Frage der Bedeckung“ der Kosten. Zunächst erachtete man eine Subvention von 4000 Kronen „für die Beschränkung der Arbeiten auf den östlichen Landesteil“ als ausreichend, schließlich aber wurde die Summe „auf 3000 K herabgemindert, von welchen aus den Erträgnissen des Treitlfonds ${ }^{27}$ die mathematisch-naturwissenschaftliche Klasse einen Beitrag von 2000, die philosophisch-historische Klasse einen Beitrag von 1000 K. leisten“ sollte. Unter dem Vorbehalt des alleinigen Verfügungsrechtes der Prähistorischen Kommission über die „wissenschaftliche Ausbeute“ wurde Bayers Antrag in der Sitzung vom 14. März 1918 genehmigt. ${ }^{28}$

Bayer befand sich indessen wieder auf dem Weg nach Palästina, wo er in seiner Funktion als k.u.k. Verbindungsoffizier unter schwierigsten Bedingungen an verschiedenen Lokalitäten weitere „Aufsammlungen“ durchführte. Das dabei geborgene archäologische Material sollte Wien jedoch nie erreichen. Während nämlich ein Teil der Funde noch in Nazareth verlorenging, verschwand der andere nach der Übernahme durch italienische Beamte in Triest und gilt seither als verschollen. ${ }^{29}$

26 KenNer 1918. - Sitzungsprotokoll 1918b.

27 Die für die Gesamtakademie bestimmte Erbschaft Treitl (1895) stellt eine der bedeutendsten der kaiserlichen Akademie der Wissenschaften zu Teil gewordenen Stiftungen dar. Sie geht auf den Wiener Bürger und Gewerbetreibenden Josef Treitl zurück, der die Akademie 1880 testamentarisch zur Universalerbin seines Vermögens einsetzte, das für wissenschaftliche Zwecke, „zu deren Erreichung die Fürsorge nicht ohnehin anderen speziellen wissenschaftlichen Instituten oder der Staatsverwaltung obliegt“", verwendet werden sollte: Meister 1947, 112, 340.

28 Sitzungsprotokoll $1918 \mathrm{~b}$

29 ANTL-WeIser 2007, 163-167. - Bayers Bericht über den zweiten Palästinaaufenthalt erschien 1919 im Anzeiger der mathematischnaturwissenschaftlichen Klasse der Akademie der Wissenschaften in Wien: BAYER 1919.
Bereits 1917 dachte Bayer auch über die „Aufgaben“ nach, die er „unmittelbar nach dem Kriege“ in Angriff nehmen wollte und erstellte dazu eine Liste, deren Schwerpunkt die Herausgabe zweier umfassender Werke über den Menschen im Eiszeitalter bildete. ${ }^{30}$ Das erste sollte als „allg. Werk mit gleichmäßiger Behandlung aller Länder" eine „periodenweise Vorführung der Menschheitsgeschichte“ darstellen, das zweite hingegen in drei Bänden den Menschen des Eiszeitalters in Österreich behandeln. ${ }^{31}$

Im Zuge seiner Eiszeitforschungen trat Bayer zwei Jahre später, nunmehr als Leiter der Anthropologisch-ethnographischen Abteilung am Naturhistorischen Museum Wien, wieder mit einem „Subventionsansuchen von K 3000 zwecks Durchführung archaeolog. geolog. Arbeiten und zwar palaeolith. Kulturschichten in den Ziegeleien beim Bahnhof Gross Weikersdorf, Grabung im grossen LössAufschluss bei Krems“ und „Tiefengrabung bei Aggsbach“ in Niederösterreich an die Prähistorische Kommission heran. Diesmal wurde sein Antrag jedoch abgelehnt, da sich vor allem Eduard Brückner (1862-1927) und Eduard Suess „vom geologischen Standpunkt“ dagegen aussprachen, bezweifelten sie doch, dass „durch die vorgeschlagenen Grabungen an einzelnen Stellen erhebliche Ergebnisse bezüglich der Gliederung des Löss zu gewinnen seien." Rudolf Much (1862-1936) befürwortete zwar eine „Subvention für Ausgrabungen an der Fundstelle Weikersdorf“, die er „vorgeschichtlich“ für Erfolg versprechend hielt, die „Ausführung“ der Arbeiten erachtete er jedoch als „nicht drängend“, weshalb die Prähistorische Kommission Bayer bedauernd mitteilte, „mangels verfügbarer Mittel die Subvention derzeit nicht gewähren zu können".32

Aufgrund ihrer beschränkten finanzielle Lage sah sich die Prähistorische Kommission im selben Jahr auch veranlasst, die von J. Szombathy in seinem Ansuchen zur Unterstützung der prähistorischen Ausgrabungen bei Gemeinle-

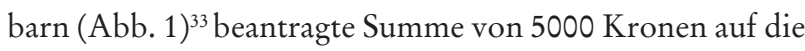
Hälfte zu reduzieren. Allerdings wurde Szombathy gleichzeitig in Aussicht gestellt, dass die Kommission „im Falle die Grabungen Erfolg versprechen“ geneigt wäre, „die Fortsetzung der Arbeiten im nächsten Jahre zu unterstützen“. ${ }^{34}$

Szombathy, der 1918 über Antrag der mathematisch-naturwissenschaftlichen Klasse auf Beschluss der

30 BAyer 1917, 134.

$31 \mathrm{Zu}$ Österreich zählte Bayer damals noch ganz selbstverständlich die „Sudetenländer (Böhmen, Mähren u. Schlesien)“ und „GalizienPolen-Ukraine“: BAYER 1917, 134. - Siehe auch BAYER 1927.

32 Sitzung vom 18.6.1919: SitzungsProtokoll 1919c.

33 Kastralgemeinde Gemeinlebarn, Gemeinde Traismauer, Verwaltungsbezirk St. Pölten (Niederösterreich).

34 Sitzung vom 18.6.1919: SitzungSPROTOKOLL 1919c. 
Gesamtakademie aus den Erträgnissen des Wedl-Legates ${ }^{35}$ 3000 Kronen zur Drucklegung seiner „Kraniometrischen Umrechnungstabellen“ erhalten hatte, ${ }^{36}$ war seit der Gründung der Prähistorischen Kommission einer ihrer wichtigsten Protagonisten. Von Hochstetters Schüler und Assistenten, der bereits an den ersten Ausgrabungen des k.k. naturhistorischen Hofmuseums in Hallstatt (1877) teilgenommen hatte, war Szombathy, obwohl er der Kommission nie als Mitglied angehörte und sich selbst auch nur als „anonymer Famulus der Prähist. Comm. “37 bezeichnete, vor allem nach Hauers Tod zur führenden Persönlichkeit der Prähistorischen Kommission aufgestiegen. Über Jahrzehnte bestimmte er die Grabungsvorhaben, die auch fast ausnahmslos unter seiner Leitung zur Ausführung kamen. Als Leiter und Kustos der prähistorischen Sammlung des k.k. naturhistorischen Hofmuseum sowie einflussreiches Mitglied der Anthropologischen Gesellschaft und Konservator wie Mitglied der k.k. Zentralkommission für Denkmalpflege führte er die von Hochstetter konzipierte enge, sich wissenschaftlich, personell und finanziell ergänzende Zusammenarbeit der Prähistorischen Kommission mit dem Museum, aber auch der Anthropologischen Gesellschaft und der Zentralkommission weiter, wodurch die Kontinuität in der Erforschung prähistorischer Fundstätten sichergestellt werden konnte. ${ }^{38}$

Szombathy war es auch, der 1890 in den „Mittheilungen der Prähistorischen Commission“ über „Die Tumuli von Gemeinlebarn“ berichtete, ${ }^{39}$ die Konservator Prälat Adalbert Dungel (1842-1923) 1885 mit einer Subvention der Prähistorischen Kommission von 50 Gulden untersucht hatte. ${ }^{40}$

Nachdem im Frühjahr 1885 bei Bauarbeiten für die Eisenbahnstrecke Tulln-St. Pölten nahe der Bahnstation Gemeinlebarn Reste prähistorischer Gräber zu Tage getreten waren, hatte Dungel in der Umgebung von Gemeinlebarn Nachforschungen angestellt und im Westen der Ortschaft nördlich der Bahnlinie drei durch wiederholtes Pflügen

35 Das Legat Wedl, benannt nach dem Stifter Karl Wedl (18151891), Professor für Histologie an der Universität Wien und korrespondierendes Akademiemitglied, der sein gesamtes Vermögen der kaiserlichen Akademie der Wissenschaften vermachte, wurde seit 1892 zur Pflege der Naturwissenschaften nach freiem Ermessen der mathematisch-naturwissenschaftlichen Klasse verwendet: MEISTER $1947,343$.

36 Sitzungsprotokoll 1918a. - Szombathy 1918a. - Vgl. SzombaTHY $1918 \mathrm{~b}$.

37 Zitiert nach Heinrich 2003, 26.

38 MAder 2018, Kap. 2.2 und 2.4.1.

39 Szombathy 1890.

40 Mader 2018, Kap. 3.4.3. stark abgeflachte Hügelgräber ausgemacht, deren Durchforschung Brandbestattungen mit überwiegend reich verzierten Keramik-, Bronze- und Eisenbeigaben der älteren Eisenzeit ergaben. ${ }^{41}$

Im November desselben Jahres begann das k.k. naturhistorische Hofmuseum mit ersten Untersuchungen in unmittelbarer Nähe der „Haltestelle Gemeinlebarn“. Die dabei freigelegten Bestattungen ließen auf ein bronzezeitliches Flachgräberfeld schließen, das die Prähistorische Kommission 1886 näher untersuchen wollte. „Oertliche Verhältnisse" verhinderten jedoch das Vorhaben. ${ }^{42}$ Erst 1889 konnte die Anthropologische Gesellschaft größere Ausgrabungen unter der Leitung von Szombathy durchführen, der, nachdem Oberlehrer Alois Kofler 1911 eine kleinere Grabung vorgenommen hatte, die Untersuchungen 1916 für das k.k. naturhistorische Hofmuseum fortsetzte. ${ }^{43}$

Die „bisher aufgedeckten Bestattungen“ ordnete Szombathy, nachdem er „Skelettgräber der mittleren Stufen der Bronceperiode, dann Brandgräber der jüngsten Stufe der Bronceperiode und endlich einige wenige Brandgräber der mittleren Stufe der Hallstattperiode“ vorgefunden hatte, „drei Altersstufen“ zu. Gerade dieses „örtliche Zusammentreffen verschiedener Alters- und Kulturstufen“ verlieh den Funden von Gemeinlebarn einen hervorragenden Platz unter den einheimischen Urgeschichtsfunden“, weshalb Szombathy es "gewiss als sehr erwünscht“ bezeichnete, dass „alles was der Boden von Gemeinlebarn der Urgeschichtsforschung zu bieten vermag, systematisch gehoben werde“. Durch „die Untersuchung der noch unberührten Teile des Gräberfeldes“ erwartete er sich „eine Ergänzung des bisher zutage getretenen Bildes und wertvolle nähere Aufschlüsse über die Beziehungen der hier vertretenen Kulturstufen zu einander“.44 Das Naturhistorische Museum aber sah sich finanziell außer Stande, die für die Aufdeckung und Untersuchung einer ca. $2500 \mathrm{~m}^{2}$ großen Fläche erforderlichen Mittel alleine zu tragen, weshalb Szombathy sich im Juni 1919 mit einem Subventionsgesuch über 5000 Kronen „zur systematischen Untersuchung der prähistorischen Nekropole von Gemeinlebarn“ an die Prähistorische Kommission wandte und trotz seines Ruhestandes ${ }^{45}$ auch „gerne bereit“

41 Szombathy 1890.

42 Mader 2018, Kap. 3.4.3.

43 Szombathy 1920a. - Szombathy 1929, 1-4.

44 Szombathy an die Hohe Akademie der Wissenschaften, 9.6.1919: SzombatHy 1919a.

45 Szombathy war Ende Jänner 1916 in den dauernden Ruhestand versetzt worden, verblieb jedoch als „honorierte wissenschaftliche Hilfskraft“ bis Josef Bayers Rückkehr aus dem Kriegsdienst (2. Jänner 1919) in der Prähistorischen Sammlung, die sonst während der Kriegsjahre völlig verweist gewesen wäre: НEInRICH 2003, 30. 


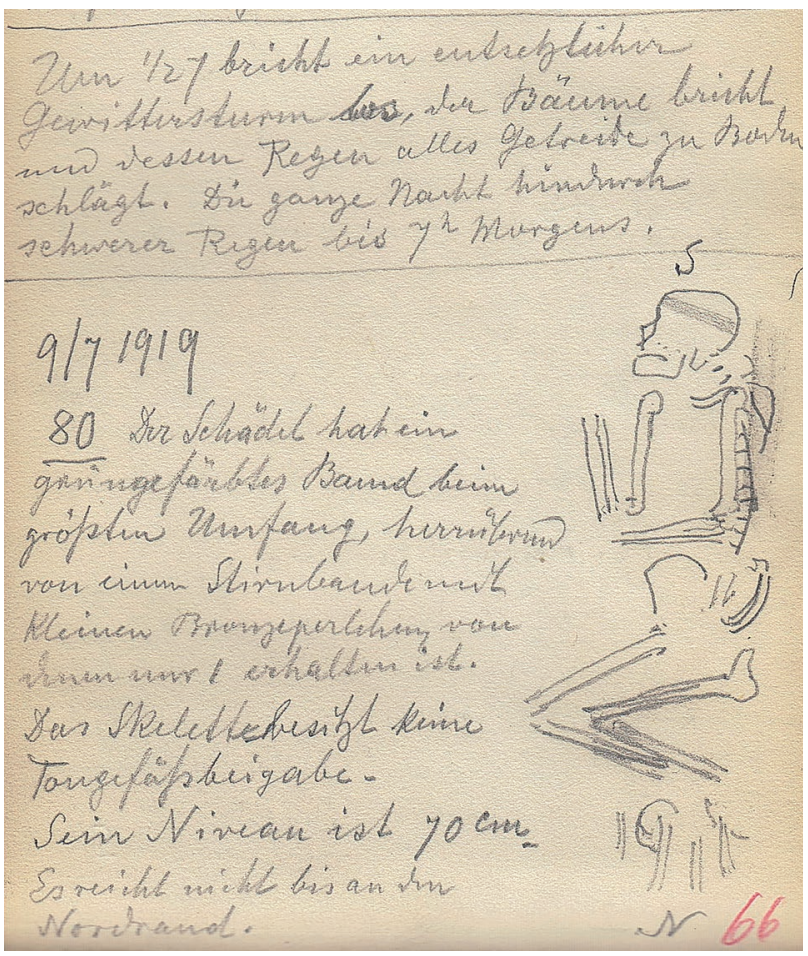

Abb. 3. Skizze von Gemeinlebarn Grab 80, aus Tagebuch 3 von J. Szombathy, Gemeinlebarn 9.7.1919, S. 66 (Fundaktenarchiv, Prähistorische Abteilung, Naturhistorisches Museum Wien).

war, „sich der etwas umständlichen Arbeit zu unterziehen“ (Abb. 3).46

Bereits im November berichtete Szombathy über die erfolgreiche Durchführung der Ausgrabungen, die auf drei westlich der Eisenbahnhaltestelle gelegenen Ackerparzellen „auf einer zusammenhängenden Bodenfläche von $664 \mathrm{~m}^{2 “}$ vorgenommen wurden und 32 Fundstellen, „nämlich 19 Skelettgräber, 10 Brandgräber und 3 wahrscheinlich zur alten Besiedlung gehörige Wohnstätten“ ergaben, die er „dem älteren Teile der Bronzezeit“ (Skelettgräber) und „der Zeit vom Ausgange der Bronzeperiode bis in die Mitte der Hallstattperiode“ (Brandgräber) zuordnete. ${ }^{47}$

Noch im Dezember 1919 suchte Szombathy um eine weitere Subvention in der Höhe „von 5000 bis 6000 Kronen zur Fortsetzung" der Ausgrabungen in Gemeinlebarn an, die er nicht zuletzt auch deshalb für dringend nötig hielt, „damit nicht Private störend in die systematische Untersuchungen eingreifen, was bei dem lebhaft erwachenden Interesse der Grundbesitzer zu fürchten ist“ ${ }^{\text {“ }}{ }^{48}$

46 Szombathy 1919a. - Sitzung vom 12.6.1919: SitzungSprotoKOLL $1919 \mathrm{~b}$.

47 Bericht Szombathys, 10.11.1919: Szombatнy 1919b.

48 Szombathy an die hohe Akademie der Wissenschaften, 28.12.1919: SzOMвATHY 1919c. - Sitzung vom 30.12.1919: SitZUNGSPROTOKOLL 1919 e.
Die Prähistorische Kommission bewilligte zwar Szombathys Ansuchen, konnte jedoch „mit Rücksicht auf die ihr zu Gebote stehenden geringen Mittel“ auch 1920 lediglich 2500 Kronen zur Verfügung stellen. ${ }^{49}$ Dennoch bezeichnete Szombathy die im Vergleich zu der von Seiten des Museums und privater Spender aufgebrachten Summe verhältnismäßig geringe Subvention der Akademie als „tragende Säule des Aktivums, an die sich erst in der Folge die grösseren Zuschüsse reihten ". ${ }^{50}$

Wie im Vorjahr waren auch die Ausgrabungen vom Sommer 1920 von Erfolg begleitet. Wieder wurde eine größere Fläche untersucht und dabei „88 besondere Fundstellen“, darunter „76 bronzezeitliche Skelettgräber mit 77 Skeletten, 7 der Hallstattperiode angehörige Brandgräber und 5 Gräber unbestimmten Alters mit Resten von Feuerstellen“ aufgedeckt. Als „weitere Ergänzung unseres Wissens“ führte Szombathy zwei Brandgräber an, deren „rot- und schwarz-bemalte, geometrisch verzierte Tongefässe" mit den Gefässen „aus den grossen Grabhügeln von Gemeinlebarn [...] übereinstimmen“, woraus er schloss, „dass die Flachgräber bis in die Zeit der Tumuli, d.i. die mittlere Stufe der Hallstatt-Periode reichen " würden und daher auch „beide Bestattungsarten nicht verschiedenen Völkern zugeschrieben zu werden brauchen, sondern nur verschiedenen Rangstufen innerhalb ein und derselben Bevölkerung ". ${ }^{51}$

Pünktlich vor Jahresende gestattete sich Szombathy, der Prähistorischen Kommission zur Fortführung der Untersuchungen in Gemeinlebarn neuerlich ein Subventionsansuchen vorzubringen, das er mit der Gefährdung zweier Parzellen bzw. des hier befindlichen „Teiles der alten Nekropole" durch drohende Verbauung begründete. ${ }^{52}$ Wie jedoch aus Szombathys Schreiben vom 30. September 1921 an die Prähistorische Kommission hervorgeht, hatten die Ausgrabungen in diesem Jahr ohne Unterstützung von Seiten der Akademie oder des Naturhistorischen Museums stattgefunden, sie wurden zur Gänze „aus Privatmitteln gedeckt ${ }^{\text {“. }}{ }^{53}$ Trotzdem erstattete Szombathy sowohl der Prähistorischen Kommission als auch dem Staats-Denkmalamt einen kurzen Bericht über die positiven Resultate der in diesem Jahr, wenn auch in kleinerem Rahmen durchgeführten Grabungen, und wies darauf hin, dass das „prähistorische Flachgräberfelde von Gemeinlebarn“" trotz 240 bisher geborgener Gräber, von denen 191 Skelettgräber der Bronzezeit und 49 dazwischen eingestreute Gräber Brandgräber der Hallstattperiode seien, mit den „bisherigen Grabungen

49 Bericht der Prähistorischen Kommission, 7.7.1920: MucH 1920b. 50 Szombathy an die Prähistorische Kommission, 12.12.1920: SzOMBATHY 1920 b.

51 Bericht zu Gemeinlebarn, 12.12.1920: Szомватнy 1920b.

52 Subventionsantrag, 15.12.1920: Szомватну 1920c.

53 Szombathy 1921. 
noch nicht erschöpft“ wäre und er "seine Untersuchung“ daher im nächsten Jahre fortsetzen wolle. ${ }^{54}$ Wieder aber stellte die Finanzierung der Ausgrabung das größte Problem dar, doch Szombathy gelang es, auch 1922 „die nötigen Geldmittel“ durch private Spenden aufzutreiben. ${ }^{55}$ Auf diese Weise konnte er die Untersuchungen des Gräberfeldes weitgehend ${ }^{56}$ abschließen und legte wenige Jahre später auch eine umfassende Publikation vor. ${ }^{57}$

Ein gleichfalls „alter Bekannter“ der Prähistorischen Kommission aus der Zeit der Monarchie ist der bereits oben erwähnte Walter Schmid, der sich nun, da die Süd- oder Untersteiermark ${ }^{58}$ nicht mehr zu Österreich gehörte, auf die archäologische Durchforschung der Mittel- und Obersteiermark konzentrieren wollte, wobei für ihn die Frage nach der Lokalisierung des keltischen Noreia und die Verbreitung der sogenannten „ostnorischen Kultur“ - jener in den 1870er Jahren aus dem Fehlen einer ausgeprägten Latènekultur entstandenen Theorie, wonach sich in der Steiermark eine retardierende Hallstattkultur bis kurz vor der Ankunft der Römer gehalten habe - im Zentrum seiner Interessen standen. ${ }^{59}$

So bat er im April 1919 „um Gewährung einer Subvention von $1000 \mathrm{~K}$ für die Erforschung der bisher noch wenig geklärten vorgeschichtlichen Verhältnisse von Obersteiermark" ${ }^{60}$ Obmann Steindachner hielt das Vorhaben für „wissenschaftlich sehr wünschenswert“ und Schmid „hiezu“ für „die geeignetste Persönlichkeit“. Obwohl sein Antrag von der Prähistorischen Kommission bewilligt wurde, ${ }^{61}$ war Schmid die Durchführung seines Vorhabens im Sommer 1919 „wegen Verkehrsschwierigkeiten“ nicht möglich. Unter dem Hinweis auf den „nach den heutigen Preisverhältnissen“ hohen finanziellen Aufwand seiner im gebirgigen Gelände beabsichtigten Erforschung der „vorgeschichtlichen Erzvorkommen“ bat er deshalb 1920 um eine weitere Unterstützung in der Höhe von 1000 Kronen..$^{62}$ „In Anbetracht des Interesses, das gerade der prähistorischen

54 SZOMBathy 1921.

55 Fundakte Gemeinlebarn.

56 In den folgenden Jahren traten immer wieder Gräber und Funde zu Tage, und es wurden kleinere Nachgrabungen auf Kosten des Naturhistorischen Museums Wien vorgenommen. - Siehe dazu: FundAKTE Gemeinlebarn . - Szombathys Tagebücher 4 und 5: SzombaTHY TAGEBÜCHER.

57 Szombathy 1929.

$58 \mathrm{Zu}$ Schmids Forschungen in der Süd- oder Untersteiermark siehe MADER 2018, Kap. 3.9.

59 Modl 2015a, 88. - Modl 2015b, 102.

60 Schmid, Ansuchen, 25.4.1919: ScHmid 1919a.

61 Sitzung vom 31.5.1919: Sitzungsprotokoll 1919a. - STEINDACHNER 1919.

62 Schmid Ansuchen, 11.4.1920: ScHmid 1920.
Erzgewinnung zukommt“, wurde auch dieses Ansuchen bewilligt. ${ }^{63}$

Ende April 1921 teilte Schmid mit, „im Vorjahre mit Mitteln der Akademie Reste vorgeschichtlicher und römischer Bergbaue in Kärnten und Steiermark untersucht und besonders zwischen Hüttenberg und Neumarkt wertvolle Aufschlüsse erzielt“ zu haben, „die auch die Frage der vorgesch. Stadt Noreia berühren“. Gleichzeitig ersuchte er die Akademie für die Fortsetzung seiner Forschungen, die er während des kommenden Sommers auch zum Abschluss bringen wollte, um einen neuerlichen Zuschuss von 2000 Kronen, der von der Prähistorischen Kommission auch in diesem Jahr in voller Höhe gewährt wurde. ${ }^{64}$

\section{2 „Geduld nötig“. Die Auswirkungen der wirtschaftlichen Notlage bis 1924}

Walter Schmid mag durch die geradezu regelmäßige wie ungekürzte Subventionierung seiner Untersuchungen im Vergleich zu Szombathy begünstigt erscheinen, ein Blick auf dessen Abrechnungen der Grabungskosten von Gemeinlebarn relativiert jedoch Schmids Unterstützung durch die Prähistorische Kommission. Während nämlich die Arbeiterlöhne im Jahr 1919 bei einem Stundenlohn von 2,50 Kronen insgesamt 1948,75 Kronen, die Verpflegung 685,00 Kronen, Packmaterial für die Funde 11,74 und Reise- bzw. Frachtspesen 183,06 Kronen ausmachten, betrug der Aufwand bei gleichem Zeitraum und etwas größerer Grabungsfläche ein Jahr später 8055,00 Kronen für Löhne, 1726,00 Kronen für Verpflegung, 361,90 Kronen für Packmaterial, 156,40 Kronen für den Transport von Funden und Gepäck und 195,18 Kronen für Reiseauslagen. Im Jahr 1921 waren die Ausgaben bei kürzerer Grabungszeit und etwa halber Fläche aber bereits auf das Dreifache angestiegen. ${ }^{65}$ Angesichts der drastisch voranschreitenden Geldentwertung schien es offenbar auch den Grundbesitzern leichter gefallen zu sein, auf die sonst übliche Grabungsentschädigung zu verzichten. Anstelle barer Münze zeigte sich Szombathy mit Schokolade und „Kubazigarren“66 erkenntlich.

Die wirtschaftlichen Notlage, in die die kleine Republik Österreich infolge des Ersten Weltkrieges durch den Verlust von Agrargebieten, Industrierevieren und Rohstoffquellen, aber auch die Verpflichtung zu Reparationszahlungen geraten war, hatte so bedrohliche Ausmaße angenommen,

\footnotetext{
63 Sitzung vom 12.7.1920: SitZungSPROTOKOLL 1920.

64 Schmid 1921.

65 Grabungsabrechnungen 1919-1921: Fundakte Gemeinlebarn. 66 Laut Szombathys Abrechnung kostete 1 kubanische Zigarre im Jahr 1920 3,80 Kronen.
} 
dass zu Beginn der 1920er Jahre bereits die Lebensfähigkeit des Landes in Zweifel gezogen wurde.

In entsprechender Weise gestaltete sich auch die finanzielle Situation der Prähistorischen Kommission. Seit 1918 war die Dotation von je 1000 Kronen aus den Mitteln der mathematisch-naturwissenschaftlichen und der philosophisch-historischen Klasse unverändert geblieben. ${ }^{67} 1921$ blieb sie überhaupt aus, und Schmids Subventionsantrag konnte nur aufgrund einer privaten Spende ${ }^{68}$ in der Höhe von 2000 Kronen bewilligt werden. In Anbetracht der tristen pekuniären Verhältnisse war allerdings auch weiterhin nicht an die bereits im Frühjahr 1919 beschlossene und bisher aufgeschobene Drucklegung von Schmids Manuskript über die noch während der Monarchie durchgeführten Untersuchungen bei Windischgraz (Slovenj Gradec) und Altenmarkt (Stari trg) im Bacherngebiet (Pohorje, Slowenien) als „notwendige Ergänzung “69 der ersten 1915 in den „Mitteilungen der Prähistorischen Kommission“ erschienenen Abhandlung über die Ringwälle des Bacherngebietes ${ }^{70} \mathrm{zu}$ denken. Das Ansuchen des Leiters der Geologischen Abteilung am Joanneum Vinzenz Hilber (1853-1931) um Veröffentlichung einer lediglich „40 Seiten u. 7 Tafeln“ umfassenden Arbeit über „Vor- und Frühgeschichtliche Forschungen in Steiermark“ in den „Mitteilungen der Prähistorischen Kommission “71 wurde in der Sitzung vom 15.7.1921 „mit dem Hinweis auf den Mangel aller Mittel zur Wiederaufnahme von Publikationen der Kommission“72 überhaupt abgelehnt.

Nicht ohne Grund hatte Schmid schon im Oktober 1919 die rhetorische Frage gestellt, „Das Leben in Wien wird im Augenblicke nicht besonders aufmunternd sein?" und hinzugefügt, „Auch in Graz ist es trüb, doch lassen wir die Hoffnung nicht sinken, dass es anders werden muss. “73 Eine Wende zum Positiven war jedoch vorerst nicht absehbar.

Bayer hielt es für „offenkundig“, dass „der Staat [...] nicht in der Lage ist, aus eigener Kraft den wissenschaftlichen Betrieb auf der alten Höhe zu erhalten“, weshalb er in seiner Funktion als Leiter der Anthropologisch-ethnographischen

67 Auszüge aus der Buchhaltung der Österreichischen Akademie der Wissenschaften, Archiv der Prähistorischen Kommission, Ordner B41 (1918) und B42 (1919).

68 Die Spende von Richard Böhmker (1870-1954), Kommerzialrat und Sammler, kam über Vermittlung des damaligen Obmannes der Prähistorischen Kommission R. Much zustande: SitzungsprotoKOLL 1921.

69 Sitzungsprotokoll 1919d.

70 SCHMid 1915.

71 Hilber an die Akademie der Wissenschaften, 11.7.1921: Hilber 1921.

72 SitzungSPROTOKOLl 1921.

73 Schmid an die Prähistorische Kommission, 21.10.1919: Schмid $1919 b$.
Abteilung am nunmehrigen Bundesmuseum „vielfach Beziehungen zum neutralen Ausland angeknüpft“ hatte, „um der katastrophalen Gestaltung unserer wissenschaftlichen Verhältnisse so weit als möglich aus eigener Initiative entgegenzuarbeiten“ ${ }^{74} \mathrm{Da}$ er dabei „häufig auf grosses Interesse für unsere einheimische Fachliteratur gestossen“ war und sich daraus auch die Möglichkeit, im Tauschwege „heute unzugängliche ausländische Literatur zu erwerben“, ergeben hatte, wandte sich Bayer am 18. Dezember 1920 mit der Bitte um Überlassung von 25 Exemplaren ihrer „Mitteilungen " an die Prähistorische Kommission, ${ }^{75}$ die jedoch selbst diesen Antrag, obwohl Bayers Vorhaben der internationalen Verbreitung ihrer Schriften dienlich gewesen wäre, ohne weitere Begründung „einstimmig“ ablehnte. ${ }^{76}$

Wie Szombathy und Bayer hatte auch Schmid die Eigeninitiative ergriffen und sich um die Finanzierung des Druckes seines Manuskriptes bemüht, da er der Streichung aller Abbildungen und Kürzungen des Textes zur Reduzierung der Kosten keinesfalls zustimmen wollte. Schließlich gelang es ihm, von der „Emergency Society“ 200.000 Kronen zu erhalten. ${ }^{77}$ Trotzdem reichten die zur Verfügung stehenden Mittel angesichts der ins Astronomische steigenden Preise nicht aus und von Seiten der Prähistorischen Kommission hieß es weiterhin „Geduld nötig“ “78

1924 erwachte die Prähistorische Kommission mit der Herausgabe der vierten Nummer des zweiten Bandes ihrer Mitteilungen aus der Lethargie der Jahre 1922 und 1923. ${ }^{79}$ Nachdem ihr Anfang April vorgebrachtes Ansuchen - die Barschaft der Prähistorischen Kommission betrug damals 203.697 Kronen (!) - „jede der beiden Klassen“ möge „als Dotation für das Jahr 1924 den Betrag von 3 1⁄2 Millionen $\mathrm{K}$ “ zur Verfügung stellen, bewilligt worden war, ${ }^{80}$ konnte endlich die Herausgabe des zweiten Teils von Schmids Arbeit zu den Ringwällen des Bacherngebietes erfolgen. ${ }^{81}$ Aufgrund der mit über 6 Millionen Kronen veranschlagten

74 Bayer an die Prähistorische Kommission, 18.12.1920: BAYER 1920. 75 BAYER 1920.

76 SitzungSPROTOKOLl 1921.

77 Schmid an Hofrat, 22.8.1922: ScHmid 1922b.

78 Handschriftlicher Vermerk vom 24.8.1922 am Schreiben Schmids vom 19.8.1922 an die Kaiserliche (sic!) Akademie der Wissenschaften: SCHMID 1922a.

79 Für die Jahre 1922 und 1923 finden sich weder im Archiv der PK noch in den Protokollbüchern der Akademie Archivalien bzw. Einträge zur Tätigkeit der PK. Einzige Ausnahme ist eine Postkarte der Universitätsbibliothek Freiburg im Breisgau, die am 13. November 1923 Band 2/3 der „Mitteilungen der Prähistorischen Kommission“ als fehlend meldet. Auf der Postkarte wurde vermerkt „Angewiesen 20/11/23“: POSTKARTE 1923.

80 SitZungSPROTOKOLl 1924a. - SitZUNGSPROTOKOLl 1924b. - SitZUNGSPROTOKOLL 1924c.

81 SCHMid 1924. 
Druckkosten für Schmids Abhandlung aber sollte die Wiederaufnahme der Mitteilungen in diesem Jahr die einzige Aktivität der Prähistorischen Kommission bleiben.

Erst 1925 sollte die Prähistorische Kommission ihre Tätigkeit auch wieder im Bereich der Bodenforschung fortsetzen.

\subsection{Ein Aufschwung zeichnet sich ab. Neue Grabungen in Nie-} derösterreich und der Steiermark 1925-1931

Und wieder war es W. Schmid, der sich beeilte, einen Subventionsantrag einzubringen. Am 16. Februar 1925 stellte er im Namen der Altertumssammlung des Joanneums ein vom damaligen Präsidenten des Kuratoriums des Landesmuseums, Alexander Luschin-Ebengreuth (1841-1932), befürwortetes Ansuchen, in dem er um Gewährung einer Subvention in der Höhe von „300 Schillingen“82 für „Nachforschungen nach vorgeschichtlichen Siedelungen im Gebiete von Burgstall bei Wies“ bat (Abb. 1). ${ }^{83}$ Schmids Ausführungen zufolge waren „in Burgstall außerhalb der Gräberfelder Reste von Weihehörnern (Votivfeuerböcken) gefunden“ worden, „die einen sicheren Rückschluß auf das Vorhandensein von vorgeschichtlichen Wohnungen gestatten“, ${ }^{84}$ und deren Spuren er im Zuge seiner „ostnorischen“ Forschungen nachgehen wollte. Die Prähistorische Kommission, die schon 1882 mit der Subvention der Ausgrabungen von Wenzel Radimský (1832-1895) an der Erforschung der im Umkreis des Burgstallkogels liegenden hallstattzeitlichen "Sulmthaler Tumuli“ teilgehabt hatte, ${ }^{85}$ bewilligte Schmid „den Betrag von 150 S. [...] geknüpft an die Bedingung der Einsendung eines kurzen Berichtes“ über die Grabungsergebnisse. ${ }^{86}$

Anstelle des verlangten Berichtes aber legte Schmid im folgenden Jahr ein neuerliches Ansuchen auf Unterstützung der „Grabungen auf der hallstattzeitlichen Wohnstätte Burgstall in Steiermark " vor. ${ }^{87}$ Zuvor hatte er in einem Schreiben an die Prähistorische Kommission erklärt, dass die für 1925 geplanten Forschungen am Burgstall „nicht verwirklicht werden“ konnten, da das dafür vorgesehene „Feld mit zweijährigem Klee bestellt war“. Er beteuerte jedoch „für den Herbst 1926 [...] bereits die Vereinbarung der Grabung getroffen“ zu haben. Mit der bewilligten Dotation aber hatte er „ein Bauernhaus aus dem Uebergange

82 Am 1. März 1925 wurde in Österreich der Schilling als Währung eingeführt. 1 Schilling entsprach 10.000 Kronen.

83 Kastralgemeinde Burgstall, Marktgemeinde Großklein, politischer Bezirk Leibnitz.

84 Schmid 1925.

85 Dazu Mader 2018, Kap. 3.8.8.

86 Sitzung vom 10.7.1925: SitZUNGSPROTOKOLL 1925.

87 Schmid, 10.7.1926: Schmid 1926b. von der spätkeltischen zur frührömischen Periode in Gleisdorf in der Oststeiermark Mitte März 1926 durchforscht“ (Abb. 1), worüber er einen „kurzen Bericht“ zur Vorlage brachte. Demnach hatte Schmid im Bereich der städtischen Ziegelei von Gleisdorf, ${ }^{88}$ wo im Herbst des Vorjahres vom Heimatforscher Kaplan Josef Radl „bereits ein Töpferofen und drei Wohngruben durchforscht ${ }^{\text {“ } 89}$ worden waren, „eine frührömische Siedlung untersucht, die aus Wohnhaus, Hof und Wirtschaftsgebäude bestand (24:17 m). “ In der „Bauart des Bauernhofes“, dessen „Gestalt“ Schmid mit jener „des heutigen Vierkanthofes, wie er besonders im Osten von Gleisdorf in der Oststeiermark und im Burgenlande häufig erscheint“ verglich (Abb. 4), sah er eine Anlehnung „an den prähistorischen Hausbau“, da „im Schottersockel noch kein Mörtel verwendet ist und die Fugen der Balken des Hauses mit Lehm abgestrichen sind, das Dach aber bereits mit römischen Leistenziegeln gedeckt ist. Reste ähnlicher provinzieller Bauweise wurden“, wie Schmid abschließend feststellte, „in Altenmarkt bei Windischgraz“ (Stari trg bei Slovenj Gradec, Slowenien) und „in den spätkeltischen Vogesensiedlungen [...] beobachtet. “90

Obwohl die Prähistorische Kommission Schmids Vorgehen, die für 1925 bestimmte Subvention „ohne die Commission zu verständigen“ für einen „anderen Zweck als sie gegeben wurde“ zu verwenden, ausdrücklich missbilligte, bewilligte sie für die Untersuchungen am Burgstallkogel noch einmal 150 Schilling und zeigte auch an den Grabungsresultaten von Gleisdorf Interesse. Aus Schmids einseitigem Bericht über das „norisch-römische Bauernhaus“ wurde schließlich unter Einbezug aller vor und nach Schmids Grabung vom Frühjahr 1926 zu Tage gekommenen Fundmaterialien eine umfangreiche Abhandlung über den zu einem Vicus gehörigen römischen Gebäudekomplex mit Töpferofen, ${ }^{91}$ welche die Prähistorische Kommission „auf Wunsch“ von Emil Reisch dem Österreichischen Archäologischen Institut zur Veröffentlichung übergab. ${ }^{92}$

„Ich konnte erst Mitte März die Grabungen in Burgstall, bei denen ich zwei Häuser durchforschte, durchführen; gedenke aber über die Ergebnisse im Laufe des Mai den definitiven Bericht mit Plänen und Abbildungen vorzulegen“, unterrichtete Schmid am 16. April 1927 die Akademie vom

88 Katastralgemeinde Gleisdorf, Stadtgemeinde Gleisdorf, politischer Bezirk Weiz.

89 Sснмid $1926 \mathrm{c}$.

90 Schmid an die Prähistorische Kommission, Graz 26.4.1926 und Bericht „Ausgrabung eines Bauernhauses in Gleisdorf“: ScHmID $1926 a$.

91 Mode 2015b, 106.

92 EgGer 1929. - Schmid 1929a. 


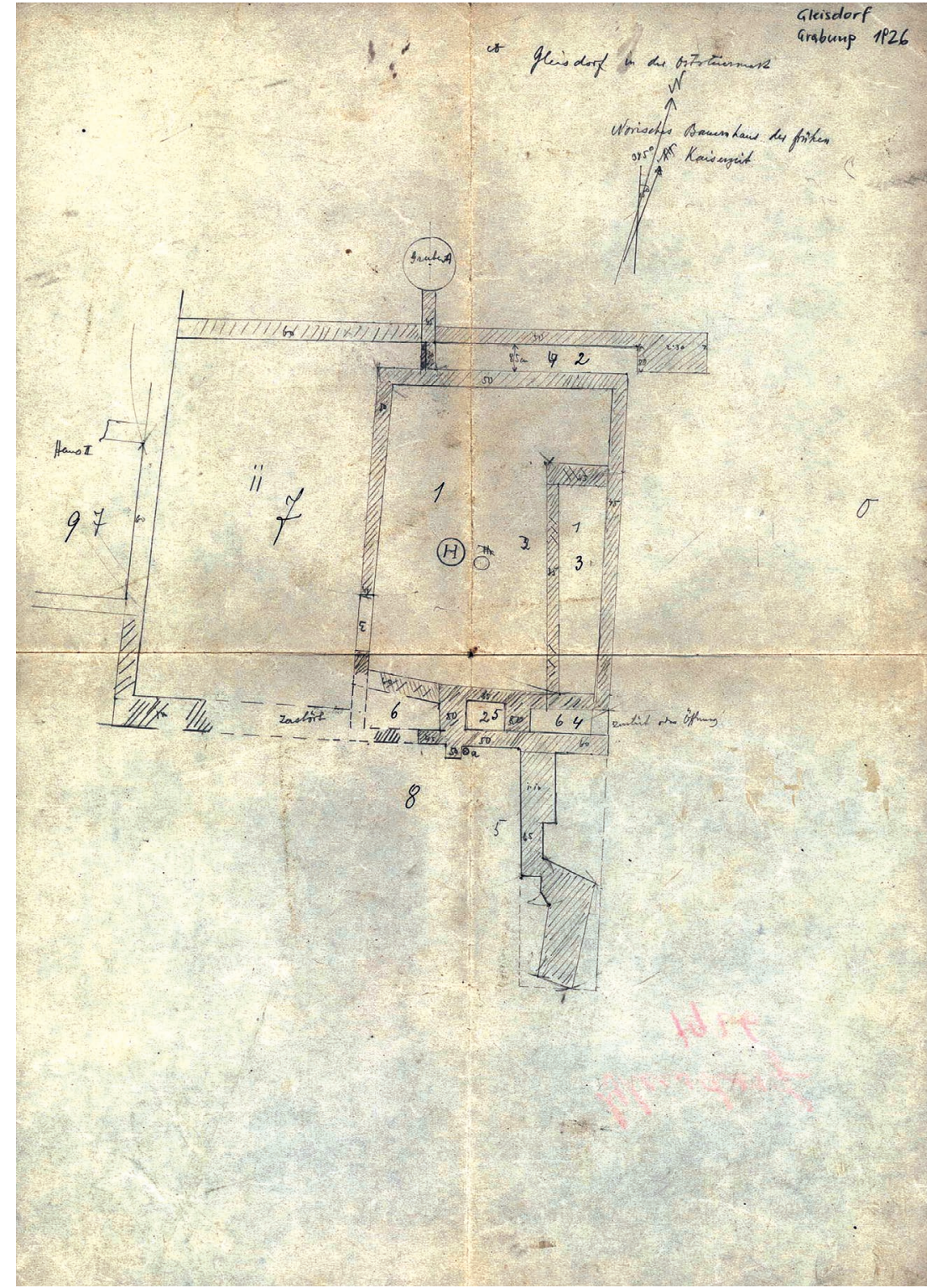

Abb. 4. Plan „Gleisdorf in der Oststeiermark, Norisches Bauernhaus der frühen Kaiserzeit" von W. Schmid 1926 (Zeichnung: Ortsakt Gleisdorf, Archiv Archäologiemuseum und Münzkabinett, Universalmuseum Joanneum Graz). neuerlich verspäteten Fortgang seiner Forschungen, ${ }^{93}$ die er nun „auf dem Burgstall“, dem „höchsten Punkte des Plateaus" zwischen der Saggau und Sulm, wo schon früher die „ausgedehnten Gräberfelder [...] deren bedeutendste die Fürstengräber mit Panzern und reich mit figürlichen Schmuck versehenen Zisten sind"94 aufgedeckt wurden, vorgenommen hatte. Im Laufe der nur wenige Tage dauernden Untersuchungen konnte Schmid Reste einer unbefestigten „bis an die Spitze der Kuppe ${ }^{\text {“95 }}$ reichenden Siedlung feststellen und „zwei Hütten“ ausgraben, die er als „Wohnhaus“ und „Wirtschaftsgebäude“ deutete und dem

93 SCHMID 1927.

94 „Burgstall bei Klein Glein“: Schмid o. J.

95 „Klein-Glein“: Schmid o. J.
„Charakter der Gefässreste“ nach „der späthallstättischen Zeit" zuordnete (Abb. 5). ${ }^{96}$

Nachdem Schmid 1927 ,in der Umgebung von Neumarkt Untersuchungen angestellt“ hatte, „die ein wertvolles Material aus der Uebergangszeit von der spätkeltischen in die römische Periode ergaben“ und dabei auch „mehrere vorgeschichtliche Fundstätten festgestellt“ wurden, „deren Erforschung für die Entwicklung der spätkeltischen und provinzialrömischen Kultur längs des grossen Verkehrsweges über den Hohentauern von grosser Bedeutung wäre“, wandte er sich Ende März 1928 an die Prähistorische

96 Schmid 1930a, 79. 


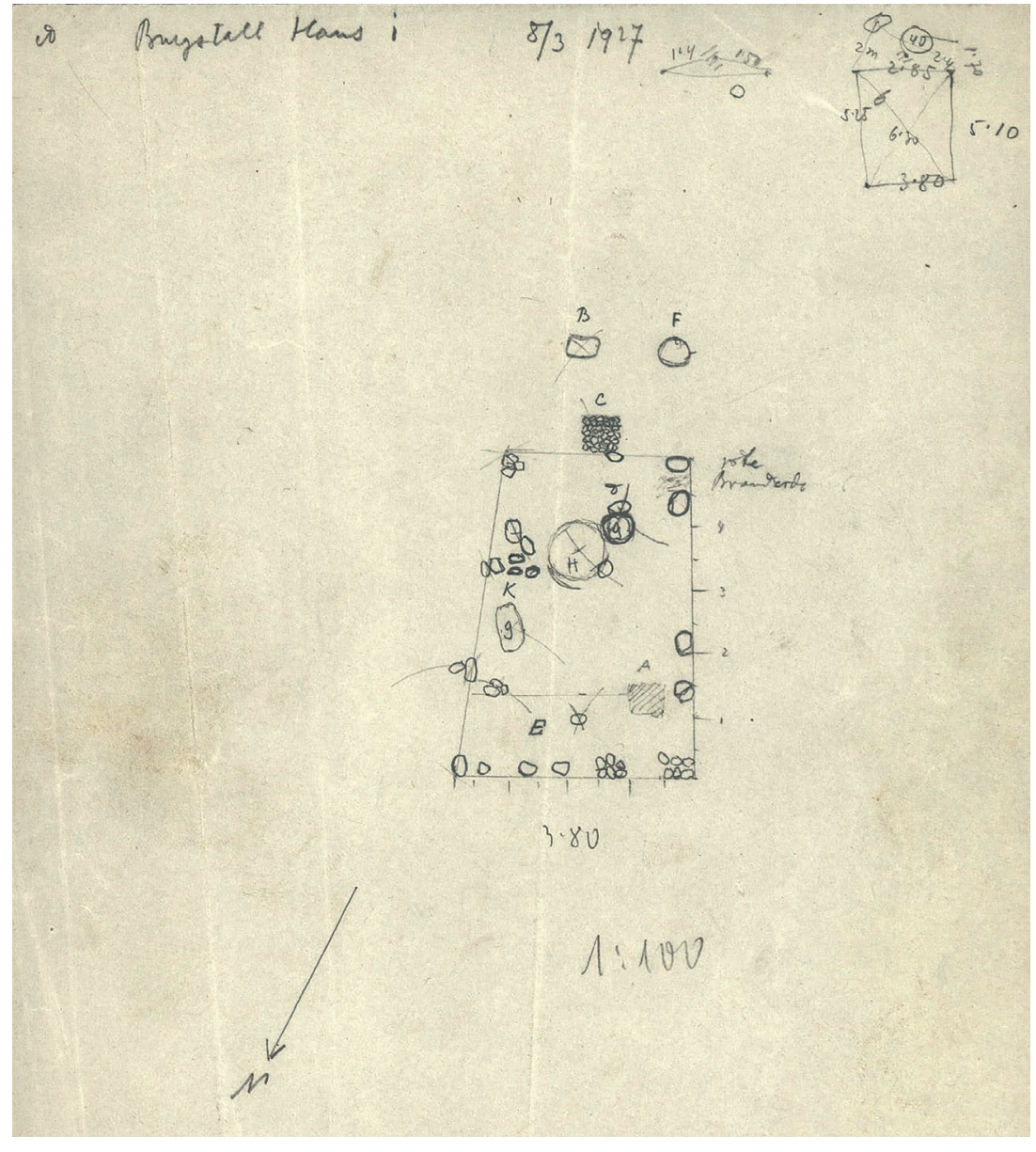

Abb. 5. Plan „Burgstall Haus 1“ von W. Schmid, Burgstall 8.3.1927 (Zeichnung: Ordner Burgstallkogel Klein-Klein, Archiv Archäologiemuseum und Münzkabinett, Universalmuseum Joanneum Graz).
Kommission und bat „für die Durchführung dieser Untersuchungen einen Betrag von 500 Schillingen“ zu bewilligen. ${ }^{97}$ Diesmal wurde sein Ansuchen nicht von Erfolg begleitet. „Von der erbetenen Subventionierung Ihrer Grabungen bei Neumarkt mußte wegen mangelnder Mittel Abstand genommen werden", ${ }^{98}$ hieß es im Antwortschreiben an Schmid, der sich jedoch keineswegs entmutigen ließ und 1929 „seine Bitte aus dem vorigen Jahre“ wiederholte. Um seinem Ansuchen zusätzlich Nachdruck zu verleihen, fügte er hinzu, „Neumarkt ist in archäologischer Beziehung einer der wichtigsten Orte, in dem Spuren von vorgeschichtlicher Besiedelung bereits festgestellt worden sind“". ${ }^{99}$

Die Prähistorische Kommission bewilligte Schmid eine Unterstützung von 350 Schilling und bereits Ende Oktober 1929 teilte Schmid mit, „sechs Häuser ausgegraben“ zu haben und legte gleichzeitig einen ausführlichen Bericht über seine „Forschungen im tauriskischen Noreia“, das er in

97 Schmid 1928.

98 Much an Schmid, 14.7.1828: Much 1928.

99 ScHMid 1929 b.
St. Margarethen bei Silberberg (Abb. 1) ${ }^{100}$ gefunden zu haben glaubte, vor. Hier hatte ihn, als er von „erhöhter Warte das ganze Gebiet, das sich in breiten Terrassen mit steil abfallenden Rändern ausbreitete“ betrachtete, „der Gedanke durchzuckt [...]: der heilige Boden von Noreia!“. ${ }^{101}$ Schmid befasste sich schon länger mit der Frage nach der Lokalisierung der keltischen Stadt Noreia, in deren Nähe es antiken Schriftquellen zufolge 113. v. Chr. zur siegreichen Schlacht der Kimber und Teutonen über die Römer gekommen war. Bestärkt durch Strabos Angaben, Noreia wäre „1200 Stadien $(213 \mathrm{~km})$ von Aquileia entfernt“ und ,in seiner Umgebung“ würden sich „Goldwäschen und Eisenbergwerke befinden“, die er im seit alters her bekannten Vorkommen und Abbau von Eisen, Gold und Silber in unmittelbarer Nähe des Ortes bestätigt fand, sah Schmid bereits in den Ergebnissen der ersten Ausgrabung den eindeutigen Beweis „für die Gleichstellung der vorgeschichtlichen Siedlung in

100 Katastralgemeinde Noreia, Marktgemeinde Mühlen, Bezirkshauptmannschaft Murau.

101 Tagebucheintrag Schmids „Versuchsgrabungen im Königreich ...", Schmid Nachlass, Archiv Archäologiemuseum und Münzkabinett, Universalmuseum Joanneum Graz. 


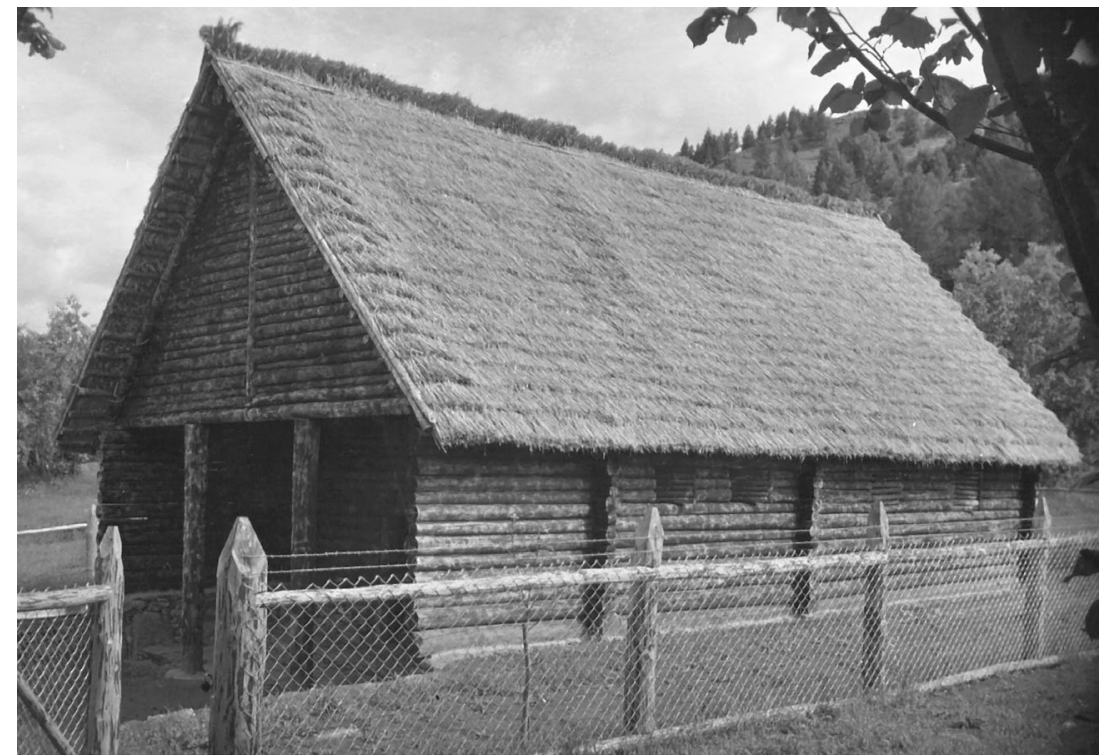

Abb. 6. „Königshaus“" von Noreia, Fotografie um 1935 (Foto: Sammlung Fürhacker, Unterzeiring).
St. Margarethen mit dem keltischen Noreia“. Auf den unterhalb der Ortschaft liegenden Terrassen hatte er durchwegs Spuren dichterer Besiedlung festgestellt und sechs Gebäude aufgedeckt, wovon er „Haus 2“ auf dem „sog. Lusenboden“ aufgrund der außerordentlichen Größe und „einzig“ dastehenden Bauart nicht nur als „Überraschung“ bezeichnete, sondern auch als „Haus des Königs“ deutete. ${ }^{102}$

Auf seine Erkenntnisse verwies Schmid auch in der Begründung seines 1930 an die Prähistorische Kommission gestellten Ansuchens um eine „Subvention von S 500.-“ zur Fortsetzung der „Grabungen im tauriskischen Noreia“. ${ }^{103}$ Die Unterstützung wurde unter Kürzung des Betrags auf die Hälfte gewährt. ${ }^{104}$ Deren Auszahlung aber verzögerte sich offenbar, da Schmid im Mai seine Bitte um Unterstützung der Forschungen in St. Margarethen unter Vorlage eines weiteren Berichts über seine „in den letzten Wochen vor Ostern 1930“ stattgefundenen Ausgrabungen wiederholte. ${ }^{105}$

1931 folgten schließlich zwei weitere Berichte, in denen Schmid die Ergebnisse der Herbstgrabung 1930, die der Feststellung der Besiedlungsdichte „der grössten Terrasse“, auf der sich auch das „Königshaus“ befindet, dienen sollte, und die Resultate der während der zweiten Aprilhälfte 1931 vorgenommenen Untersuchung von insgesamt 12 Gebäuden darlegte. ${ }^{106}$

102 Schmid 1929c. - „Noreia die Hauptstadt des ostalpinen Königreiches Norikum“: SCHMID 1930c.

103 Schmid an die Prähistorische Kommission, 22.1.1930: SсHмID 1930b.

104 Sitzung vom 21.3.1930: SitZUngSPROTOKOLl 1930a.

105 Schmid an die Prähistorische Kommission, 17.5.1930: SснміD 1930d.

106 SCHMID 1931.
In seiner Begeisterung, Noreia wiederentdeckt zu haben, trieb Schmid nicht nur die Grabungen mit großem Einsatz voran, er berichtete auch in anschaulicher Weise regelmäßig in der Tagespresse über die Fortschritte seiner Forschungen. Schließlich wurde auch das sogenannte „Königshaus" rekonstruiert (Abb. 6), und Schmid konnte sogar die Steiermärkische Landesregierung davon überzeugen, St. Margarethen am Silberberg offiziell in Noreia umzubenennen. ${ }^{107}$

Weniger überzeugt hingegen zeigte sich die Prähistorische Kommission, als Schmid Anfang Februar 1931 wieder mit einem Subventionsgesuch zur „Fortführung der Grabungen in Noreia" an sie herantrat. In ihrer Sitzung vom 25. Juni entschied sie in Anwesenheit der Mitglieder F. E. Suess, O. Menghin, J. Kubitschek, E. Reisch, E. Schweidler und Obmann R. Much „nach längerer Aussprache [...] das Ansuchen von Prof. W. Schmid um Gewährung von S 500 für Fortsetzung der Grabungen bei St. Margareten am Silberberg“ abzulehnen, „da die Komm. im Gegensatz zu Prof. Schmid die Überzeugung gewonnen hat, dass dessen Grabungen gezeigt haben, dass es sich dort nicht um das alte Noreia handeln könne, und weitere Grabungen kaum Ergebnisse versprechen, die das Bild verändern könnten oder von großem selbständigen Interesse sein dürften. “108

Nichtsdestotrotz stellte Schmid 1932 ein weiteres Ansuchen, das jedoch wie jenes im Vorjahr keine Berücksichtigung fand. ${ }^{109}$

107 Schmid an die Steiermärkische Landesregierung, 7.2.1930: ScHмid 1930c.

108 Sitzung vom 25.6.1931: SitZUNGSPROTOKOLL 1931b. 109 Sitzungsprotokoll 1932b. 
Ungeachtet der Zweifel, die die Prähistorische Kommission, aber auch einige von Schmids Kollegen an der Noreia Theorie hegten, hielt Schmid selbst daran fest und führte seine Forschungen bis 1933 weiter. ${ }^{110}$ Seine Gegner aber sollten Recht behalten, neueren Untersuchungen zufolge hatte Schmid nicht das berühmte Noreia, sondern Reste einer spätmittelalterlichen Bergbausiedlung ausgegraben. ${ }^{11}$

Mit der Wiederaufnahme der Bodenforschung im Jahre 1925 förderte die Prähistorische Kommission auch wieder Untersuchungen in Niederösterreich, die im Gegensatz zu jenen in der Steiermark, die nach wie vor in Schmids Händen lagen, nun von einer neuen Generation von Prähistorikern bzw. Mitarbeitern getragen wurden.

So ersuchte Mitte März 1925 H. Mitscha-Märheim „um Gewährung einer Subvention zur Durchführung einer planmäßigen Ausgrabung, welche die Stellung der umwallten Ansiedlung auf dem Oberleiser Berge in vor- und frühgeschichtlicher Zeit klären soll“ (Abb. 1). ${ }^{112}$

Der spätere Universitätsprofessor Herbert MitschaMärheim (1900-1976) ${ }^{113}$ mit Lehrbefugnis für „Nichtrömische Archäologie des 1. Jahrtausends in Mitteleuropa“, der nach Abschluss des Studiums der Urgeschichte und der mittelalterlichen Geschichte an der Universität Wien (19181922) 1923 als unbesoldeter Assistent an das unter der Direktion von Oswald Menghin stehende Urgeschichtliche Institut kam, hatte, nachdem er zu Beginn des folgenden Jahres mit der Leitung der kulturwissenschaftlichen Abteilung des Niederösterreichischen Landesmuseums betraut wurde, ${ }^{114}$ in seiner neuen Funktion Gelegenheit, eine Reihe größerer und kleinerer wissenschaftlicher Ausgrabungen in Niederösterreich durchzuführen. ${ }^{115}$ Mitscha-Märheim, der sich bereits zu einem Zeitpunkt, als frühgeschichtliche Forschungen „an unserer urgeschichtlichen Lehrkanzel noch in keiner Weise berücksichtigt wurden ", 116 für die archäologische Hinterlassenschaft der Germanen, Awaren und Slawen zu interessieren begann und 1925 in der "Wiener Prähistorischen Zeitschrift“ über ein germanisches Gräberfeld bei Mistelbach berichtet hatte, ${ }^{117}$ wandte sich in diesen Jahren auch der Erforschung des Oberleiserberges (Abb. 7)

110 SCHMID 1932.

111 HaAs-Trummer 2007, 119-140. - Modl 2015b, 101. 112 Mitscha-Märheim an die Akademie, 14.3.1925: MiтschA-MäRHEIM 1925a. - Oberleiserberg bei Ernstbrunn, Gemeinde Klement, Verwaltungsbezirk Korneuburg.

113 Zu Mitscha-Märheims Biografie und Schriftenverzeichnis: PeRsonalakt Mitscha-Märheim. - PitTioni 1978.

114 Personalakt Mitscha-Märheim.

115 Dazu Pittioni 1978, 554 (Schriftenverzeichnis).

116 Zitiert nach PitTioni 1978, 547.

117 Mitscha-Märheim 1925b.

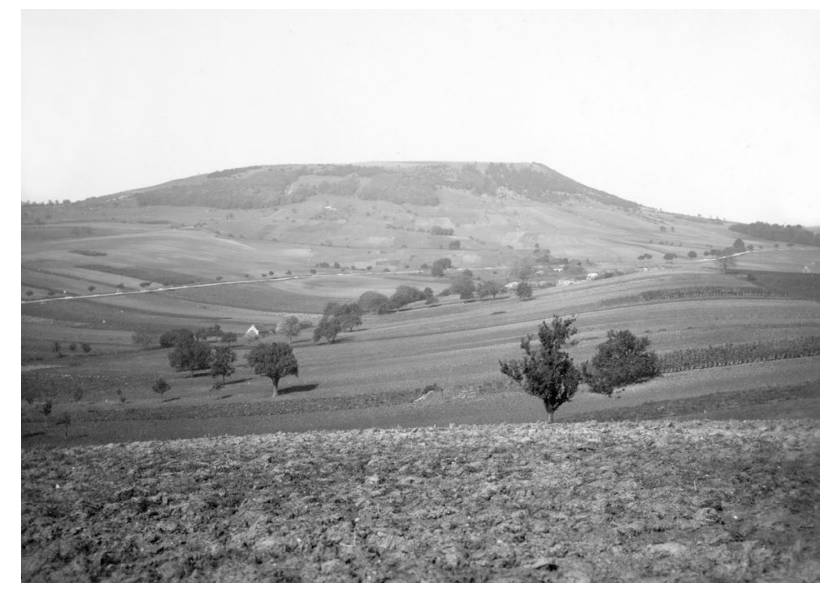

Abb. 7. Oberleiserberg, historische Aufnahme (Foto: Fachbereich für Ur- und Frühgeschichte, Landessammlungen Niederösterreich, Schloss Asparn/Zaya).

zu. Auf die hier befindlichen Wallanlagen und zahlreichen Funde „vor- und frühgeschichtlicher Gegenstände - vor allem auch römischer Ziegel“ hatte erstmals Matthäus Much (1832-1909) in den „Mittheilungen der Anthropologischen Gesellschaft in Wien“ $(1872,1874)$ aufmerksam gemacht. Vinzenz Kudernatsch (1867-1946), Sammler, „eifriger Altertumsfreund“ und Korrespondent der k.k. Zentralkommision für Denkmalpflege, hatte, ehe sich „in jüngster Zeit“ vor allem Eduard Nowotny (1862-1935) mit den römischen Funden beschäftigte, „alljährlich die Bergoberfläche nach Funden“ abgegangen und „manches gute Stück“ geborgen. Aufgrund der abgelegenen Lage und „schlechten Verkehrsverhältnisse der Vorkriegszeit“ aber blieb „der Fundplatz trotz alledem fast gänzlich unbekannt“ und auch „von Raubgräbern verschont.“ Die Aussichten für eine Grabung erschienen daher hier „ungleich günstiger“ als an anderen Fundstätten und Mitscha-Märheim, der 1925 auch zum Konservator für das Fundwesen im Bezirk Mistelbach ernannt worden war, ${ }^{118}$ versprach sich "durch systematische Arbeiten [...] eine Reihe von interessanten Problemen der Heimatgeschichte (wie etwa die Frage der römischen Besiedlung dieser Gegend [...]) einer Lösung“ zuführen zu können. ${ }^{119}$

In ihrer Sitzung vom 10. Juli 1925 beschloss die Prähistorische Kommission nach „eingehender“ Beratung „einstimmig“, Mitscha-Märheim 500 Schilling „zum Zweck einer Grabung auf dem Oberleiserberg“ zu bewilligen (Abb. 8). Dabei wurde zur „Bedingung“ gestellt, „daß eine Veröffentlichung der Forschungsresultate zunächst der Akademie zum Druck angetragen“ und „die Funde einem

118 BRÜCKLER, Nimeth 2001, 178-179.

119 Mitscha-Märheim, Nischer-Falkenhof 1929, 391-292. 


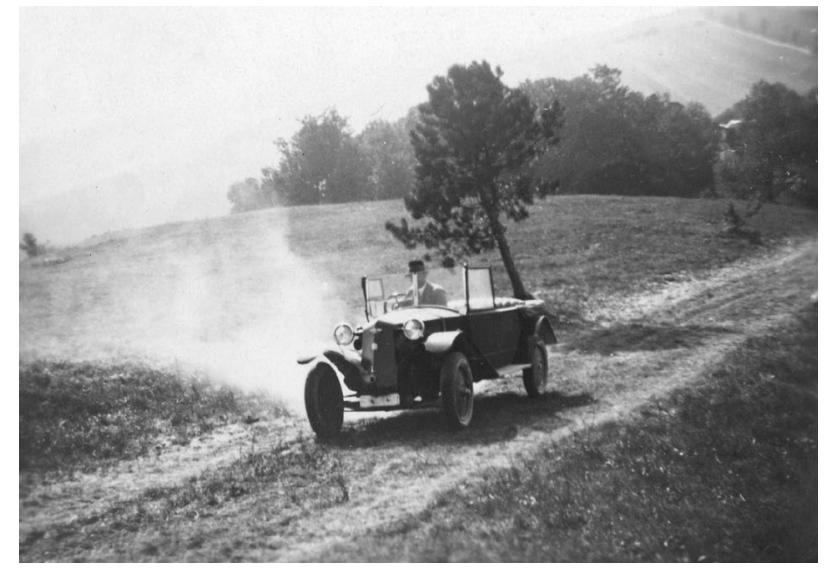

Abb. 8. H. Mitscha-Märheim unterwegs zu Ausgrabungen (Foto: Fachbereich für Ur- und Frühgeschichte, Landessammlungen Niederösterreich, Schloss Asparn/Zaya).

Museum - aber nicht lokalen Charakters - übergeben werden sollen." ${ }^{120}$ Die hier geforderte Übergabe des Fundmaterials entsprach der seit Gründung der Prähistorischen Kommission bestehenden Übereinkunft, wonach die Fundobjekte, die aufgrund der Subvention als Eigentum der Akademie galten, dem k.k. naturhistorischen Hofmuseum zur Bereicherung der Prähistorischen Sammlung als Geschenk überlassen wurden. ${ }^{121}$

Im Herbst 1925 teilte Mitscha-Märheim mit, die von der Akademie unterstützten Ausgrabungen „gemeinsam mit Regierungsrat Dr. E. Nischer im Auftrage der Direktion der n.ö. Landessammlungen“ mit „in jeder Hinsicht“ befriedigendem Resultat „veranstaltet“ zu haben. ${ }^{122} \mathrm{Da}$ die Untersuchungen im westlichen Bereich „zur einwandfreien Feststellung eines römischen Kastells“ geführt hatten (Abb. 9), beantragte Mitscha-Märheim 1926 „mit Rücksicht“ auf die in diesem Jahre günstigen „landwirtschaftlichen Bebauungsverhältnisse“, die Ausgrabungen auch „auf der Nordhälfte des Plateaus ermöglichen würden“, wo Oberflächenfunde „von Ursicinusziegeln [...] einen valentinianischen Steinbau erwarten“ ließen, eine weitere Grabungssubvention, um „das begonnene Werk in grossen Zügen wenigstens zum Abschluss“ bringen zu können. ${ }^{123}$

Die von reicher Ausbeute, vor allem aber durch den weit gestreuten zeitlichen Kontext charakterisierte Fundlage am Plateau des Oberleiserberges, ließ jedoch auch 1926, trotz

120 Sitzung vom 10.7.1925: SiTZUNGSPROTOKOLL 1925.

121 Mader 2018, Kap. 2.2.

122 Mitscha-Märheim an die Akademie, 20.10.1925: MitschA-MärHEIM 1925 c.

123 Mitscha-Märheim an die Akademie, 20.4.1926: MitschA-MärHEIM 1926. einer weiteren Unterstützung durch die Prähistorische Kommission von 500 Schilling und einer zusätzlichen Subvention von Seiten der Limeskommission in der Höhe von 200 Schilling, noch keinen Abschluss der Arbeiten zu. Im Gegenteil erachtete es Ernst Nischer-Falkenhof im Sommer 1927, als überhaupt keine Mittel für Ausgrabungen zu Verfügung standen, dennoch für notwendig, seinen „fünfwöchigen Aufenthalt“ in Oberleis dafür zu nützen, um an einigen Stellen, „die zum Teil besonders wichtig erschienen, zum Teil bisher wegen der Anbauverhältnisse noch nicht erforscht werden konnten, Suchgräben zu ziehen". ${ }^{124}$

Während die „Suchgräben Nr. 6, 7, 8, 9 und 10 [...] keine Funde ergaben und zeigten, daß diese Stellen nicht besiedelt waren“, erbrachten die ersten Schnitte einerseits den Hinweis auf ein „Zweites, kleineres, gemauertes Gebäude“, das, wie Nischer-Falkenhof festhielt, „sicher“ nicht römisch war, aufgrund der Bauweise aber „sowohl in germanische wie slawische Zeit“ datiert werden könnte, und andererseits vier am Ostrand des Plateaus gelegene „Wohngruben“, die jeweils Scherben von Latène- und Hallstattkeramik, im Falle der ersten „8 m nordwestlich des Kreuzes“ gelegenen Grube „zu unterst“ auch „bronzezeitliche Fundstücke“ enthielten. „Da sich bisher noch gar keine Anzeichen von Gräbern ergeben hatten“, die „Jahrtausende lange und zeitweise sehr dichte Besiedlung“ aber „die Anlage größerer Friedhöfe bedingt haben muß“, untersuchte Nischer-Falkenhof auch „die Berghänge, um - wenn schon nicht aus der Terraingestaltung - so doch aus Oberflächenfunden auf die Lage der Gräberfelder" schließen zu können. Ohne definitiv fündig zu werden, zog er jedoch für weitere Untersuchungen vier Stellen an der Westhälfte des Oberleiserberges in Betracht. Tatsächlich wurden später sieben Körperbestattungen nördlich des Westtores in geringer Entfernung des Walls gefunden. In seinem Bericht über die Sommergrabung 1927 führte Nischer-Falkenhof auch die während der Jahre 1925 und 1926 auf dem Plateau aufgelesenen Streufunde an, worunter sich „das Bruchteil eines Schuhleistenkeiles“, mehrere Nadeln der Bronze- und Hallstattzeit, latènezeitlicher Schmuck, keltische Münzen sowie verschiedene Kleinfunde des 1. bis 4. nachchristlichen Jahrhunderts befanden. ${ }^{125}$

Im November 1927 brachten Mitscha-Märheim und Nischer-Falkenhof unter Vorlage von Nischers Bericht über seine „private“ Grabung neuerlich ein Ansuchen um Subvention ein, das ein detailliertes 8 Punkte umfassendes Programm enthielt, für dessen Durchführung „ein Betrag von etwa 800 bis 1000 Schilling" veranschlagt wurde.

124 Nischer-Falkenhof 1927. 125 Nischer-Falkenhof 1927. 

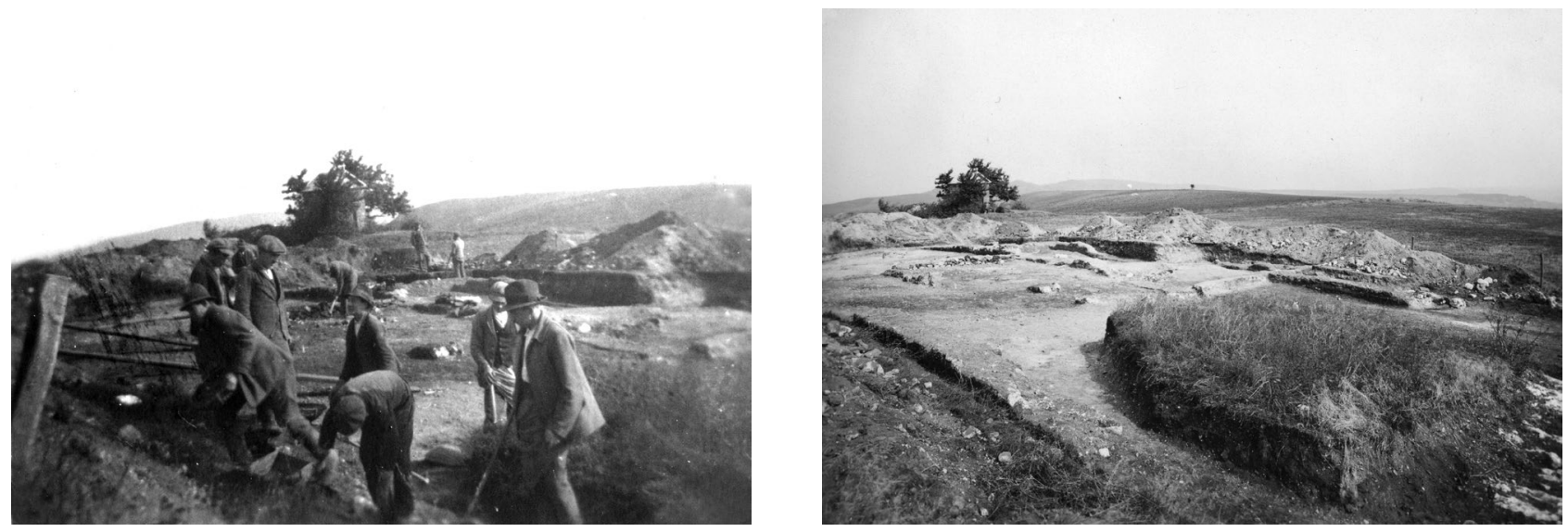

Abb. 9. Oberleiserberg, Ausgrabungen im Kastellbereich (Fotos: Fachbereich für Ur- und Frühgeschichte, Landessammlungen Niederösterreich, Schloss Asparn/Zaya).

Diesmal sollten die Ausgrabungen nicht nur in Fortsetzung bereits untersuchter Flächen, sondern auch an jenen Stellen weitergeführt werden, wo besonders häufig Oberflächenfunde beobachtet wurden, Auffälligkeiten im Terrain sichtbar oder Nekropolen zu erwarten waren. Darüber hinaus sollten auch bisher gänzlich unerforschte Bereiche „in der Südhälfte des Plateaus zwischen dem Südtore und dem Latène-Haus“ sowie eine „Mulde an der N. W. Front“ zur Untersuchung gelangen (Abb. 10). ${ }^{126}$

Bereits in Ihrer Sitzung vom 31. März 1927 hatte die Prähistorische Kommission „in Aussicht“ genommen, „den noch nicht vollendeten II. Band der Mitteilungen der prähist. Komm. mit der Arbeit des H. Mitscha über seine Ausgrabungen auf dem Leiser Berg zum Abschluß zu bringen“. ${ }^{127}$ Dennoch entschied sie am 16. März 1928, die „weitere materielle Förderung der Ausgrabungen auf dem Leiserberg [...] einem Zeitpunkt“ vorzubehalten, „an dem ein bestimmteres Urteil über die seitens der Kommission zur Verfügung stehenden Mittel möglich ist“, sah sich aber aufgrund des Kostenvoranschlages der Druckerei Holzhausen trotzdem in der Lage, Mitscha-Märheims und NischerFalkenhofs Grabungsbericht wie vorgesehen als nächstes Heft ihrer Mitteilungen „in Druck zu bringen“, allerdings sollte „den Verfassern [...] eine Reduktion der Abbildungen dringend" empfohlen werden. ${ }^{128}$

Um jedoch die Forschungen auf dem Oberleiserberg nicht zu gefährden, befürwortete die Prähistorische Kommission Nischer-Falkenhofs Subventionsgesuch an das Bundesministerium für Unterricht, das in der Folge 300 Schilling als Kostenzuschuss bewilligte, ${ }^{129}$ und beschloss in

126 Mitscha-Märheim, Nischer-Falkenhof 1927.

127 SitZungSPROTOKOLL 1927.

128 SitzungSPROTOKOLl 1928a.

129 Loebenstein an Nischer-Falkenhof, 24.4.1928: Loebenstein 1928. der Sitzung vom 13. Juli „nachträglich in Beziehung auf die geplante Leiserbergpublikation [...], daß eventuelle Ersparungen gegenüber dem Voranschlag den Herrn Dr. Nischer und Dr. Mitscha Märheim zur Fortsetzung der Grabungen zur Verfügung stehen sollten“. ${ }^{130}$

Im Herbst 1929 erschien schließlich als 5. Heft des II. Bandes der „Mitteilungen der Prähistorischen Kommission" Mitscha-Märheims und Nischer-Falkenhofs Arbeit über den Oberleiserberg als „Zentrum vor- und frühgeschichtlicher Besiedlung“, die durch einen von der Wiener Paläobotanikern Elise Hofmann (1889-1955) verfassten Anhang über „Verkohlte Pflanzenreste aus dem Raum des römischen Kastells“ ergänzt wurde. Voller Befriedigung schlossen die beiden Autoren, wobei Nischer auch das Verdienst der Erstellung der Pläne zukam, ihre Publikation mit der Feststellung, „So haben wir denn am Oberleiserberg zum erstenmal im nördlichen Niederösterreich den Nachweis einer von der Steinzeit bis ins späte Mittelalter durchgehenden Besiedlung erbracht. " ${ }^{131}$ Damit sollte das Kapitel Oberleis jedoch keineswegs geschlossen sein.

1928 wurde auch beim Friedhof von Unterleis (Abb. 1) $)^{132}$ das Vorkommen römischer Ziegel beobachtet, die „eine so ansehnliche Ausdehnung der römischen Station vermuten “ ließen, ${ }^{133}$ dass Mitscha-Märheim und Nischer-Falkenhof es für notwendig erachteten, auch hier Ausgrabungen vorzunehmen. Nischer-Falkenhof bekam dafür 1929 neben einer Unterstützung des Unterrichtsministeriums in der Höhe von 300 Schilling weitere 400 Schilling aus den Mitteln der Prähistorischen Kommission, die allerdings nicht nur für

130 Sitzungsprotokoll 1928 b.

131 Mitscha-Märheim, Nischer-Falkenhof 1929, 434.

132 Katastralgemeinde Niederleis, Gemeinde Niederleis, Verwaltungsbezirk Korneuburg.

133 Nischer-Falkenhof, Mitscha-Märheim 1931, 439. 


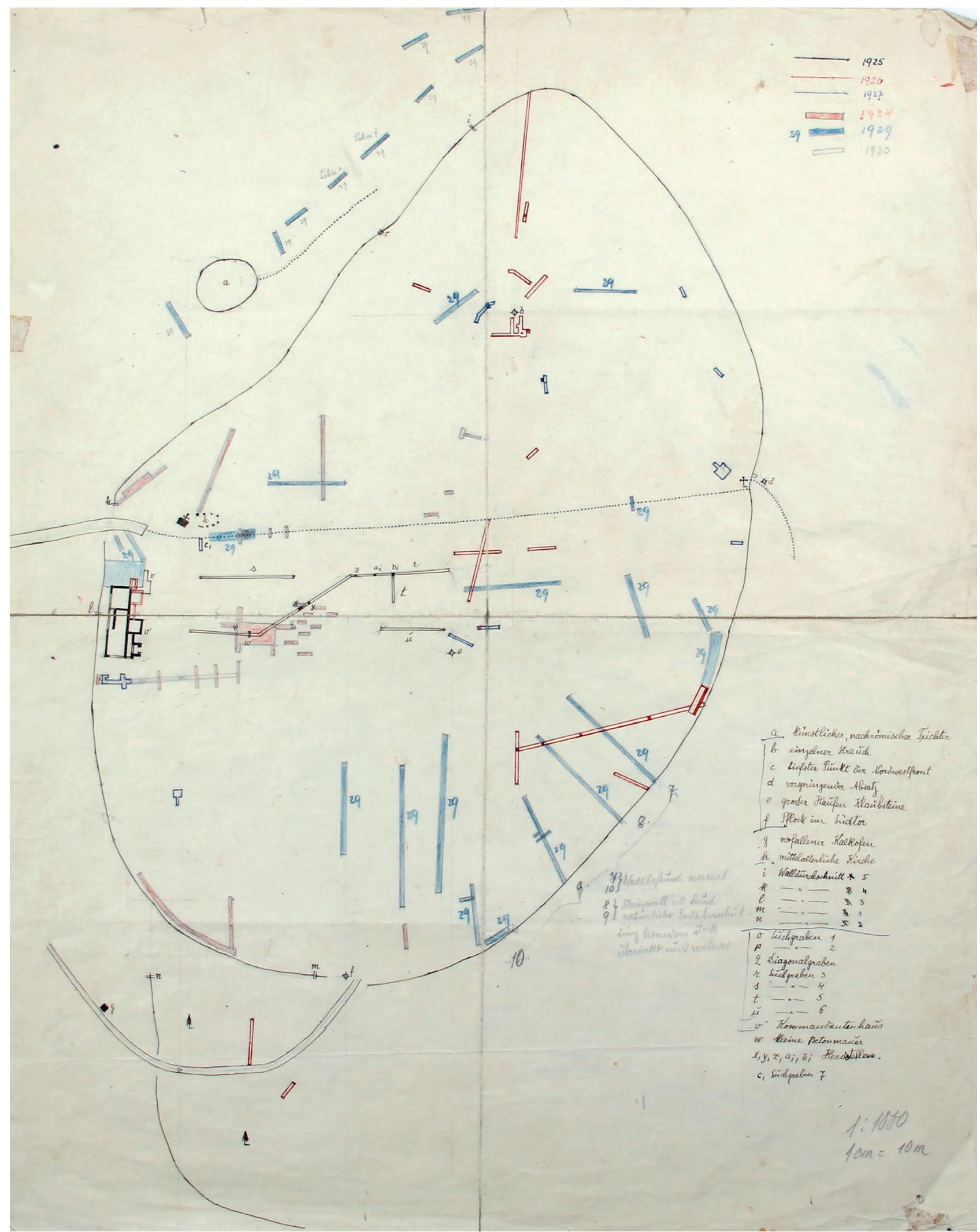

Abb. 10. Oberleiserberg, Grabungsplan 1925-1930 von E. Nischer-Falkenhof (Zeichnung: Fachbereich für Ur- und Frühgeschichte, Landessammlungen Niederösterreich, Schloss Asparn/Zaya). 


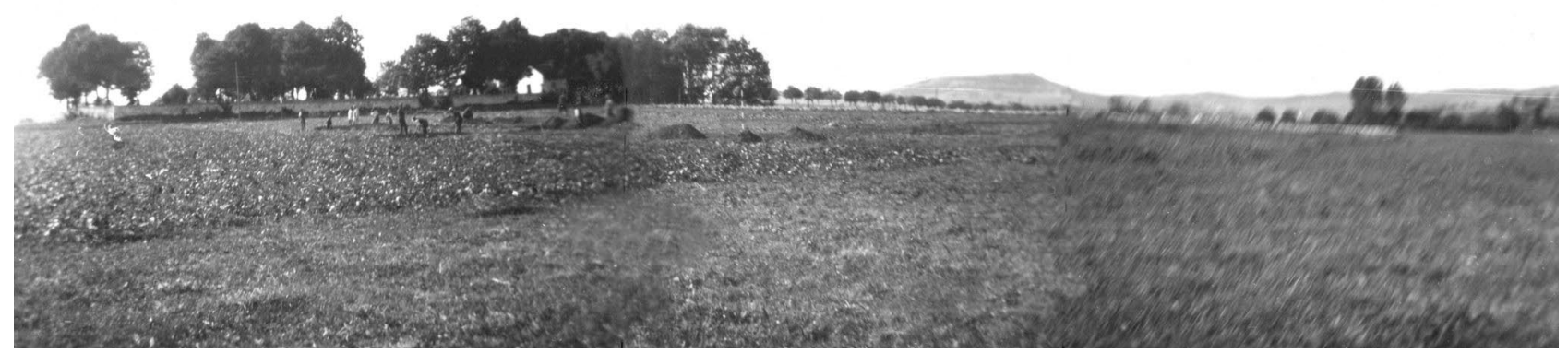

Abb. 11. Ausgrabungen in Niederleis (Foto: Fachbereich für Ur- und Frühgeschichte, Landessammlungen Niederösterreich, Schloss Asparn/ Zaya).

Niederleis (Abb. 11), sondern auch für Nachgrabungen in Oberleis und Vermessungen am Umlaufberg am Kamp vorgesehen waren. ${ }^{134}$ Die Resultate der im September und Oktober desselben Jahres durchgeführten Untersuchungen wurden 1931 unter dem Titel „Die römische Station bei Niederleis und abschließende Untersuchungen auf dem Oberleiserberge“ als 6. Heft des II. Bandes der Mitteilungen der Prähistorischen Kommission veröffentlicht. ${ }^{135}$

Nachdem sich Mitscha-Märheim 1927 nach dem unerwarteten Tod seines Vaters für einige Jahre aus der Archäologie weitgehend zurückziehen musste, um die Leitung des Landgutes Ebendorf bei Mistelbach, das die „materielle Lebensgrundlage “136 seiner Familie darstellte, zu übernehmen, widmete sich Nischer-Falkenhof nicht nur dem Fortgang der Untersuchungen bei Ober- und Niederleis, sondern unternahm in der Folge auch Forschungen an zwei weiteren ähnlich geartet erscheinenden Höhenbefestigungen am Umlaufberg bei Altenburg am Kamp (Abb. 1) ${ }^{137}$ und am Braunsberg bei Hainburg (Abb. 1). ${ }^{138}$

Ernst Nischer-Falkenhof (1879-1961) trat nach Absolvierung der Theresianischen Militärakademie in Wiener Neustadt und über zehnjährigem Militärdienst 1913 in die Kartenabteilung des Kriegsarchives ein, studierte an der Wiener Universität ab 1915 „Römische Geschichte“, promovierte 1918, wurde im selben Jahr zum Vorstand der Kartenabteilung befördert und 1920 als Oberstaatsarchivar

134 Majer an Nischer-Falkenhof, 8.5.1929: MAJER 1929. - SitZUnGSPROTOKOLL 1929a.

135 Nischer-Falkenhof, Mitscha-Märheim 1931.

136 Mitscha-Märheim 1963.

137 Katastralgemeinde Altenburg, Gemeinde Altenburg, Verwaltungsbezirk Horn.

138 Braunsberg, Gemeinde Hainburg an der Donau, Verwaltungsbezirk Bruck an der Leitha. in den Staatsdienst übernommen. ${ }^{139} 1923$ erschien in Wien sein Werk über „Die Römer im Gebiete des ehemaligen Österreich-Ungarn“. ${ }^{140}$ Neben dem Kartenwesen widmete sich Nischer-Falkenhof vor allem den Altertumswissenschaften, eine Spezialisierung, die ihm in späteren Jahren von übergeordneter Stelle als „zu viel“141 angekreidet wurde, sich in der archäologischen Praxis aber als sehr nutzbringend erwies.

„Wie Herr Konservator Dr. H. Mitscha-Märheim und ich bereits in dem Berichte über die von uns auf dem Oberleiserberge durchgeführten Ausgrabungen erwähnten, besteht eines der wichtigsten Ergebnisse unserer Arbeit in der Feststellung des kleinen römischen Kastells innerhalb der germanischen Ansiedlung, da sich daraus bedeutsame Schlüsse auf die Art der Besetzung des Landes nördlich der Donau nach dem Friedensschlusse des Jahres 180. n. Chr. ergeben. Wir erwähnten ferner ein gleichartiges Kastell, das Herr Dr. A. Gnirs ${ }^{142}$ auf dem Zeiselberge bei Muschau (Tschechoslowakei) ausgegraben hat, und daß wir einen dritten derartigen Bau in Stillfried a. d. March annehmen“, leitete Nischer-Falkenhof Ende April 1929 sein Subventionsansuchen an die Prähistorische Kommission ein ${ }^{143}$ und fuhr fort: „Die Größe, Stärke und Lage der vorgeschichtlichen Befestigung auf dem Umlauf am Kamp, den ich bereits im Jahre 1923 eingehend besichtigt und flüchtig vermessen

139 Hillbrand 1962.

140 Nischer-Falkenhof 1923.

141 Von 1931 bis 1936 war Nischer-Falkenhof stellvertretender Direktor des Kriegsarchivs, 1936 ging er drei Monate nach seiner Ernennung zum Generalstaatsarchivar „wegen vaterlandstreuer Gesinnung “ vorzeitig in den Ruhestand. Die Direktion des Kriegsarchives hatte von 1925 bis 1938 der spätere Nationalsozialist E. Glaise von Horstenau über: Broucek 1983, 88.

142 Anton Gnirs (1873-1933) führte von 1926 bis 1928 erstmals Ausgrabungen auf dem Burgstall (Hradisko) bei Muschau (Mušov) in Mähren durch.

143 Nischer-Falkenhof an die Prähistorische Kommission, 17.4.1929: Nischer-Falkenhof 1929. 
habe, legt die Wahrscheinlichkeit nahe, daß auch dort eine befestigte römische Anlage zu suchen sei“. Da hier „in absehbarer Zeit“ ein Teil des Baumbestandes gefällt werden sollte, war „zu befürchten“, dass dabei „jetzt vielfach noch sehr gut erkennbare Steinwälle stark in Mitleidenschaft gezogen werden“ würden, weshalb Nischer-Falkenhof „im Einvernehmen mit dem Bundesdenkmalamte die Vermessung dieses Platzes durchführen lassen“ wollte. Der Antrag wurde unter gleichzeitiger Verwendung des Betrages von 400 Schilling für die Vermessungen am Umlauf bei Altenburg und die Nachgrabungen in Ober- und Unterleis bewilligt. ${ }^{144}$

Nachdem im Sommer durch den pensionierten Mappeur Oberst St. Palkovics ein Plan des Umlaufberges im Maßstab 1:2500 aufgenommen worden war, sollten Mitscha-Märheim und Nischer-Falkenhof im folgenden Jahr mit „Unterstützung der Österreichisch-Deutschen Wissenschaftshilfe“ und des Instituts für Urgeschichte Ausgrabungen durchführen. ${ }^{145}$ Die Ausgrabungen, in deren Vorfeld eine scharfe Auseinandersetzung um die Grabungsrechte zwischen J. Bayer ${ }^{146}$ und O. Menghin ${ }^{147}$ entbrannte, führten schließlich zu genau jenem Ergebnis, zu dem Bayer bereits früher gekommen war: Der Umlauf war zwar in „der späten La Tène Zeit“ besiedelt, aber nicht befestigt, weshalb „der Stelle keinesfalls der Rang eines Oppidums zukommt“. ${ }^{148}$

Nischer-Falkenhofs erstem Ansuchen um Unterstützung von Grabungen auf dem Braunsberg bei Hainburg sprach die Prähistorische Kommission in der Sitzung vom 19. Dezember 1930 zwar „die grundsätzliche Geneigtheit“ aus, „deren Höhe“ aber wollte sie einen „späterem Entschluss vorbehalten“. ${ }^{149}$ Ein halbes Jahr später bestätigte Nischer-Falkenhof „mit verbindlichstem Dank“ den „Erhalt

144 Nischer-Falkenhof an die Prähistorische Kommission, 17.4.1929: Nischer-FALKenhof 1929. - Sitzung vom 27.6.1929: SitZUNGSPROTOKOLL 1929b. - Radermacher an Nischer-Falkenhof 15.7.1929: RADERMACHER 1929.

145 Nischer-Falkenhof 1931a, 90.

146 J. Bayer beharrte aufgrund seiner im Sommer 1928 auf Kosten des Naturhistorischen Museums unternommenen erstmaligen Grabung auf dem Umlauf „auf dem Prioritätsrecht auf die Fundstelle“. Bayer an das Bundesdenkmalamt, 29.1.1930: BAYER 1930a.

147 Menghin wertete Bayers Protest „als Versuch, in die wissenschaftliche Tätigkeit“ seines Institutes „einzugreifen“ und drohte „mit einer Beschwerde an das Bundesministerium für Unterricht“. - Schubert-Soldern an die Direktion der Anthropologischen und Prähistorischen Abteilung des Naturhistorischen Museums in Wien, 17.2.1930: SCHUBERT-SOLdERN 1930.

148 Bayer an Jahn, 10.6.1930: Bayer 1930b. - Vgl. dazu NischerFalkenhof 1931a, 96, 106-108.

149 SitZUngSPROTOKOLL $1930 \mathrm{~b}$. von S. 500.-“ und teilte im selben Schreiben mit, dass die „Aufnahme von Fliegerbildern des in Betracht kommenden Geländeabschnittes [...] in den nächsten Tagen stattfinden“ werde und der Beginn der Ausgrabung am Braunsberg „und gleichzeitig auch der Geländevermessung - die wieder durch Herrn Obersten d. R. Palkovics erfolgen soll“ auf den 16. September angesetzt sei. ${ }^{150}$

Die vorerst als Probegrabung gedachten Arbeiten, an denen auch Mitscha-Märheim teilnahm, sollten in Hinblick auf weitere systematische Forschungen „möglichst klaren Aufschluss“ geben und beschränkten sich daher auf die Wallkonstruktion, die Anlage des Haupttores und einige Erfolg versprechende Stellen „im Innern der Festigung“, wo Suchgräben angelegt werden sollten. Im Laufe der Untersuchungen konnte der gesamte Verlauf des Hauptwalles und Teilstücke des Vorwalles, die „höchstwahrscheinlich der letzten Stufe der Latènezeit“ angehören, festgestellt werden. Etwa im Zentrum des vom Hauptwall umschlossenen Bereiches wurde ein „kleines Blockhaus“ der „jüngsten Stufe der Latènezeit“" mit Herdstelle und reichhaltigem Inventar aufgedeckt. In größerer Tiefe und nur außerhalb des Hauses fanden sich zahlreiche „Kleinfunde [...] der Hallstattzeit“. Spuren „einer bronzezeitlichen oder noch älteren Besiedlung “ konnten Nischer-Falkenhof und Mitscha-Märheim nicht nachweisen, sie waren aber zur Überzeugung gekommen, dass die dichteste und zugleich ausgedehnteste Besiedlung des Braunsberges „in die Stufe C der Hallstattzeit (Kalenderbergkultur) fällt", während die Spätlatènesiedlung, soweit sie „bisher“ erkennen konnten, „in der Hauptsache auf den Raum innerhalb der Wälle beschränkt blieb“. Die „nur ganz vereinzelten Funde aus römischer Zeit“ hingegen ließen darauf schließen, dass „die Besiedlung des Braunsberges nicht allzulange vor oder nach der Besitznahme des Landes durch die Römer aufgehört haben muß“. Die „Größe und Bedeutung der prähistorischen Stadt" auf dem Braunsberg war für Nischer-Falkenhof und Mitscha-Mährheim evident. ${ }^{151}$ Umso mehr bedauerten sie, dass die Grabungen trotz des vielversprechenden Anfanges keine Fortsetzung fanden, da offenbar weder das an den ersten Untersuchungen mit finanzieller Unterstützung der Österreichisch-Deutschen Wissenschaftshilfe ebenfalls beteiligte Institut für Urgeschichte noch die Prähistorische Kommission ${ }^{152}$ über entsprechende finanzielle Mittel verfügten.

150 Nischer-Falkenhof an die Prähistorische Kommission, 15.7.1931: Nischer-Falkenhof 1931 b.

151 Nischer-Falkenhof, Mitscha-Märheim 1932. - NischerFALKENHOF 1935

152 SitZungSPROTOKOLL 1932a. 
Durch den Diebstahl und die mysteriöse Wiederauffindung eines tönernen Mondidols, das als Teil eines Grabinventars in der Prähistorischen Sammlung des Naturhistorischen Museums in Wien leihweise ausgestellt war, erlangte Au am Leithagebirge ${ }^{153}$ als urzeitlicher Fundort allgemeine Aufmerksamkeit (Abb. 1). ${ }^{154}$

Alexander Seracsin hatte das Mondidol im Mai 1925 in einem Brandgrab, dessen Reste bei Erdarbeiten im Hof eines Hauses zu Tage gekommen waren, freigelegt und in der Folge weitere fünf Fundstellen mit Brandbestattungen aufgedeckt, aus deren Beigaben er hier „mit aller Wahrscheinlichkeit" auf die Existenz eines hallstattzeitlichen Flachgräberfeldes schloss. ${ }^{155}$

A. Seracsin (1883-1952), einem alten Banater Grenzergeschlecht entstammend, fand nach Absolvierung der Militär-Realschule in Mährisch-Weißkirchen (Hranice na Morave, Tschechische Republik) und dem Besuch der landwirtschaftlichen Schule in Mödling als Adjunkt auf den kaiserlichen Güterdomänen Anstellung und kam schließlich nach Mannersdorf am Leithagebirge, ${ }^{156}$ von wo er zu Erkundungen in die Umgebung aufbrach, erstmals mit archäologischen Funden in Kontakt kam und sich daraufhin im Selbststudium die notwendigen wissenschaftlichen Kenntnisse zur prähistorischen Durchforschung des Leithagebirges und dessen Umgebung aneignete. Zum Wirtschaftsrat in Wien avanciert blieb Seracsin seinem Forschungsbereich treu und publizierte seit 1916 regelmäßig die Resultate seiner vornehmlich auf eigene Kosten vorgenommenen Ausgrabungen. ${ }^{157}$

1926 aber reichten „die von ihm aufgebrachten Geldmittel“ nicht mehr aus, um „Grabungen in zweckmäßigem Umfange durchführen zu können“, und da weder „das Bundesdenkmalamt" noch "die an der Sache interessierten $\mathrm{Mu}$ seen" einen Beitrag leisten konnten, wandte sich Seracsin im Frühjahr an die Prähistorische Kommission, die ihm eine Subvention „zu archäologischen Ausgrabungen am Fuß des Leithagebirges" in der Höhe von 700 Schilling gewährte. ${ }^{158}$ Nachdem nämlich südlich von $\mathrm{Au}$ am Leithagebirge „beim Vertiefen von Strassengräben ein Latènegrab zutage“ gekommen war, „dessen Inhalt aus mehreren Gefässen,

153 Katastralgemeinde Au am Leithagebirge, Gemeinde Au am Leithagebirge, Verwaltungsbezirk Bruck an der Leitha.

154 Das Mondidol wurde, nachdem der Diebstahl im Sommer 1929 festgestellt worden war, im Mai 1951 von einem Saalaufseher hinter den damals in Saal XII frei aufgestellten Urnen deponiert entdeckt: Fundakte Au am Leithagebirge.

155 Seracsin 1929a.

156 In Mannerdorf am Leithagebirge bekleidete Seracsin von 1919 bis 1921 auch das Amt des Bürgermeisters.

157 Pittioni 1952. - Franz 1953 (mit Seracsins Werkverzeichnis).

158 Seracsin an die Prähistorische Kommission, 14.5.1926: SERACSIN 1926a. - Seracsin 1926b.
Pufferarmbändern und Fibeln aus Bronze bestand“, sah sich Seracsin zu Versuchsgrabungen veranlasst, die er auf den „angrenzenden Parzellen“ der „Ried Kleine Hutweide“ vornehmen wollte. In der Folge wurden 23 Bestattungen eines ausgedehnten Latènegräberfeldes, „das in manchen Zügen von dem bereits bekannten abweicht und hinsichtlich des Grabbaues, der Grabriten und Grabbeigaben das grösste Interesse beansprucht“, geborgen. Gerade die „Anlage der Gräber“, deren Deutung Seracsin „mangels geeigneter Parallelen“ große Schwierigkeiten bereitete und die er „für Österreich, wenn nicht für Mitteleuropa überhaupt" als "Novum" bezeichnete, diente ihm auch als wichtiges Argument zur Begründung seines am 23. Mai 1929 neuerlich an die Prähistorische Kommission gerichteten Ansuchens um einen Zuschuss in der Höhe von 300 Schilling zur Fortsetzung seiner Ausgrabungen. ${ }^{159} \mathrm{Im}$ Februar 1930 berichtete er dann, „eine ganze derartige Grabanlage“ freigelegt zu haben und stellte fest: „Die Gräber - Steinpackungen - liegen exzentrisch in einem aus Trockenmauern hergestellten nach einer Seite offenem Vierecke oder es werden mehrere Gräber durch derartige Trockenmauern verbunden" ${ }^{160}$

Wie schon im Vorjahre wurde Seracsin auch 1930 und 1931 eine Subvention von 400 bzw. 500 Schilling zur „Weiterführung der Untersuchung des latènezeitlichen Gräberfeldes von $\mathrm{Au}$ am Leithagebirge “ gewährt, ${ }^{161}$ deren Resultat die Aufdeckung weiterer sieben Körperbestattungen der frühen und mittleren Latènezeit mit reichen Keramik- und Bronzebeigaben darstellte. ${ }^{162}$

Ähnlich wie Seracsin hatte auch Leonhard Franz (1895-1974) seine 1927 begonnene „Pfahlbauforschung in Oberösterreich [...] bisher vollkommen aus eigenen Mitteln bestritten“. Franz, der sein Studium der Sprachwissenschaften und Archäologie in Wien nach einem längeren Praktikum in Göteborg 1921 mit dem Doktorat abschloss und danach am Urgeschichtlichen Institut vom Volontär zum außerordentlichen Assistenten (1925) avancierte, hatte sich 1926 an der Universität Wien bei Menghin mit einer Arbeit unter dem Titel „Steinzeitstudien“ und einem Probevortrag zum Thema „Magisches in der älteren Kunst“ für das Fach „Urgeschichte des Menschen" habilitiert ${ }^{163}$ und 1927 gemeinsam mit dem Anthropologen und Hoernes Schüler Josef Weninger

159 SERACSIN 1929b.

160 Seracsin an die Prähistorische Kommission, 3.2.1930: SERAcsin 1930.

161 Sitzung vom 21.3.1930: SitzungSPROTOKoll 1930a. - Sitzung vom 25.4.1931: SitZUNGSPROTOKOLL 1931a.

162 Ortsmappe Au am Leithagebirge. - Seracsin 1932. - NebeHAY 1973.

163 Habilitationsverfahren Franz. 
(1886-1959) ${ }^{164}$ „eine ausführliche Bearbeitung der Funde aus den prähistorischen Pfahlbauten im Mondsee herausgebracht“. ${ }^{165} \mathrm{Da}$ Franz auch aufgrund seiner im selben Jahr mit Erfolg durchgeführten Untersuchungen „die weitere Erforschung der oberösterreichischen Pfahlbauten“ beabsichtige, ersuchte er die Prähistorische Kommission zweimal umUnterstützung seines Vorhabens. Nachdem er 1928 eine eher geringe Subvention von 200 Schilling erhalten hatte, ${ }^{166}$ wies er 1929 in seinem Gesuch an die Prähistorische Kommission ausdrücklich darauf hin, dass die Pfahlbauforschung in Österreich, „sehr zum Unterschiede von Deutschland (wo z. B. gegenwärtig mit riesigen Geldmitteln das Pfahlbaudorf bei Sipplingen am Bodensee freigelegt wird) und der Schweiz, sehr im Argen“ liege, „trotz vielversprechenden Anfängen im vorigen Jahrhundert", womit er auch auf die frühen Aktivitäten der kaiserlichen Akademie der Wissenschaften der Jahre 1864 und 1875 anspielte. ${ }^{167}$ Abgesehen davon, dass „vor allem“ die Seen Oberösterreichs „zweifellos noch eine Menge unbekannter Pfahlbaustellen bergen“ und auch „die bereits bekannten noch eine reiche Fülle ungehobener Funde enthalten“, gab es noch „eine Menge allgemein wichtiger Fragen“ zu lösen, „z. B. warum die Pfahldörfer aufgegeben worden sind, wie die Pfahlbauer ihre Toten bestattet haben, wie die Besiedelung der Umgebung der Pfahlbauseen in späterer vorgeschichtlicher Zeit ausgesehen hat “. ${ }^{168}$

In diesem Sinne schwebte Franz 1929 „als nächstes Ziel“ die „Erforschung des Attersees vor“ (Abb. 1). Da jedoch „die Eigenart des Untersuchungsgegenstandes besonders große Geldmittel“ erforderte - so „muß doch z. B. ein Boot gemietet werden“- bat er diesmal „um Gewährung einer Arbeitsunterstützung von S. 600.“ und versprach, alle Funde „nach Weisung der Akademie einer öffentlichen Sammlung in Österreich“ zu übergeben. Trotz des ambitionierten

164 J. Weninger hatte sich 1926 in Wien für Physische Anthropologie habilitiert und war im Oktober 1927 zum a.o. Professor und Vorstand des Anthropologischen Institutes der Universität Wien ernannt worden. - Vgl. Breitinger 1959. - Personalakt Weninger.

165 Franz an die Prähistorische Kommission: Franz 1929. - Beim genannten Werk handelt es sich um Franz, WENINGER 1927.

166 Franz an die Prähistorische Kommission, 8.3.1928: Franz 1928. - Sitzung vom 16.3.1928: SitzUngsProtokoll 1928a.

167 Am 7. Juli 1864 wurde eine „Commission zur Begutachtung des Antrages auf Untersuchung der österreichischen Seen hinsichtlich des Vorkommens von Pfahlbauten“ ernannt, die sich wenige Tage später für die Durchführung des Projektes aussprach. In der Folge wurden die Seen von Oberösterreich, Kärnten und Krain sowie der Gardasee, der Plattensee und der Neusiedlersee untersucht. 1875 gewährte die Akademie eine größere Unterstützung zur Weiterführung der im Laibacher Moor (Ljubljansko barje, Slowenien) erfolgreich begonnenen Ausgrabungen zum Nachweis der hier schon länger vermuteten Pfahlbauten: Mader 2018, Kap. 2.1.

168 FRANZ 1929.
Vorhabens gewährte die Prähistorische Kommission Franz jedoch nur einen Zuschuss in der Höhe von 300 Schilling. ${ }^{169}$

3.4 "Von der Gewährung von Subventionen wird abgesehen“. Ein neuer Stillstand 1932-1935

Nachdem in der finanziellen Situation der Prähistorischen Kommission mit 1924 eine Phase der Erholung eingetreten war, die sowohl in der Forschungs- als auch Publikationstätigkeit einen deutlichen Aufschwung bewirkte, stellte sich 1932 eine neuerliche Periode der Stagnation ein.

Die von beiden Klassen an die Prähistorische Kommission ergehenden Dotationen, die ab 1925 mit jeweils 600 und ab 1927 je 800 Schilling festgesetzt waren, fielen in diesem Jahr aus. Während die mathematisch-naturwissenschaftliche Klasse ausschließlich Vorhaben traditionell naturwissenschaftlicher Fächer unterstützte, verlautete von Seiten der philosophisch-historischen Klasse, „dass der gegenwärtige Finanzstand der Klasse es erforderlich mache, dass in diesem Jahre von einer Dotierung der Kommissionen sowie von der Gewährung von Subventionen abgesehen werde“. ${ }^{170}$ Der prekären Lage entsprechend gewährte die Prähistorische Kommission 1932 weder für laufende noch neue Projekte Subventionen. Dies betraf, abgesehen von W. Schmids wiederholtem und schon im Vorjahr definitiv abgelehnten Ansuchen zur Unterstützung der Noreia-Forschungen, vor allem die Weiterführung von Nischer-Falkenhofs Ausgrabungen am Braunsberg bei Hainburg aber auch die vom Abt des Benediktinerstiftes St. Paul und Konservator für das Fundwesen im Bezirk Wolfsberg (Kärnten) Richard Strelli (1875-1940) ${ }^{171}$ geplanten prähistorischen Untersuchungen in Allersdorf bei St. Paul im Lavanttal. ${ }^{172}$

Von 1933 bis 1935 kam die Prähistorische Kommission schließlich gänzlich zum Erliegen. Bis auf eine Mitteilung der Società Piemontese di Archeologia in Turin über die Änderung ihrer Adresse und ein Schreiben des Royal Anthropological Institute in London, das die Zusendung der Mitteilungen „since December, 1931, when we received Band II. nr. 6 " urgiert, ${ }^{173}$ ist auch in den Archivbeständen der Prähistorischen Kommission keinerlei Material vorhanden.

169 Franz 1929. - Sitzung vom 27.6.1929: SitzungSPROTOKOLL $1929 \mathrm{~b}$.

170 Sitzung vom 26.10.1932: SitzungsProtokoll 1932c.

171 BrüCKLER, Nimeth 2001, 265. - Burz 1991.

172 StRelli 1932.- Zu Strellis archäologischen Forschungen im Lavanttal siehe ZIMMERMANN 1984-1985. - Zu Allersdorf, wo ein römischer Gutshof aufgedeckt wurde, siehe Modrijan, PicCOTTINi 1991, 331-332.

173 Bonino 1933. - Das Schreiben des Royal Anthropological Institute trägt den handschriftlichen Vermerk: „Karte exp. 13/V. 33. (Seit II/6 nichts mehr erschienen)“: FLEMING 1933. 
Erst für den Spätherbst des Jahres 1936 scheint wieder ein Sitzungsprotokoll der Prähistorischen Kommission auf.

3.5 Seine „bisherige Entwicklung gibt zu den größten Hoffnungen für die Zukunft Anlaß“. Oswald Menghin und die Prähistorische Kommission 1936-1938

Am 27. November 1936 waren die Kommissionsmitglieder F. Hochstetter, ${ }^{174}$ F. E. Suess, ${ }^{175}$ E. Schweidler, O. Menghin und R. Egger wieder zu einer Sitzung zusammengetroffen. Auf dem Programm der Sitzung standen zwei Punkte: 1. Wahl eines Obmannes der Kommission und 2. Anfrage des Peabody Museum of Cambridge (Mass.) wegen Fortführung der Publikation der „Mitteilungen der Prähistorischen Kommission“. Zu Punkt 2 beschloss die Kommission nicht nur die Anfrage „dahin zu beantworten, dass die Publikationen der Kommission weitergeführt werden sollen“, sondern „zu diesem Zwecke“ auch „an beide Klassen der Akademie“ heranzutreten, „damit diese die nötigen Mittel bereitstellen“. ${ }^{176}$

Die Ernennung eines neuen Obmannes war durch Rudolf Muchs Tod am 8. März 1936 notwendig geworden. Die Wahl fiel auf das wirkliche Akademiemitglied Oswald Menghin (1888-1973), der der Prähistorischen Kommission seit 1929 angehörte.

Mit Menghin hatte zum ersten Mal in der Geschichte der Prähistorischen Kommission auch ein Prähistoriker den Vorsitz übernommen, nachdem die Obmannschaft mit F. von Hochstetter (von 1878 bis 1884) und F. von Hauer (von 1884 bis 1899) über zwei Jahrzehnte in geologischen, mit F. Steindachner (von 1899 bis 1919) 20 Jahre in zoologischen und schließlich mit R. Much ${ }^{177}$ ab 1920 in Händen eines Vertreters der germanischen Altertumskunde und Sprachwissenschaft gelegen hatte. Ein Umstand, der in erster Linie mit der Geschichte der prähistorischen Archäologie, die sich in Österreich erst Ende des 19. Jhs. mit Moriz Hoernes' Ernennung zum außerordentlichen Professor für

174 Ferdinand Hochstetter war der Neffe von Ferdinand von Hochstetter, dem Begründer der Prähistorischen Kommission.

175 Franz Eduard Suess war der Prähistorischen Kommission durch seinen Vater Eduard Suess, Gründungs- und langjähriges Kommissionsmitglied, familiär verbunden.

176 Sitzungsprotokoll 1936 a.

177 Rudolf Much war durch seinen Vater Matthäus Much mit urgeschichtlichen Forschungen vertraut. Er studierte in Wien klassische Philologie, Naturwissenschaften und Germanistik und war während seines Studiums vorübergehend Volontär an der Anthropologischethnographischen Abteilung des k.k. naturhistorischen Hofmuseums (ab 1885). 1893 habilitierte er sich. Seit 1904 war er an der Universität Wien als ordentlicher Professor für Germanische Altertumskunde und Sprachgeschichte sowie skandinavische Sprachen und Literaturen tätig. - Siehe Biographisches Lexikon 1975.
Urgeschichte des Menschen an der Universität Wien (1899) als selbständige Disziplin etablierte, aber auch mit der Akademiemitgliedschaft als Voraussetzung zur Teilnahme an einer Kommission zu tun hat. ${ }^{178}$

Ein analoges Bild zeigt die Zusammensetzung der Mitglieder der Prähistorischen Kommission. Auch hier ist Menghin der erste „studierte“ Prähistoriker, während die übrigen Kommissionsmitglieder fachnahen Disziplinen angehören.

So war im Zeitraum von 1918 bis 1938 die mathematisch-naturwissenschaftliche Klasse durch Leopold Adametz (1861-1941), Ordinarius für Tierproduktionslehre und Morphologie der Haustiere an der Hochschule für Bodenkultur in Wien (ab 1937), Friedrich Becke (1855-1931), Petrograf, Mineraloge und Nachfolger auf Gustav Tschermaks Lehrkanzel in Wien (ab 1918), Eduard Brückner (1862-1927), Geograf (ab 1919), Carl Diener (1862-1928), ebenfalls Geograf, Geologe und Extraordinarius für Paläontologie an der Universität Wien (ab 1918), Ferdinand Hochstetter (1861-1954), Anatom (ab 1920), Egon Schweidler (1873-1948), Mathematiker, Physiker und einer der Pioniere in der Erforschung der Radioaktivität (ab 1929), Franz Steindachner (1834-1919), Ichthyologe und Intendant des naturhistorischen Hofmuseums von 1888 bis 1919, Franz Eduard Suess (1867-1941), Geologe (ab 1928), sowie Carl Toldt (1840-1920), Histologe und Ordinarius für Anatomie in Prag und Wien (1889-1920), vertreten.

Die philosophisch-historische Klasse hingegen entsandte Rudolf Egger (1882-1969), Professor für Römische Geschichte, Altertumskunde und Epigraphik in Wien (ab 1931), Hermann Junker (1877-1962), Ordinarius für Ägyptologie und Leiter des eigens für ihn eingerichteten Instituts für Ägyptologie und Afrikanistik in Wien (ab 1919), Joseph Karabaček (1845-1918), Ordinarius für Geschichte des Orients und ihrer Hilfswissenschaften in Wien und Direktors der Hofbibliothek (1902-1918), Friedrich Kenner (18341922), klassischer Archäologie, Direktor des k.k. Münzund Antikenkabinett und erster Obmann der Limeskommission (von 1886 bis 1918), Josef Kubitschek (1858-1936), Professor für römische Altertumskunde in Graz und Wien und Generalkonservator für Archäologie und Prähistorie (ab 1925), Rudolf Much (1862-1936), Ordinarius für germanische Altertumskunde und Sprachgeschichte und skandinavische Sprachen und Literaturen in Wien (ab 1918), Camillo Praschniker (1884-1949), klassischer Archäologe und Altertumswissenschaftler (ab 1937), und schließlich Emil Reisch (1863-1933), gleichfalls klassischer Archäologie und Philologie, der bis zu seiner Emeritierung im Jahre 1933,

178 Mader 2018, Kap. 2.2. 
ehe das Amt Praschniker und Egger übernahmen, auch die Direktion des Österreichischen Archäologischen Institutes innehatte (ab 1909). ${ }^{179}$

O. Menghin wurde 1920 von R. Much erstmals zur Wahl als korrespondierendes Mitglied der Akademie vorgeschlagen. In seiner Begründung betonte Much, „Menghin“ hätte sich „dauernd als starke Arbeitskraft von umfassendem Wissen und ausgezeichneter Schulung“ bewährt und es wäre „besonders auch sein weiter Blick und die Vielseitigkeit seiner Interessen hervorzuheben“. Darüber hinaus lobte er Menghins Bemühen, „mit allen Grenzwissenschaften in Fühlung zu treten und allen Richtungen innerhalb seiner eigenen gerecht $\mathrm{zu}$ werden “ und unterstrich, dass dessen Ernennung zum Extraordinarius „seinerzeit von reichsdeutscher Seite besonders freudig begrüßt worden“ war, weil Menghin „in seinen Arbeiten auch volles Verständnis für die völkerkundlich-siedlungsgeschichtlichen Probleme bekundet hatte, welche in den letzten Jahrzehnten im Vordergrund der deutschen Forschung gestanden haben“. Menghins „bisherige Entwicklung“ gab für Much „zu den größten Hoffnungen für die Zukunft Anlaß“, und er schloss mit der Feststellung, „es läßt sich jetzt schon sagen, daß weder die Universitäten Deutschlands, noch die der öst. ungar. Nachfolgestaaten eine ihm ebenbürtige Kraft auf seinem Forschungsgebiet aufzuweisen haben ". ${ }^{180}$ Die Wahl zum korrespondierenden Mitglied erfolgte allerdings erst 1927 nach mehreren Anläufen. Ähnlich verlief auch Menghins Ernennung zum wirklichen Akademiemitglied, die zwar schon im folgenden Jahr zum Vorschlag, tatsächlich aber erst 1936 zu Stande kam. ${ }^{181}$

Als Menghin im selben Jahr auch zum Obmann der Prähistorischen Kommission bestellt wurde, war er in der österreichischen Urgeschichtsforschung bereits zur dominierenden Figur aufgestiegen. Nach dem Studium bei M. Hoernes hatte sich Menghin 1913 in Wien mit einer Studie zur Archäologie der jüngeren Steinzeit in Tirol und einem „Probevortrag“ zur Räterfrage habilitiert und wurde nach Hoernes' Tod im Juli 1917 im folgenden Jahr als Extraordinarius auf dessen Lehrstuhl berufen. ${ }^{182} \mathrm{Als}$ Menghin 1921 an der Deutschen Universität in Prag als einziger Kandidat für das Ordinariat für Prähistorische Archäologie vorgeschlagen wurde, gelang ihm unter Androhung, Wien zu verlassen, ein Jahr später auch hier die Ernennung zum ordentlichen Professor. ${ }^{183} 1924$ nannte Menghin das unter

179 Sitzungsprotokolle der Prähistorischen Kommission 1918-1937. - Meister 1947, 284.

180 Vorschlag R. Much, 30.05.1920: Мuch 1920a.

181 SitZungSPROTOKOLl 1936b.

182 Personalakt Menghin.

183 Personalakt Menghin. seiner Leitung stehende aus Moriz Hoernes' Prähistorischem Lehrapparat hervorgegangene Prähistorische Institut in Urgeschichtliches Institut der Universität Wien um.

Bereits seit den frühen 1920er Jahren stand Menghin unter den Einfluss der von Wilhelm Schmidt (1868-1954) und Wilhelm Koppers (1886-1961) vertretenen Wiener Ethnologischen Schule, deren „Kulturkreislehre“ er auf die Urgeschichte übertrug und damit einen neuen kulturhistorisch ausgerichteten methodischen Ansatz schuf, der vor allem in der Behandlung seiner 1931 erschienenen „Weltgeschichte der Steinzeit" Anwendung fand. ${ }^{184}$

Mit Beginn der 1930er Jahre dehnte Menghin seinen Wirkungskreis auch auf Ägypten aus, wo er gemeinsam mit Hermann Junker und seinem ägyptischen Kollegen Mustapha Amer Ausgrabungen für die Akademie unternahm und außerdem vorübergehend als Gastprofessor für Urgeschichte an der Universität Kairo tätig war. In diese Zeit fällt auch Menghins Vortrag über die Judenfrage, den er in der Ortsgruppe Kairo der NSDAP hielt. ${ }^{185}$ Gleichzeitig erschien sein ebenso deutlich von rassistisch antisemitischer Einstellung geprägter Band „Geist und Blut“ (1933). ${ }^{186}$ Eine Einstellung, die auch seine politische Karriere bestimmte, und die ihn von der Mitgliedschaft im Geheimbund „Deutsche Gemeinschaft" und den ersten nationalsozialistischen Kontakten im Jahre 1923 über die 1936 „als Vertreter der nationalen Opposition“ in den Führerrat der Wiener Vaterländischen Front erfolgte Berufung bis zum Unterrichtsminister im Kabinett Seyß-Inquart (1938) führen sollte. ${ }^{187}$

Da Menghin Ende November 1936 zum Obmann der Prähistorischen Kommission gewählt wurde, konnte er erst 1937 in seiner neuen Position aktiv werden.

Wie Richard Pittionis Schreiben an die Akademie der Wissenschaften vom 26. April $1937 \mathrm{zu}$ entnehmen ist, hatte sich Menghin sofort an die Realisierung der im Vorjahr angekündigten Weiterführung der Mitteilungen der Prähistorischen Kommission gemacht und Pittioni mit der Einreichung eines Manuskriptes beauftragt. Die von Pittioni und dem Bergbauingenieur Ernst Preuschen verfasste Abhandlung über „Untersuchungen im Bergbaugebiete Kelchalpe bei Kitzbühel Tirol“" wurde von der Prähistorischen Kommission am 18. Juni „als Heft 1-3 des 3. Bandes“ der Mitteilungen zur Veröffentlichung angenommen, und bereits zu Jahresende lag die fertige Publikation vor. In der Dezember

184 Dazu Menghin 1923. - Menghin 1927. - Urban 1997, 11 und Fußnote 184 .

185 URBAN 1997, 8.

186 Dazu Urban 1997, 5-8, der hier an Hand von Textbeispielen Menghins Geisteshaltung dokumentiert.

187 Urban 1997, 4. - Zu O. Menghins Biografie und Werk siehe PitTIONI 1974. - GEEHR 1986. - URBAN 1997. - URBAN 2010. 
Sitzung verlautete Menghin, dass nach Einschätzung der finanziellen Lage „im nächsten Jahr“ mit der Herausgabe eines weiteren Heftes „gerechnet werden“ durfte. ${ }^{188}$ Gleichzeitig veranlasste er, Pittionis soeben erschienene Arbeit 31 Universitätsbibliotheken in Deutschland, der Schweiz, Belgien, Skandinavien aber auch in Budapest, Prag, Breslau und Padua zum „Selbstkostenpreis von S. 20.-“ anzubieten. ${ }^{189}$

Richard Pittioni (1906-1985), der 1924 noch als Mittelschüler der 1914 unter M. Hoernes gegründeten Wiener Prähistorischen Gesellschaft beitrat, ${ }^{190}$ wo er auch seinen späteren Lehrer O. Menghin persönlich kennenlernte, war seit 1929 in der Nachfolge von L. Franz, der das ursprünglich Menghin angebotene Extraordinariat für Urgeschichte in Prag übernommen hatte, als Assistent am Urgeschichtlichen Institut in Wien tätig, wo er seit 1932 als Privatdozent für Prähistorische Archäologie auch regelmäßig Lehrveranstaltungen hielt. ${ }^{191}$

Seit 1930 widmete sich Pittioni dem urzeitlichen Bergbau und führte nach ersten kartografischen Aufnahmen im Sommer $1931 \mathrm{ab} 1932$ systematische Ausgrabungen auf der Kelchalpe durch (Abb. 1), auf deren „Reste uralten Bergbaues“ bereits M. Much $1879^{192}$ aufmerksam gemacht hatte.

Die aufwändigen gemeinsam mit den beiden Montaningenieuren Ernst Preuschen (1898-1973) ${ }^{193}$ und Karl Zschocke $(† 1962)^{194}$ vorgenommenen Untersuchungen, die reiche Erkenntnisse zur Aufbereitung des Kupfererzes sowie Reste einer mit diesen Arbeiten in Zusammenhang stehenden Siedlung der späten Bronzezeit erbrachten, wurden zwar in Kitzbühel von öffentlicher wie privater Seite nach Kräften unterstützt, erforderten aber allein schon durch die Präparation der zahlreich zu Tage gekommenen Holzgeräte größere Mittel. Nachdem 1935 die „Notgemeinschaft der deutschen Wissenschaften“ die „lange Dauer der Grabung“ durch einen beträchtlichen Zuschuss ermöglicht hatte, ${ }^{195}$

188 Der Kassastand der Prähistorischen Kommission betrug zu diesem Zeitpunkt „rund 800 S.-“ und Menghin erwartete für 1938 „von jeder Kl. 800 S.-“: SitZungSPRotokoll 1937d.

189 Sitzungsprotokoll 1937a. - Sitzungsprotokoll 1937e. Den zahlreichen Bestellungen zufolge stieß Pittionis Werk auf größtes Interesse.

190 Die Wiener Prähistorische Gesellschaft wurde 1914 von Moriz Hoernes, Oswald Menghin und Georg Kyrle gegründet.

191 Personalakt Pittioni.

192 Preuschen, Pittioni 1937, 3.

193 Zur Biografie und Bibliografie von E. Preuschen siehe PitTioni 1973.

194 Zschocke und Preuschen hatten bereits 1932 eine Arbeit über das urzeitliche Bergbaugebiet von Mühlbach-Bischofshofen publiziert: Zschocke, Preuschen 1932.

195 Preuschen, Pittioni 1937, 11. subventionierte die Akademie der Wissenschaften Pittionis Forschungen während der folgenden drei Jahre. Die „Feldarbeit des Sommers 1936“ wurde mit einem Betrag von 650 Schilling aus der Zach-Widmung ${ }^{196}$ unterstützt. Für die „Untersuchung des urzeitlichen Bergbaues auf Kupfererz bei Kitzbühel“ bewilligte die Akademie 1937 „aus den Erträgnissen der Treitl-Stiftung einen Betrag von S 600,-“ und 1938 wurden zur Fortsetzung der Ausgrabungen 350 Schilling abermals aus der Zach Stiftung flüssig gemacht. ${ }^{197}$

Neben der von Menghin zweifellos als vorrangig betrachteten Drucklegung von Pittionis Manuskript zur Montanarchäologie standen 1937 zwei weitere Vorhaben am Programm der Prähistorischen Kommission.

Das eine betraf „das Gesuch des Prof. Karl Pink um Gewährung einer Subvention für eine numismatische Studienreise nach Ungarn, Rumänien und Jugoslawien“, das in der Sitzung der philosophisch-historischen Klasse am 23. Juni 1937 „auf Anregung“ Menghins „der Prähistorischen Kommission abgetreten“ wurde. ${ }^{198}$ Karl Pink (1884-1965), damaliger Kustos am Kunsthistorischen Museum und Privatdozent für antike Numismatik, ${ }^{199}$ hatte sich, „da unser Museum keinen Fond mehr hat" an die Akademie um Unterstützung einer Reise gewandt, die er zur „unbedingt“ nötigen Ergänzung seiner „Arbeit über die gesamte keltischillyrische Prägung des Ostens“, deren Drucklegung ihm von „Prof. Alföldi der Univ. Budapest [...] in großzügiger Weise“ zugesagt worden war, unternehmen wollte. ${ }^{200}$

Da Pinks Werk laut Gutachten von Kommissionsmitglied R. Egger „ein Desiderat der Wissenschaft“ erfüllte und „auch für den Fall, dass es in Budapest verlegt wird“, Unterstützung verdiente, gewährte die Prähistorische Kommission einen Zuschuss von 300 Schilling. ${ }^{201}$

196 Konsul Erwin Zach hatte 1922 sein im Ersten Weltkrieg von den Engländern in Singapur beschlagnahmtes Vermögen der Akademie der Wissenschaft geschenkt. Die Erträgnisse der Erwin Zach-Widmung wurden der Gesamtakademie oder beiden Klassen zu gleichen Teilen zur Verfügung gestellt. Die „Kommission für die Zach-Widmung" wurde 1977 aufgelöst und ging in der neu gegründeten Kommission für die Widmungen und Erbschaften der mathematischnaturwissenschaftlichen Klasse auf: Archivbehelf Zach-Widmung, Archiv der Österreichischen Akademie der Wissenschaften, Wien. - Meister 1947, 159.

197 Pittioni an die Akademie, 29.9.1937: Pittioni 1937. - SubventiONEN 1936-1938.

198 SitZungsprotokoll $1937 \mathrm{~b}$.

199 Zu Pinks Biografie und Schriftenverzeichnis siehe BRUCK 1965. 200 Pink an die Akademie, 7.6.1937: PINK 1937.

201 Egger an die philosophisch-historische Klasse, 14.6.1937: EGGER 1937. - Sitzung vom 2.7.1937: Sitzungsprotokoll 1937c. - Pinks Werk über die „Münzprägung der Ostkelten und ihrer Nachbarn“ erschien zwei Jahre später in Budapest: PINk 1939. 
Das andere Vorhaben des Jahres 1937 hingegen betraf Menghin selbst, der bereits einmal, 1929, im Jahre seiner Ernennung zum Kommissionsmitglied, ein Subventionsansuchen an die Prähistorische Kommission gestellt hatte. Damals beabsichtigte er, im niederösterreichischen Lengenfeld bei Krems „einen prähistorischen Steinbruch, in dem offenbar gewerbsmässig Mühlsteine hergestellt worden sind“, genauer zu untersuchen. Da sein „Gewährsmann“202 hier „vorher ein frühhallstättisches Dorf gefunden“ hatte, „das fast in jeder Wohnstätte ein Mühlsteinlager aufwies“, erwartete sich Menghin von der Erforschung des Steinbruchs „ein ganz neues Kapitel der heimischen Urgeschichte“, und betonte: „Es ist also die Siedlung der Leute, die diese Industrie betrieben, schon festgestellt und auch in der Wiener Prähistorischen Zeitschrift publiziert, der Steinbruch selbst harrt aber noch der näheren Untersuchung“. Trotzdem wurde Menghins Ansuchen aus finanziellen Gründen zu Gunsten der Forschungsprojekte von W. Schmid, E. Nischer-Falkenhof, L. Franz und A. Seracsin „vorläufig zurückgestellt“,203 später aber auch nicht wieder aufgenommen.

Acht Jahre danach gewährte die Prähistorische Kommission ihrem Obmann „eine Subvention von 300 S zu Forschungen in Tirol und Vorarlberg ". ${ }^{204}$ Seinem im Dezember vorgelegten Bericht zufolge hatte Menghin eine vom 25. August bis 8. September dauernde Reise mit einer zweitägigen gemeinsam mit „Kustos Hild vom Vorarlberger Landesmuseum“ auf dem „Hochwindenkopf“ (Gemeinde Göfis) (Abb. 1) durchgeführten Grabung, wo er die „zweite prähistorische Befestigungsanlage in Vorarlberg“ feststellen konnte, und ausgedehnten Begehungen in Tirol verbracht, während derer er als „hervorragende Entdeckung“ eine „schöne Wallburg“ mit prähistorischen Scherben am Nordrand des Plateaus von Axams (Gemeinde Birgitz) verzeichnete, die er „im kommenden Jahre genauer zu untersuchen“ beabsichtigte. Den Abschluss der Reise bildete eine „Tastgrabung auf dem Hochkapellenhügel bei Brixlegg“ (Abb. 1), wo Menghin „reiche Überreste bronzezeitlicher Besiedelung sichern“ konnte. ${ }^{205}$

Nachdem die Prähistorische Kommission 1937 unter ihrem neuen Obmann sowohl in der Subventionierung von Forschungsvorhaben als auch in der Fortsetzung ihrer Publikationsreihe wieder Präsenz gezeigt hatte, wurde sie in

202 Menghin bezieht sich auf Anton Hrodegh, der in der Wiener Prähistorischen Zeitschrift über „Wohngruben“ berichtete, die 1923 in Lengenfeld im Bereich der Ziegelei Mühlfeldbreiten angeschnitten wurden. - Siehe Hrodegh 1924, 45.

203 Menghin an die Prähistorische Kommission, 24.5.1929: MenGHIN 1929.

204 Sitzung vom 18.6.1937: SitZUNGSPROTOKOLL 1937a.

205 Bericht Menghins: Menghin 1937. - Dazu Menghin 1942. der Sitzung vom 17. Dezember ebenfalls „über Anregung des Vors[itzenden]“ durch Zuwahl der „Herren Adametz und Praschniker" auf acht Mitglieder erweitert. ${ }^{206}$ In derselben Sitzung warf Menghin auch die „Prinzipielle Frage über die Betätigung der Kommission außerhalb Österreichs“ auf und vertrat den Standpunkt, dass „nach Einsicht in den Gründungsakt der Kommission nur österr. Urgeschichte in der Komm. gepflegt werden soll“. Menghins Meinung folgend beschloss die Prähistorische Kommission, an „diesem Grundsatz festzuhalten“. ${ }^{207}$

Ein „Grundsatz“, der nicht nur auf einer willkürlichen die historischen Gegebenheiten außer Acht lassenden Auslegung beruht, sondern zwei Jahre später auch im Gegensatz zu Menghins Formulierung einer der Hauptaufgaben der Prähistorischen Kommission steht, wonach jene „ihr Augenmerk darauf richten müsse, auf die urgeschichtliche Forschung der Donau- und Balkanländer befruchtend einzuwirken“. Ein vom ideologischen Hintergrund der Einvernahme des Ostens getragener Vorsatz, der durch Menghins gleichzeitig geäußerten Vorschlag zur „Veröffentlichung einer Zeitschrift“, in der „die in so vielen Sprachen erscheinende prähistorische Forschungsarbeit des Ostens zusammenfassende Würdigung findet" und in der Versicherung, „falls die Mittel dazu reichen, wird die Kommission jedenfalls alles tun, um in ihrem Bereiche die Beziehungen zu den Ländern des Südosten zu beleben“ nur noch verdeutlicht wird. ${ }^{208}$

1938 fällt für die Prähistorische Kommission neuerlich der Vorhang. Wieder sind es politische Umwälzungen, die, wie schon zwei Jahrzehnte zuvor, auch für die Wissenschaft nicht ohne Auswirkungen bleiben. Diesmal jedoch bringen die Veränderungen keine Reduktion auf territorialer, sondern auf geistiger Ebene mit sich. Mit Österreichs „Anschluss“ an das Deutsche Reich im März 1938 beginnt ein neues von deutschnationaler Ideologie überschattetes Kapitel in der Geschichte der Prähistorischen Kommission, deren künftige Ausrichtung O. Menghin bereits am 11. Oktober in einem Schreiben an die mathematisch-naturwissenschaftliche Klasse klar umriss.

Darin heißt es, „Hohe Klasse! Der Urgeschichtsforschung wird im nationalsozialistischen Staate besondere Beachtung geschenkt, da ihre Ergebnisse für Rassen- und Volkstumsfragen von besonderer Wichtigkeit sind. Die Prähistorische Kommission der Akademie der Wissenschaften

206 Leopold Adametz gehörte der mathematisch-naturwissenschaftlichen, Camillo Praschniker der philosophisch-historischen Klasse an.

207 SitZungSPROTOKOLL 1937e.

208 Menghin 1939. 
muß es daher als ihre Pflicht betrachten, ihre Tätigkeit möglichst lebhaft zu gestalten, was einerseits durch Veranstaltung und Förderung von Ausgrabungen, andererseits durch verstärkte Publikationstätigkeit geschehen kann. Ich bitte die hohe Klasse daher, der Prähistorischen Kommission auch in diesem Jahre einen namhaften Betrag für ihre Arbeiten zur Verfügung zu stellen. Im letzten Jahre wurden 1000 Schilling gewidmet; ich bitte mindestens den gleichen Betrag, auf Mark umgerechnet, zu bewilligen. Heil Hitler! Oswald Menghin“.209

\section{Schlussfolgerungen}

Die zwei Jahrzehnte umfassende Geschichte der Prähistorischen Kommission von 1918 bis 1938 steht in besonderem Maße unter dem Einfluss der historisch-politischen Ereignisse, die die Zwischenkriegszeit vom Zusammenbruch der Österreichisch-Ungarischen Monarchie über die Erste Republik und den Austrofaschismus bis zum „Anschluss“ Österreichs charakterisieren. War es zuerst die drastische Reduzierung ihres Wirkungskreises durch den Verlust der Kronländer und der damit verbundenen Forschungsgebiete, so war es in der Folge die wirtschaftliche Notlage Österreichs, die die Tätigkeit der Prähistorischen Kommission nicht nur einschränkte, sondern zweimal sogar lahmlegte. Während der Zwischenkriegszeit war die Prähistorische Kommission zumeist nicht mehr in der Lage, Ausgrabungsprojekte wie früher ausschließlich aus eigenen Mitteln zu finanzieren. Auch die Gewährung von Zuschüssen aus Stiftungsmitteln der Akademie konnte daran nichts ändern. Dennoch kam gerade der Akademie die wichtige Funktion eines „Krystallisationszentrums“ zu, „an das sich die übrigen Beihilfen erst anschlossen“. ${ }^{210}$ Nicht selten wurden Ausgrabungskosten von mehreren Sponsoren, zu denen neben wissenschaftlichen und musealen Institutionen auch Privatpersonen gehörten, gleichzeitig getragen. 1929 sollte im Falle der Untersuchungen in Niederleis erstmals auch das Archäologische Institut des Deutschen Reiches einen finanziellen Beitrag leisten. ${ }^{211}$

Trotz allem war der zweimalige Stillstand der Prähistorischen Kommission nicht zu verhindern. Ein Stillstand, der die Tätigkeit der Prähistorischen Kommission nicht nur zeitlich unterbrach, sondern auch die wissenschaftliche Kontinuität unterband, da, mit Ausnahme der Forschungen von W. Schmid, dessen Mitarbeit von 1912 bis 1930 andauerte, keines der bereits vorher verfolgten Projekte wieder

209 Menghin 1938.

210 Szombathy an die Prähistorische Kommission, 16.12.1920: Szombathy 1920 d.

211 Nischer-Falkenhof, Mitscha-Märheim 1931, 439. aufgenommen wurde. Die Intervalle der Jahre 1922 bis 1924 und 1932 bis 1936 markieren daher jeweils einen neuen Abschnitt in der Geschichte der Prähistorischen Kommission.

Während nämlich die Prähistorische Kommission in der unmittelbaren Nachkriegsphase von 1918 bis 1921 in geradezu „alter Manier und Kontinuität“ mit der Wiederaufnahme der Grabungen in Gemeinlebarn durch J. Szombathy, W. Schmids Untersuchungen in der Obersteiermark und der in den „Mitteilungen der Prähistorischen Kommission“ geplanten Drucklegung des zweiten Teils von Schmids Abhandlung über die während des Krieges durchgeführten Ringwallforschungen im Bacherngebiet in ihrer Tätigkeit fortfuhr, zeichnete sich in der zweiten Phase von 1925 bis 1931 ein deutlicher Umschwung ab, der sowohl in einer neuen Generation von Prähistorikern bzw. Mitarbeitern als auch neuen Forschungsbereichen deutlichen Ausdruck fand. Neben L. Franz, der sich der Pfahlbauforschung am Attersee (Oberösterreich) widmete, und A. Seracsin, der die hallstattzeitliche Nekropole in Au am Leithagebirge (Niederösterreich) untersuchte, stand die Siedlungsarchäologie im Vordergrund: Neben Schmids Forschungen zur „Ostnorischen Kultur“ in der Steier$\operatorname{mark}^{212}$ sind dies vor allem $\mathrm{H}$. Mitscha-Märheims gemeinsam mit E. Nischer-Falkenhof unternommene Ausgrabungen auf dem Oberleiserberg (Niederösterreich), einer von der Bronze- über die Latène- und Römerzeit bis ins Mittelalter bewohnten Höhensiedlung. Für die Prähistorische Kommission bedeuteten die Untersuchungen auf dem Oberleiserberg aber auch den Beginn der durch Mitscha-Märheim initiierten Frühgeschichtsforschung, ${ }^{213}$ deren Resultate Ausgangspunkt und Grundlage umfangreicher moderner Forschungsprojekte werden sollten. ${ }^{214}$

Die dritte und letzte Phase von 1937 bis 1938 hingegen stand deutlich unter dem Einfluss O. Menghins, der die Prähistorische Kommission nach dem 1932 eingetretenen Stillstand als neuer Obmann 1937 durch forcierte Präsenz in Forschung und Publikationstätigkeit wieder aufleben ließ, wozu ihm in erster Linie R. Pittionis montanarchäologische

212 Wenn Schmid mit seinen Forschungen zur „ostnorischen Kultur" auch gewissermaßen einem Phantom nachjagte, so hatten seine Untersuchungen in der Steiermark doch nicht unwesentlich zur Belebung der Siedlungsarchäologie beigetragen.

213 Die bisher vornehmlich in Krain aufgedeckten römerzeitlichen und frühmittelalterlichen Bestattungen waren als Zufallsentdeckungen im Rahmen prähistorischer Ausgrabungen zu Tage gekommen: MADER 2018.

214 An dieser Stelle soll vor allem die von Herwig Friesinger als Schüler Mitscha-Märheims 1976 am Institut für Ur-und Frühgeschichte der Universität Wien in Kooperation mit der Österreichischen Akademie der Wissenschaften wiederaufgenommene Forschung am Oberleiserberg genannt werden. 
Forschungen und die Abhandlung über den urzeitlichen Kupferbergbau in Tirol, aber auch seine eigenen Wallburgenuntersuchungen in Westösterreich und nicht zuletzt die Unterstützung von K. Pinks numismatischer Studienreise auf dem Balkan dienten.

Über Menghin und dessen Schüler Franz, Mitscha-Märheim und Pittioni kam es vor allem auf personeller Ebene zur Verbindung der Prähistorischen Kommission mit dem Institut für Urgeschichte der Universität Wien, eine Verbindung, die die traditionelle, seit 1921 abgebrochene $\mathrm{Zu}$ sammenarbeit mit dem Naturhistorischen Museum ersetzte und der die Institutssammlung auch die Überlassung von Fundmaterial verdankt.

Die mit der Unterstützung von insgesamt elf Ausgrabungsvorhaben hauptsächlich auf Niederösterreich und die Steiermark konzentrierte Tätigkeit der Prähistorischen Kommission konnte allen Schwierigkeiten zum Trotz vor allem durch die Einbeziehung der Forschungsbereiche der Siedlungs- und der Montanarchäologie, im Besonderen aber der Frühgeschichtsforschung, neue Wege beschreiten und damit eine bis in neueste Zeit reichende Nachhaltigkeit bewirken.

\section{Danksagung}

Mein besonderer Dank gilt der Kulturabteilung der Stadt Wien, die diese Forschung durch eine Förderung 2015 und 2016 ermöglichte (Magistratsabteilung 7 - Kultur, Wissenschafts- und Forschungsförderung der Stadt Wien).

\section{Literatur}

AnTL-Weiser 2007

W. Antl-Weiser, Die Studien des Oberleutnants Josef Bayer in Palästina in den Jahren 1917 und 1918, Mitteilungen der Anthropologischen Gesellschaft in Wien 136-137/2006-2007, 2007, $145-171$.

BAYER 1913

J. BAYER, Die Chronologie des jüngeren Quartärs, Mitteilungen der Prähistorischen Kommission der Kais. Akademie der Wissenschaften 2/2/1912, 1913, 199-227.

BAYER 1917

J. BAYER, Tagebuch, Fundaktenarchiv, Prähistorische Abteilung, Naturhistorisches Museum Wien.

BAYER 1918

J. BAYER an die Akademie der Wissenschaften, Wien 27.2.1918, Nr. 174/1918, B41, Prähistorische Kommission, Archiv der Österreichischen Akademie der Wissenschaften, Wien.

BAYER 1919

J. BAYER, Bericht über die wissenschaftlichen Ergebnisse seines zweiten Palästina-Aufenthaltes (1918). Beitrag in: Sitzung der mathematisch-naturwissenschaftlichen Klasse vom 9. Jänner 1919, Anzeiger der Akademie der Wissenschaften in Wien. Mathematisch-naturwissenschaftliche Klasse 56/1, 1919, 1-3.

BAYER 1920

J. BAYer an die Prähistorische Kommission, 18.12.1920, Nr. 38/1921, B44, Prähistorische Kommission, Archiv der Österreichischen Akademie der Wissenschaften, Wien.

\section{BAYER 1927}

J. BAYER, Der Mensch im Eiszeitalter. Leipzig - Wien 1927.

BAYER 1930a

J. BAYER an das Bundesdenkmalamt, Wien 29.1.1930, Fundakte Altenburg, Fundaktenarchiv, Prähistorische Abteilung, Naturhistorisches Museum Wien.

BAYER 1930b

J. BAYER an Jahn, Wien 10.6.1930, Fundakte Altenburg, Fundaktenarchiv, Prähistorische Abteilung, Naturhistorisches Museum Wien.

BiogRAPHISCHES LEXIKON 1975

Much Rudolf. In: Österreichisches Biographisches Lexikon 18151950 Bd. 6: [Maier] Stefan-Musger August, Wien 1975, 400-401. BONINO 1933

A. Bonino an die Prähistorische Kommission, Turin Dezember 1933, B55, Prähistorische Kommission, Archiv der Österreichischen Akademie der Wissenschaften, Wien.

BREITINGER 1959

E. BReitinger, Josef Weninger, 1886-1959, Anthropologischer Anzeiger 23/2-3, 236-238.

BROUCEK 1983

P. Broucek, Ein General im Zwielicht: Die Erinnerungen Edmund Glaises von Horstenau Bd. II: Minister im Ständestaat und General im OKA. Veröffentlichungen der Kommission für Neuere Geschichte Österreichs 70, Wien - Köln - Graz 1983.

BRUCK 1965

G. BRUCK, Nachruf auf Karl Pink. Numismatische Zeitschrift 81, Wien 1965, 76-78.

BRÜCKLER, NIMETH 2001

Th. BrÜCKLeR, U. Nimeth, Personenlexikon zur Österreichischen Denkmalpflege 1850-1990, Wien 2001.

Burz 1991

U. Burz, Das Stift St. Paul im 19. und 20. Jahrhundert: Porträt Richard Strellis. In: H. Pucker (Hrsg.), Schatzhaus Kärntens. Landesausstellung St. Paul 1991, 900 Jahre Benediktinerstift, Teil 1 (Katalog). Klagenfurt 1991, 476.

CZÁky 1997

E. M. CzÁKy, 150 Jahre Österreichische Akademie der Wissenschaften 1847-1997: Bilder und Texte. Wien 1997.

EGGER 1929

R. EgGer an Schmid, Wien 24.1.1929, Ortsakt Gleisdorf, Archiv Archäologiemuseum und Münzkabinett, Universalmuseum Joanneum Graz.

EGGER 1937

R. EGGER an die philosophisch-historische Klasse, Wien 14.6.1937, Nr. 249/1937, B57, Prähistorische Kommission, Archiv der Österreichischen Akademie der Wissenschaften, Wien.

FLeMing 1933

R. M. Fleming an die Prähistorische Kommission, London 4.5.1933, B55, Prähistorische Kommission, Archiv der Österreichischen Akademie der Wissenschaften, Wien.

Franz 1928

L. FRANZ an die Prähistorische Kommission, 8.3.1928, Nr. 275/1928, B50, Prähistorische Kommission, Archiv der Österreichischen Akademie der Wissenschaften, Wien.

FRANZ 1929

L. Franz an die Prähistorische Kommission, o. D., Nr. 448/1929, B51, Prähistorische Kommission, Archiv der Österreichischen Akademie der Wissenschaften, Wien. 
FRANZ 1953

L. Franz, Alexander Ritter von Seracsin zum Gedächtnis, Mitteilungen der Anthropologischen Gesellschaft in Wien 82/1-3, 1953, 25-127.

Franz, Weninger 1927

L. Franz, J. Weninger, Die Funde aus den prähistorischen Pfahlbauten im Mondsee, Materialen zur Urgeschichte Österreichs 3. Wien 1927.

Fundakte Au am Leithagebirge

Fundakte Au am Leithagebirge, Fundaktenarchiv, Prähistorische Abteilung, Naturhistorisches Museum Wien.

FundAKTE GEMEINLEBARN

Fundakte Gemeinlebarn, Grabungsabrechnungen 1919-1921, Fundaktenarchiv, Prähistorische Abteilung, Naturhistorisches Museum Wien.

GEEHR 1986

R. S. Geehr, Oswald Menghin, ein Vertreter der katholischen Nationen. In: I. ACKerL, R. Neck (Hrsg.), Geistiges Leben im Österreich der Ersten Republik, Wien 1986, 9-24.

HaAs-Trummer 2007

K. E. HaAs-Trummer, Noreia: Von der fiktiven Keltensiedlung zum mittelalterlichen Adelssitz: Eine historische und archäologische Spurensuche bis 1600. Wien - Köln - Weimar 2007.

HABILITATIONSVERFAHREN FRANZ

Habilitationsverfahren L. C. Franz, Senat Sonderreihe 304, Sign. 294/4, Archiv der Universität Wien.

HEINRICH 2003

A. Heinrich, Josef Szombathy (1853-1943), Mitteilungen der Anthropologischen Gesellschaft in Wien 133, 2003, 1-45.

Hilber 1921

V. Hilber an die Akademie der Wissenschaften, Graz 11.7.1921, Nr. 499/1921, B44, Prähistorische Kommission, Archiv der Österreichischen Akademie der Wissenschaften, Wien.

HillbRAND 1962

E. Hillbrand, Nachruf Ernst Nischer-Falkenhof (1879-1961), Mitteilungen des österreichischen Staatsarchives 15, 1962, 700-704.

Hoernes 1914

M. Hoernes, Korrespondenz mit J. Szombathy, Perchtoldsdorf 7.9.1914, Fundaktenarchiv, Prähistorische Abteilung, Naturhistorisches Museum Wien.

HOCHSTETTER 1878

F. Hochstetter, Antrag, Wien 14.3.1878, Nr. 295/1878, B2, Prähistorische Kommission, Archiv der Österreichischen Akademie der Wissenschaften, Wien.

HRODEGH 1924

A. Hrodegh, Über Hallstattkeramik im Umkreis des niederösterreichischen Manhartsberges, Wiener Prähistorische Zeitschrift $11 / 1,1924,37-45$.

KENNER 1918

F. Kenner, Antrag, 14.3.1918, Nr. 174/1918, B41, Prähistorische Kommission, Archiv der Österreichischen Akademie der Wissenschaften, Wien.

LOEBENSTEIN 1928

Loebenstein an Nischer-Falkenhof, Wien 24.4.1928, Nr. 328/1928, B50, Prähistorische Kommission, Archiv der Österreichischen Akademie der Wissenschaften, Wien.

MADER 2018

B. Mader, Die Prähistorische Kommission der kaiserlichen Akademie der Wissenschaften in Wien 1878-1918. Mitteilungen der Prähistorischen Kommission 86, Wien 2018.

\section{MAJer 1929}

Majer an Nischer-Falkenhof, 8.5.1929, Nr. 270/1929, B51, Prähistorische Kommission, Archiv der Österreichischen Akademie der Wissenschaften, Wien.

\section{MeIster 1947}

R. Meister, Geschichte der Akademie der Wissenschaften in Wien 1847-1947. Denkschriften der Gesamtakademie 1, Wien 1947.

Menghin 1923

O. Menghin, Prähistorische Archäologie und kulturhistorische Methode. Semaine d'Ethnologie religieuse. Compte rendu Analitique de la IIIe Session tenue à Tilbourg, 6 à 14 Septembre 1922. Enghien - Mödling 1923, 203-218.

Menghin 1927

O. Menghin, Zur Geschichte der altpaläolithischen Kulturkreislehre, Wiener Prähistorische Zeitschrift 14, 1927, 33-35.

Menghin 1929

O. Menghin an die Prähistorische Kommission, Wien 24.5.1929, Nr. 447/1929, B51, Prähistorische Kommission, Archiv der Österreichischen Akademie der Wissenschaften, Wien.

Menghin 1937

O. Menghin, Bericht, 1937, Nr. 513/1937, B57, Prähistorische Kommission, Archiv der Österreichischen Akademie der Wissenschaften, Wien.

Menghin 1938

O. Menghin an die mathematisch-naturwissenschaftliche Klasse, 11.10.1938, Nr. 365/1938, B58, Prähistorische Kommission, Archiv der Österreichischen Akademie der Wissenschaften, Wien.

Menghin 1939

O. Menghin an die mathematisch-naturwissenschaftliche Klasse, 15.5.1939, 261/1939, B59, Prähistorische Kommission, Archiv der Österreichischen Akademie der Wissenschaften, Wien.

Menghin 1942

O. Menghin, Urgeschichtliche Feldforschungen in Nordtirol 19391941, Wiener Prähistorische Zeitschrift 29, 1942, 156-194.

Mikoletzky 2008

L. Mikoletzky, Saint-Germain und Karl Renner: Eine Republik wird diktiert. In: H. Konrad, W. Maderthaner (Hrsg.), Das Werden der Ersten Republik ... der Rest ist Österreich - Bd. I. Wien 2008, 179-186.

Mitscha-Märheim 1925a

H. Mitscha-Märheim an die Akademie, Wien 14.3.1925, Nr. 189/1925, B47, Prähistorische Kommission, Archiv der Österreichischen Akademie der Wissenschaften, Wien.

Mitscha-Märheim 1925b

H. Mitscha-Märheim, Ein germanisches Gräberfeld bei Mistelbach (Niederösterreich). Wiener Prähistorische Zeitschrift 12, 1925, 132-136.

Mitscha-Märheim 1925c

H. Mitscha-Märheim an die Akademie, Wien 20.10.1925, Nr. 189/1925, B47, Prähistorische Kommission, Archiv der Österreichischen Akademie der Wissenschaften, Wien.

MitschA-MärHEIM 1926

H. Mitscha-Märheim an die Akademie, Wien 20.4.1926, Nr. 310/1926, B48, Prähistorische Kommission, Archiv der Österreichischen Akademie der Wissenschaften, Wien.

Mitscha-Märheim 1963

H. Miтscha-Märheim, „Mein Lebenslauf“, Wien 1.7.1963, Personalakt Mitscha-Märheim, Archiv der Österreichischen Akademie der Wissenschaften, Wien. 
Mitscha-Märheim, Nischer-Falkenhof 1927

H. Mitscha-Märheim, E. Nischer-Falkenhof, Subventionsansuchen, Wien 10.11.1927, B49, Prähistorische Kommission, Archiv der Österreichischen Akademie der Wissenschaften, Wien.

Mitscha-Märheim, Nischer-Falkenhof 1929

H. Mitscha-Märheim, E. Nischer-Falkenhof, Der Oberleiserberg: Ein Zentrum vor- und frühgeschichtlicher Besiedlung, Mitteilungen der Prähistorischen Kommission 2/5, 1929, 391-438.

Mode 2015a

D. Modu, Die Etablierung des Faches (1865-1905). In: B. Hebert (Hrsg.), Urgeschichte und Römerzeit in der Steiermark. Geschichte der Steiermark 1. Wien - Köln - Weimar 2015, 76-90.

\section{ModL 2015b}

D. Modu, Kontinuität statt Umbruch (1906-1949). In: B. Hebert (Hrsg.), Urgeschichte und Römerzeit in der Steiermark Geschichte der Steiermark 1. Wien - Köln - Weimar 2015, 91-111.

Modrijan, Piccottini 1991

W. Modrijan, G. Piccottini, Das Lavanttal in urgeschichtlicher und römischer Zeit, In: J. Grabmayer, G. Hödl, H. Pucker (Bearb.), Schatzhaus Kärntens. Landesausstellung St. Paul 1991: 900 Jahre Benediktinerstift, Bd. 2: Beiträge. Klagenfurt 1991, 317-338.

Much 1920a

R. Much, Vorschlag, Wien 30.05.1920, Personalakt Menghin, Archiv der Österreichischen Akademie der Wissenschaften, Wien.

Much $1920 \mathrm{~b}$

R. Мuch, Bericht der Prähistorischen Kommission, Wien 7.7.1920, Nr. 437/1920, B43, Prähistorische Kommission, Archiv der Österreichischen Akademie der Wissenschaften, Wien.

Much 1928

R. MucH an Schmid, Wien 14.7.1828, Nr. 323/1928, B50, Prähistorische Kommission, Archiv der Österreichischen Akademie der Wissenschaften, Wien.

Nebehay 1973

St. Nebehay, Das latènezeitliche Gräberfeld von der Kleinen Hutweide bei Au am Leithagebirge, PB Bruck a.d. Leitha, NÖ, Archaeologia Austriaca Beiheft 11, 1973.

Nischer-Falkenhof 1923

E. Nischer-Falkenhof, Die Römer im Gebiete des ehemaligen Österreich-Ungarn. Wien 1923.

Nischer-Falkenhof 1927

E. Nischer-Falkenhof, Bericht Oberleis, B49, Prähistorische Kommission, Archiv der Österreichischen Akademie der Wissenschaften, Wien.

NisCHER-FALKENHOF 1929

E. Nischer-Falkenhof an die Prähistorische Kommission, Wien 17.4.1929, Nr. 301/1929, B51, Archiv der Österreichischen Akademie der Wissenschaften, Wien.

Nischer-FalKenhof 1931a

E. Nischer-Falkenhof, Die vor- und frühgeschichtliche Siedlung auf dem Umlauf am Kamp in Niederösterreich (Bez. Horn), Wiener Prähistorische Zeitschrift 18, 1931, 89-115.

Nischer-Falkenhof $1931 \mathrm{~b}$

E. Nischer-Falkenhof, an die Prähistorische Kommission, 15.7.1931, Nr. 335/1931, B53, Prähistorische Kommission, Archiv der Österreichischen Akademie der Wissenschaften, Wien.

NisCHER-FALKENHOF 1935

E. Nischer-Falkenhof, Die vorgeschichtlichen Siedlungen auf dem Braunsberg bei Hainburg a.d.D., Unsere Heimat: Monatsblatt des Vereines für Landeskunde und Heimatschutz von Niederösterreich und Wien, N. F. 8, 1935, 290-294.
Nischer-Falkenhof, Mitscha-Märheim 1931

E. Nischer-Falkenhof, H. Mitscha-Märheim, Die römische Station bei Niederleis und abschliessende Untersuchungen auf dem Oberleiserberge, Mitteilungen der Prähistorischen Kommission 2/6,1931, 439-469.

Nischer-Falkenhof, Mitscha-Märheim 1932

E. Nischer-Falkenhof, H. Mitscha-Märheim, Die prähistorischen Siedlungen auf dem Braunsberg bei Hainburg a.d. Donau, Forschungen und Fortschritte: Nachrichtenblatt der Deutschen Wissenschaft und Technik 8/2, 1932, 18.

Ortsmappe Au am Leithagebirge

OrtSmappe Au am Leithagebirge, Fachbereich für Ur- und Frühgeschichte, Landessammlungen Niederösterreich, Schloss Asparn/Zaya.

OhNe Verfasser 1888

Ohne Verfasser, Vorwort, Mittheilungen der Prähistorischen Commission der kais. Akademie der Wissenschaften 1/1/1887, 1888, iii-iv.

Personalakt Menghin

Personalakt O. Menghin, Karton 674, Signatur 4, UAllg., Allgemeines Verwaltungsarchiv III, Österreichisches Staatsarchiv Wien.

Personalakt Mitscha-Märheim

Personalakt H. Mitscha-Märheim, Archiv der Österreichischen Akademie der Wissenschaften, Wien.

Personalakt Pittioni

Personalakt R. Weninger, Archiv der Österreichischen Akademie der Wissenschaften, Wien.

Personalakt Weninger

Personalakt J. Weninger, Archiv der Österreichischen Akademie der Wissenschaften, Wien.

Petitum 1878

Petitum der mathematisch-naturwissenschaftlichen Classe, Wien 4.4.1878, Nr. 295/1878, B2, Prähistorische Kommission, Archiv der Österreichischen Akademie der Wissenschaften, Wien.

PINK 1937

K. PInk an die Akademie, Wien 7.6.1937, Nr. 249/1937, B57, Prähistorische Kommission, Archiv der Österreichischen Akademie der Wissenschaften, Wien.

PINK 1939

K. PINK, Die Münzprägung der Ostkelten und ihrer Nachbarn. Dissertationes Pannonicae II/15. Budapest 1939.

PitTioni 1937

R. PitTioni an die Akademie, 29.9.1937, Nr. 38/1937, B57, Prähistorische Kommission, Archiv der Österreichischen Akademie der Wissenschaften, Wien.

PitTioni 1952

R. Pittioni, Alexander Seracsin $\dagger$, Archaeologia Austriaca 9, 1952, 100.

PitTiONi 1973

R. Pittioni, Ernst Preuschen 1898-1973, Archaeologia Austriaca 54, 1973, 150-152.

PitTioni 1974

R. Pittioni, Oswald Menghin 1888-1973, Archaeologia Austriaca 55/1974, $1-6$.

PitTioni 1978

R. Pittioni, Herbert (von) Mitscha-Märheim: Nachruf (mit Schriftenverzeichnis), Almanach der Österreichischen Akademie der Wissenschaften 127/1977, 1978, 544-557. 


\section{PostKarte 1923}

POSTKARTE der Universitätsbibliothek Freiburg im Breisgau, 13.11.1923, B45, Prähistorische Kommission, Archiv der Österreichischen Akademie der Wissenschaften, Wien.

Preuschen, Pittioni 1937

E. Preuschen, R. Pittioni, Untersuchungen im Bergbaugebiete Kelchalpe bei Kitzbühel, Tirol: Erster Bericht über die Arbeiten 1931-1936 zur Urgeschichte des Kupferbergwesens in Tirol. Mitteilungen der Prähistorischen Kommission der Akademie der Wissenschaften 3/1-3, Vienna 1937.

RADERMACHER 1929

L. Radermacher an Nischer-Falkenhof, Wien 15.07.1929, Nr. 501/1929, B51, Prähistorische Kommission, Archiv der Österreichischen Akademie der Wissenschaften, Wien.

RHONÉ 1868

A. Rhoné, Visite au Musée de Saint-Germain. In: Congrès International d'anthropologie et d'archéologie préhistoriques, Compte rendu de la 2me Session, tenue a Paris, du 17 au 30 Aout 1867. Paris 1868, 125-131.

SCHMID 1915

W. Schмid, Die Ringwälle des Bacherngebietes: Erster Teil, Mitteilungen der Prähistorischen Kommission 2/3, Wien 1915, 229-305.

SCHMID 1919a

W. Schмid, Ansuchen, Graz 25.4.1919, Nr. 296/1919, B42, Prähistorische Kommission, Archiv der Österreichischen Akademie der Wissenschaften, Wien.

SCHMID 1919b

W. Schмid, Schmid an die Prähistorische Kommission, Graz 21.10.1919, Nr. 296/1919, B 42, Prähistorische Kommission, Archiv der Österreichischen Akademie der Wissenschaften, Wien.

SCHMID 1920

W. Schмid, Ansuchen, Graz 11.4.1920, Nr. 296/1919, B42, Prähistorische Kommission, Archiv der Österreichischen Akademie der Wissenschaften, Wien.

SCHмID 1921

W. Schмid an die Akademie der Wissenschaften, Graz 27.4.1921, Nr. 343/1921 B43, Prähistorische Kommission, Archiv der Österreichischen Akademie der Wissenschaften, Wien.

SCHMid 1922a

W. Schмid an die Akademie der Wissenschaften, Graz 19.8.1922, Nr. 343/1921, B44, Prähistorische Kommission, Archiv der Österreichischen Akademie der Wissenschaften, Wien.

SCHMID 1922b

W. Schмid, Schmid an Hofrat, Graz 22.8.1922, Nr. 343/1921, B44, Prähistorische Kommission, Archiv der Österreichischen Akademie der Wissenschaften, Wien.

SCHMID 1924

W. Schмid, Die Ringwälle des Bacherngebietes: Zweiter Teil, Mitteilungen der Prähistorischen Kommission 2/4, 1924, 365-391.

SCHMID 1925

W. Schmid an die Prähistorische Kommission, Graz 16.2.1925, Nr. 103/1925, B47, Prähistorische Kommission, Archiv der Österreichischen Akademie der Wissenschaften, Wien.

SCHMID 1926a

W. Schмid an die Prähistorische Kommission und Bericht „Ausgrabung eines Bauernhauses in Gleisdorf“, Graz 26.4.1926, Nr. 316/1926, B48, Prähistorische Kommission, Archiv der Österreichischen Akademie der Wissenschaften, Wien.
SCHMID 1926b

W. Schmid, Konzept-Erledigung, 10.7.1926, Nr. 316/1926, B48, Prähistorische Kommission, Archiv der Österreichischen Akademie der Wissenschaften, Wien.

SCHMID 1926 c

W. SснміD, Römische Forschungen in Gleisdorf, Tagespost 94, 4. April 1926, 21, Ortsakt Gleisdorf, Archiv Archäologiemuseum und Münzkabinett, Universalmuseum Joanneum Graz.

SCHMID 1927

W. Sснмid an die Akademie, Graz 16.4.1927, Nr. 264/1927, B49, Prähistorische Kommission, Archiv der Österreichischen Akademie der Wissenschaften, Wien.

SCHMID 1928

W. Schмid an die Prähistorische Kommission, Graz 27.3.1928, Nr. 323/1928, B50, Prähistorische Kommission, Archiv der Österreichischen Akademie der Wissenschaften, Wien.

SCHMID 1929a

W. Scнмid, Archäologische Forschungen in Steiermark, Jahreshefte des Österreichischen Archäologischen Institutes in Wien 25, 1929, 67-148.

SCHMID $1929 \mathrm{~b}$

W. Schмid an die Prähistorische Kommission, Graz 22.3.1929, Nr. 233/1929, B51, Prähistorische Kommission, Archiv der Österreichischen Akademie der Wissenschaften, Wien.

SCHMID 1929c

W. Schmid, Bericht 1929, Nr. 793/1929, B51, Prähistorische Kommission, Archiv der Österreichischen Akademie der Wissenschaften, Wien.

SCHMID 1930a

W. Schмid, Ostnorische Kultur, Blätter für Heimatkunde 8, 1930, 79-82.

SCHMID $1930 \mathrm{~b}$

W. Schmid an die Prähistorische Kommission, Graz 22.1.1930, Nr. 54/1930, B52, Prähistorische Kommission, Archiv der Österreichischen Akademie der Wissenschaften, Wien.

SCHMID 1930c

W. ScHMID an die Steiermärkische Landesregierung Abt. 4, 7.2.1930 / Beilage: „Noreia die Hauptstadt des ostalpinen Königreiches Norikum", Schmid Nachlass, Noreia, Archiv Archäologiemuseum und Münzkabinett, Universalmuseum Joanneum Graz.

SCHMID 1930d

W. Schmid an die Prähistorische Kommission, Graz 17.5.1930, Nr. 390/1930 B52, Prähistorische Kommission, Archiv der Österreichischen Akademie der Wissenschaften, Wien.

SCHMID 1931

W. Schmid, Forschungen in Noreia September 1930 und April 1931, Nr. 101/1931, B53, Prähistorische Kommission, Archiv der Österreichischen Akademie der Wissenschaften, Wien.

SCHMID 1932

W. Schmid, Noreia: Zusammenfassung der Grabungsergebnisse 1929 bis 1932, Mannus 24/1, 1932, 183-196.

Schмid o. J.

W. Schmid, Burgstall bei Klein Glein / Klein-Glein, Manuskripte, Ordner Burgstallkogel, Klein-Klein, Archiv Archäologiemuseum und Münzkabinett, Universalmuseum Joanneum Graz.

SCHNAPP 2006

A. Schnapp, Ur- und Frühgeschichte und Klassische Archäologie in Frankreich: ein Sonderweg. In: J. Callmer, M. Meyer, R. Struwwe, C. Theune (Hrsg.), Die Anfänge der ur- und frühgeschichtlichen Archäologie als akademisches Fach (18901930) im europäischen Vergleich. Berliner Archäologische Forschungen 2, 2006, 285-293. 
Schubert-SOLdern 1930

Schubert-Soldern an die Direktion der Anthropologischen und Prähistorischen Abteilung des Naturhistorischen Museums in Wien, Wien 17.2.1930 (mit Stellungnahme Menghins), Fundakte Altenburg, Fundaktenarchiv, Prähistorische Abteilung, Naturhistorisches Museum Wien.

SERACSIN 1926a

A. SERACsin an die prähistorische Kommission, Wien 14.5.1926, Nr. 381/1926, B48, Prähistorische Kommission, Archiv der Österreichischen Akademie der Wissenschaften, Wien.

SERACSIN 1926b

A. Seracsin, Erledigung-Konzept, Wien 10.7.1926, B48, Prähistorische Kommission, Archiv der Österreichischen Akademie der Wissenschaften, Wien.

SERACSIN 1929a

A. SERAcsin, Das Hallstattgräberfeld von Au am Leithagebirge (Niederösterreich), Prähistorische Zeitschrift 22, 1929, 229-237.

SERACSIN 1929 b

A. Seracsin an die Prähistorische Kommission, Wien 23.5.1929 und vorläufiger Bericht, Nr. 395/1929, B52, Prähistorische Kommission, Archiv der Österreichischen Akademie der Wissenschaften, Wien.

SERACSIN 1930

A. SERacsin an die Prähistorische Kommission, Wien 3.2.1930, Nr. 100/1930, B52, Prähistorische Kommission, Archiv der Österreichischen Akademie der Wissenschaften, Wien.

SERACSIN 1932

A. Seracsin, Fundberichte 1930-1931/ Niederösterreich: Au am Leithagebirge, Fundberichte aus Österreich 1/6-10, 1932, 104.

SitZUNGSPROTOKOLL 1878 a

SitZUNGSPROTOKOLL der mathematisch-naturwissenschaftlichen Classe, 4.4.1878, B903, mathematisch-naturwissenschaftliche Classe, Archiv der Österreichischen Akademie der Wissenschaften, Wien.

SitZUNGSPROTOKOLL $1878 \mathrm{~b}$

Sitzungsprotokoll der Prähistorischen Kommission, 6.6.1878, Nr. 679/1878, B2, Prähistorische Kommission, Archiv der Österreichischen Akademie der Wissenschaften, Wien.

SitZUNGSPROTOKOLL 1918a

SitZUNGSPROTOKOLL der mathematisch-naturwissenschaftlichen Klasse, 14.1.1918, Nr. 55/1918, B2023, mathematisch-naturwissenschaftliche Klasse, Archiv der Österreichischen Akademie der Wissenschaften, Wien.

SitZUNGSPROTOKOLL 1918 b

Sitzungsprotokoll der Prähistorischen Kommission, 14.3.1918, Nr. 201/1918, B41, Prähistorische Kommission, Archiv der Österreichischen Akademie der Wissenschaften, Wien.

SitZUNGSPROTOKOLL 1919a

Sitzungsprotoкoll der Prähistorischen Kommission, 31.5.1919, Nr. 296/1919, B42, Prähistorische Kommission, Archiv der Österreichischen Akademie der Wissenschaften, Wien.

SiTZUNGSPROTOKOLL $1919 \mathrm{~b}$

SitzUnGSPROTокоLL der mathematisch-naturwissenschaftlichen Klasse, 12.6.1919, Nr. 415/1919, B2065, mathematisch-naturwissenschaftliche Klasse, Archiv der Österreichischen Akademie der Wissenschaften, Wien.

SitZungSPROTOKOLL 1919c

Sitzungsprotokoll der Prähistorischen Kommission, 18.6.1919, Nr. 404/1919, B42, Prähistorische Kommission, Archiv der Österreichischen Akademie der Wissenschaften, Wien.
SitZUNGSPROTOKOLL 1919d

Sitzungsprotokoll der Prähistorischen Kommission, 20.7.1919, Nr. 430/1919, B42, Prähistorische Kommission, Archiv der Österreichischen Akademie der Wissenschaften, Wien.

SiTZUNGSPROTOKOLL 1919e

SitZUNGSPROTOKOLL der mathematisch-naturwissenschaftlichen Klasse, 30.12.1919, Nr. 812/1919, B2078, mathematisch-naturwissenschaftliche Klasse, Archiv der Österreichischen Akademie der Wissenschaften, Wien.

SitZUNGSPROTOKOLL 1920

Sitzungsprotokoll der Prähistorischen Kommission, 12.7.1920, Nr. 296/1919, B42, Prähistorische Kommission, Archiv der Österreichischen Akademie der Wissenschaften, Wien.

SiTZUNGSPROTOKOLL 1921

Sitzungsprotokoll der Prähistorischen Kommission, 15.7.1921, Nr. 499/1921, B44, Prähistorische Kommission, Archiv der Österreichischen Akademie der Wissenschaften, Wien.

SiTZUNGSPROTOKOLL 1924 a

Sitzungsprotokoll der mathematisch-naturwissenschaftlichen Klasse, B2206, Nr. 392/1924, B46, Prähistorische Kommission, Archiv der Österreichischen Akademie der Wissenschaften, Wien.

SitZUNGSPROTOKOLL 1924 b

SiTZUnGSPROTOKOLL der philosophisch-historischen Klasse, C2205, Nr. 392/1924, B46, Prähistorische Kommission, Archiv der Österreichischen Akademie der Wissenschaften, Wien.

SiTZUNGSPROTOKOLL $1924 \mathrm{c}$

Sitzungsprotokoll der Gesamtsitzung der Akademie A796, Nr. 392/1924, B46, Prähistorische Kommission, Archiv der Österreichischen Akademie der Wissenschaften, Wien.

SitZUNGSPROTOKOLL 1925

Sitzungsprotokoll der Prähistorischen Kommission, 10.7.1925, Nr. 494/1925, B47, Prähistorische Kommission, Archiv der Österreichischen Akademie der Wissenschaften, Wien.

SitZUNGSPROTOKOLL 1927

Sitzungsprotokoll der Prähistorischen Kommission, 31.3.1927, Nr. 264/1927, B49, Prähistorische Kommission, Archiv der Österreichischen Akademie der Wissenschaften, Wien.

SitZUNGSPROTOKOLL 1928a

Sitzungsprotokoll der Prähistorischen Kommission, 16.3.1928, Nr. 290/1928, B50, Prähistorische Kommission, Archiv der Österreichischen Akademie der Wissenschaften, Wien.

SitZungSPROTOKOLL 1928 b

Sitzungsprotokoll der Prähistorischen Kommission, 13.7.1928, Nr. 630/1928, B50, Prähistorische Kommission, Archiv der Österreichischen Akademie der Wissenschaften, Wien.

SiTZUNGSPROTOKOLL 1929a

SitzungsPROтокоLL der philosophisch-historischen Klasse, C2340, Nr. 301/1929, Archiv der Österreichischen Akademie der Wissenschaften, Wien.

SiTZUNGSPROTOKOLL 1929b

Sitzungsprotokoll der Prähistorischen Kommission, 27.06.1929 Nr. 501/1929, B51, Prähistorische Kommission, Archiv der Österreichischen Akademie der Wissenschaften, Wien.

SitZUNGSPROTOKOLL 1930a

Sitzungsprotokoll der Prähistorischen Kommission, 21.3.1930, Nr. 234/1930, B52, Prähistorische Kommission, Archiv der Österreichischen Akademie der Wissenschaften, Wien. 
SitZUNGSPROTOKOLL $1930 \mathrm{~b}$

Sitzungsprotóoll der Prähistorischen Kommission, 19.12.1930, Nr. 872/1930, B52, Prähistorische Kommission, Archiv der Österreichischen Akademie der Wissenschaften, Wien.

SitZungSPRotokoll 1931a

SitZungsprotokoll der Prähistorischen Kommission, 25.4.1931, Nr. 395/1931, B53, Prähistorische Kommission, Archiv der Österreichischen Akademie der Wissenschaften, Wien.

SitZUNGSPROTOKOLL 1931b

Sitzungsprotokoll der Prähistorischen Kommission, 25.6.1931, Nr. 395/1931, B53, Prähistorische Kommission, Archiv der Österreichischen Akademie der Wissenschaften, Wien.

SitZUNGSPROTOKOLl 1932a

SitZungSPROTокоLl der philosophisch-historischen Klasse, C2413, Nr. 16/1932, B54, Prähistorische Kommission, Archiv der Österreichischen Akademie der Wissenschaften, Wien.

SitZUNGSPROTOKOLL 1932b

SitzungsPRотокоLL der philosophisch-historischen Klasse, C2422, Nr. 209/1932, B54, Prähistorische Kommission, Archiv der Österreichischen Akademie der Wissenschaften, Wien.

SitZUNGSPROTOKOLL 1932c

SiTZUnGSPROTокоLl der philosophisch-historischen Klasse, 26.10.1932, C2432, B54, Prähistorische Kommission, Archiv der Österreichischen Akademie der Wissenschaften, Wien.

SitZungSPRotokoll 1936a

Sitzungsprotokoll der Prähistorischen Kommission, 27.11.1936, Nr. 552/1936, B56, Prähistorische Kommission, Archiv der Österreichischen Akademie der Wissenschaften, Wien.

SitZUnGSPROTOKOLL 1936b

SitZungSPROTOKOLL der philosophisch-historischen Klasse, C2533/ 1936, Prähistorische Kommission, Archiv der Österreichischen Akademie der Wissenschaften, Wien.

SitZUnGSPROTOKOLL 1937a

Sitzungsprotokoll der Prähistorischen Kommission, 18.6.1937, Nr. 259/1937, B57, Prähistorische Kommission, Archiv der Österreichischen Akademie der Wissenschaften, Wien.

SitZUNGSPROTOKOLL $1937 \mathrm{~b}$

SitzungSPRотокоLl der philosophisch-historischen Klasse, 23.6.1937, C2560, Archiv der Österreichischen Akademie der Wissenschaften, Wien.

SitZUnGSPROTOKOLL 1937c

SitZungsprotokoll der Prähistorischen Kommission, 2.7.1937, Nr. 249/1937, B57, Prähistorische Kommission, Archiv der Österreichischen Akademie der Wissenschaften, Wien.

SitZUNGSPROTOKOLL 1937d

SitZungsprotokoll der Prähistorischen Kommission, 12.12.1937, Nr. 513/1937, B57, Prähistorische Kommission, Archiv der Österreichischen Akademie der Wissenschaften, Wien.

SitzungSPRotokoll 1937e

Sitzungsprotoкоll der Prähistorischen Kommission, 17.12.1937, Nr. 513/1937, B57, Prähistorische Kommission, Archiv der Österreichischen Akademie der Wissenschaften, Wien.

STEFAN 1878

J. Stefan, Bericht über die mathematisch-naturwissenschaftliche Classe der Kaiserlichen Akademie der Wissenschaften erstattet von ihrem Secretär, Almanach der kaiserlichen Akademie der Wissenschaften 28, 1878, 149-219.

STEINDACHNER 1919

F. Steindachner, Befürwortung von Schmids Ansuchen, o. D., Nr. 296/1919, B42, Prähistorische Kommission, Archiv der Österreichischen Akademie der Wissenschaften, Wien.
Strelli 1932

R. Strelli, Nr. 16/1932, Nr. 209/1932, Nr. 248/1932, B54, Prähistorische Kommission, Archiv der Österreichischen Akademie der Wissenschaften, Wien.

SubVEnTIONEN 1936-1938

Subventionen der mathematisch-naturhistorischen Klasse, Nr. 157/1936, 38/1937, 62/1938, mathematisch-naturwissenschaftliche Klasse, Archiv der Österreichischen Akademie der Wissenschaften, Wien.

SUPPAN 2007

A. Suppan, Von Saint Germain zum Belvedere: Österreich und Europa von 1919-1955. In: K. Koch, W. Rauscher, A. Suppan, E. Vyslonzil (Hrsg.), Von Saint Germain zum Belvedere: Österreich und Europa 1919-1955. Außenpolitische Dokumente der Republik Österreich 1918-1938 (Sonderband), Wien - München 2007, 25-43.

SZOMBATHY 1890

J. Szombathy, Die Tumuli von Gemeinlebarn, Mittheilungen der Prähistorischen Commission 1/2, 1890, 49-77.

SZOMBATHY 1891

J. Szombathy, Planung der Grabungen, Sommer 1891, Fundaktenarchiv, Prähistorische Abteilung, Naturhistorisches Museum Wien.

SzOMbathy 1918a

J. Szombathy, Bewilligung einer Subvention zur Drucklegung seiner kraniometrischen Umrechnungstabellen. Beitrag in: Sitzung der mathematisch-naturwissenschaftlichen Klasse vom 7. Februar 1918, Anzeiger der Akademie der Wissenschaften in Wien. Mathematisch-naturwissenschaftliche Klasse 55/4, 1918, 55.

SZOMBATHY 1918b

J. Szomватнy, Tabellen zur Umrechnung der Schädelmaße auf einen Rauminhalt von 1000 Kubikzentimetern. Mitteilungen der Anthropologischen Gesellschaft in Wien Ergänzungsheft 7, Wien 1918.

Szombathy 1919a

J. Szombathy an die Hohe Akademie der Wissenschaften, Wien 9.6.1919, 415/1919, B2065, mathematisch-naturwissenschaftliche Klasse, Archiv der Österreichischen Akademie der Wissenschaften, Wien.

SzOMBATHy 1919b

J. Szombathy, Bericht, Wien 10.11.1919, Nr. 415/1919, B42, Prähistorische Kommission, Archiv der Österreichischen Akademie der Wissenschaften, Wien.

SZOMbathy $1919 \mathrm{c}$

J. Szombathy an die Hohe Akademie der Wissenschaften, Wien 28.12.1919, Nr. 812/1919, B2078, mathematisch-naturwissenschaftliche Klasse, Archiv der Österreichischen Akademie der Wissenschaften, Wien.

Szombathy 1920a

J. Szombathy, Ausgrabungen in Gemeinlebarn (N.-Ö.) im Jahre 1919, Mitteilungen der Anthropologischen Gesellschaft in Wien 50, 1920, [58]-[60].

Szombathy $1920 \mathrm{~b}$

J. Szombathy an die Prähistorische Kommission / Bericht Gemeinlebarn, Wien 12.12.1920, Nr. 804/1920, B43, Prähistorische Kommission, Archiv der Österreichischen Akademie der Wissenschaften, Wien.

SzOMBATHY 1920c

J. Szombathy, Subventionsantrag, Wien 15.12.1920, Nr. 804/1920, B43, Prähistorische Kommission, Archiv der Österreichischen Akademie der Wissenschaften, Wien. 
SZOMBATHy 1920d

J. Szombathy an die Prähistorische Kommission, Wien 16.12.1920, Nr. 804/1920, B43, Prähistorische Kommission, Archiv der Österreichischen Akademie der Wissenschaften, Wien.

SZOMBATHY 1921

J. Szombathy an die Prähistorische Kommission, 30.9.1921, Nr. 577/1921, B44, Archiv der Österreichischen Akademie der Wissenschaften, Wien.

SZOMBathy 1929

J. Szombathy, Prähistorische Flachgräber bei Gemeinlebarn in Niederösterreich. Römisch-Germanische Forschungen 3, Berlin 1929.

Szombathy Tagebücher

J. Szombathy, Fundaktenarchiv, Prähistorische Abteilung, Naturhistorisches Museum Wien.

URBAN 1997

O. H. Urban, „Er war der Mann zwischen den Fronten“: Oswald Menghin und das Urgeschichtliche Institut der Universität Wien während der Nazizeit, Archaeologia Austriaca 80/1996, 1997, $1-24$.

URBAN 2010

O. H. URban, Die Urgeschichte an der Universität Wien vor, während und nach der NS-Zeit. In: M. G. Ash, W. Niess, R. Pils (Hrsg.), Geisteswissenschaften im Nationalsozialismus: Das Beispiel der Universität Wien. Göttingen 2010, 371-395.

VOCELKA 2000

K. Vocelka, Geschichte Österreichs: Kultur-Gesellschaft-Politik. Graz - Wien - Köln 2000

ZiMMERMANN 1984-1985

E. Zimmermann, Abt Dr. Richard Strelli und die archäologische Forschung im Lavanttal, Jahresbericht des Öffentlichen Stiftsgymnasiums der Benediktiner St. Paul im Lavanttal 176, 1984-1985, 39-44.

Zschocke, Preuschen 1932

K. Zschocke, E. Preuschen, Das urzeitliche Bergbaugebiet von Mühlbach-Bischofshofen. Materialien zur Urgeschichte Österreichs 6, Wien 1932.

ZÖLLNER 1990

E. ZöLLner, Geschichte Österreichs: Von den Anfängen bis zur Gegenwart. Wien - München 1990.

Brigitta Mader Kriehubergasse 25/11

1050 Wien

Österreich

mail@brigittamader.com

(iD) orcid.org/0000-0002-5802-0691 